\title{
Dysferlin in skeletal and heart muscle: from trafficking to therapy
}

\author{
Dissertation \\ in partial fulfillment of the requirements for the degree \\ "Doctor rerum naturalium" \\ of the Georg-August-University Göttingen \\ within the doctoral program Molecular Medicine \\ of the Georg-August University School of Science (GAUSS) \\ submitted by \\ Kristina Bersch \\ from Karaganda
}

Göttingen, 2017 


\section{Thesis committee / examination board}

\section{PD Dr. Sven Thoms}

Department for Child and Adolescent Medicine

University Medical Center Göttingen

Prof. Dr. Wolfgang Brück

Department of Neuropathology

University Medical Center Göttingen

Prof. Dr. Hubertus Jarry

Animal welfare officer

University Medical Center Göttingen

Prof. Dr. Steven Johnsen

Clinic for General Visceral and Pediatric Surgery

University Medical Center Göttingen

Prof. Dr. Blanche Schwappach

Department of Molecular Biology

University Medical Center Göttingen

Dr. Ira Milosevic

European Neuroscience Institute 


\section{Affidavit}

Here I declare that my doctoral thesis entitled

"Dysferlin in skeletal and heart muscle: from trafficking to therapy"

has been written independently with no other sources and aids than quoted.

Kristina Bersch

Göttingen, June 2017 
Je mehr ich weiß, desto mehr weiß ich, dass ich nichts weiß. 


\section{Table of contents}

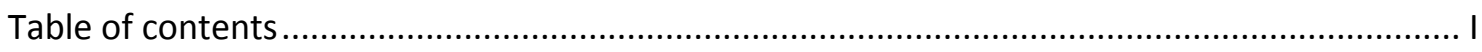

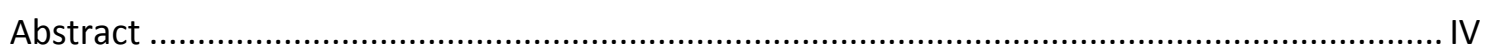

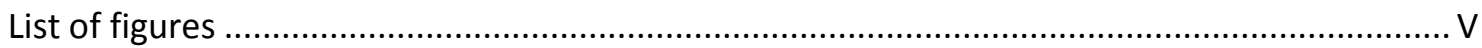

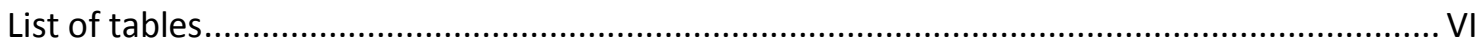

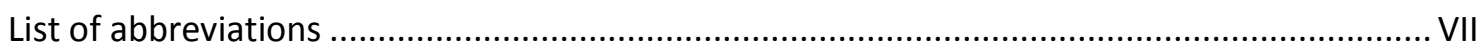

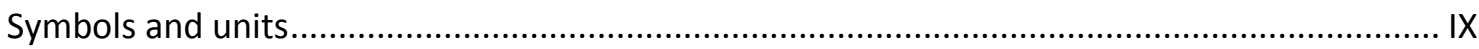

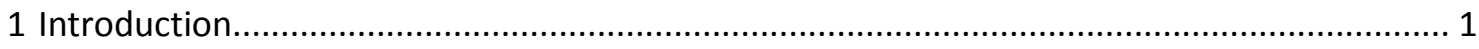

1.1 Skeletal muscle anatomy and function .......................................................... 1

1.2 Cardiac T-tubule system.............................................................................. 2

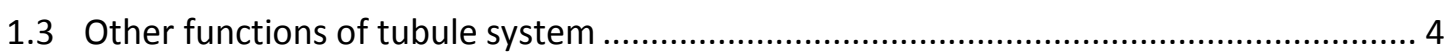

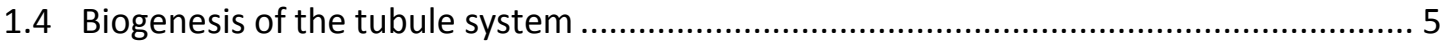

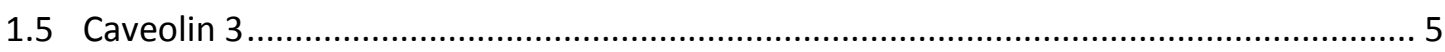

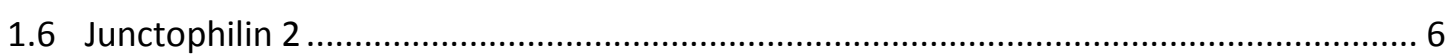

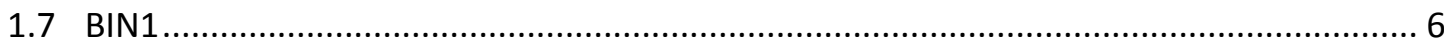

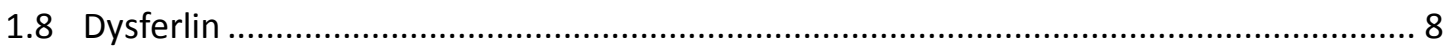

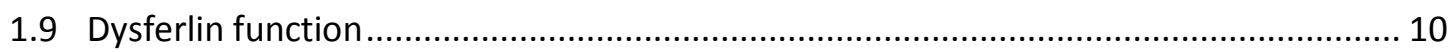

1.10 Dysferlin's involvement in T-tubule biogenesis .................................................. 11

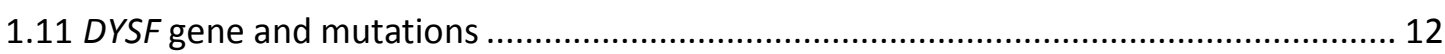

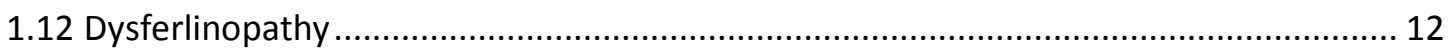

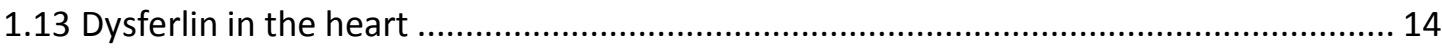

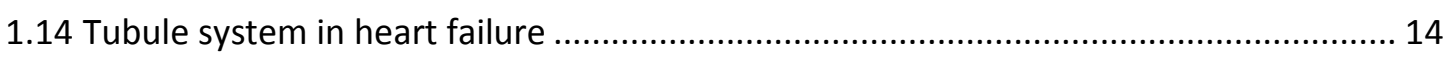

1.15 Therapeutic strategies for dysferlinopathy...................................................... 15

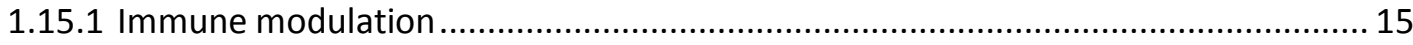

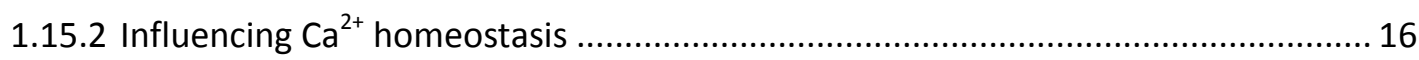

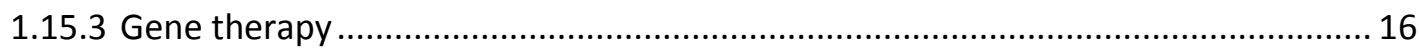

1.15.4 Reallocation of mutated dysferlin ........................................................ 18

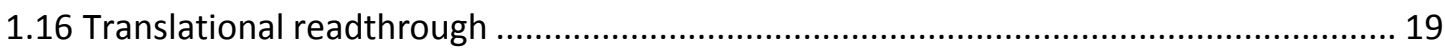

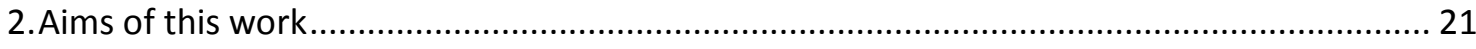

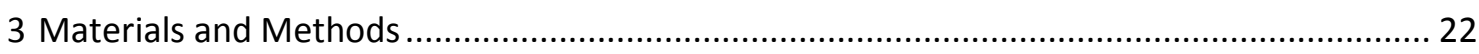

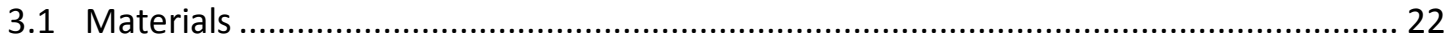

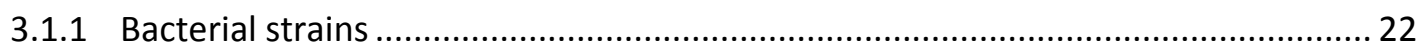

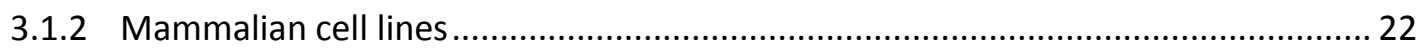

3.1.3 Human myoblasts ............................................................................ 22

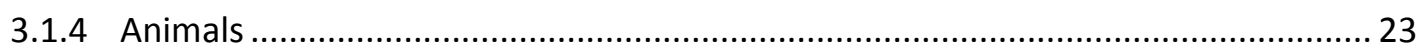

3.1.5 General material and chemicals .............................................................. 23

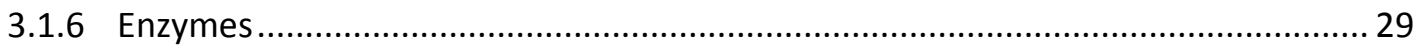

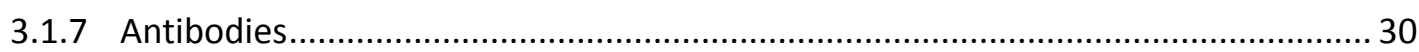




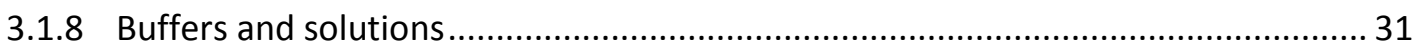

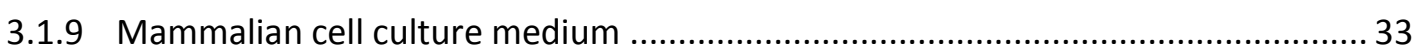

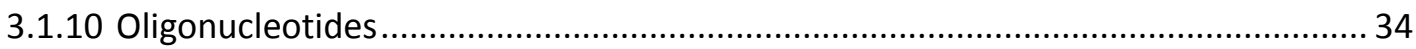

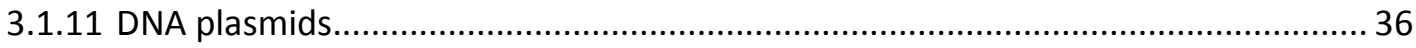

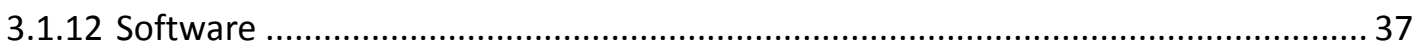

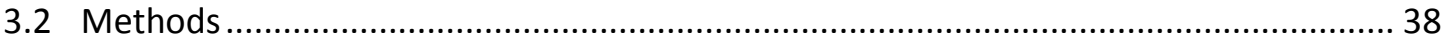

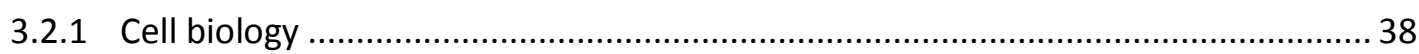

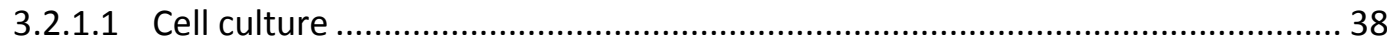

3.2.1.2 Isolation of ventricular cardiomyocytes from rats for immunofluorescence

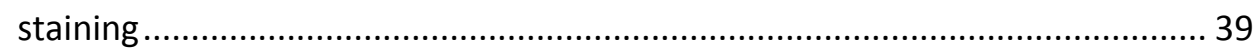

3.2.1.3 Isolation of rat hearts for preparation of protein lysates .................................. 39

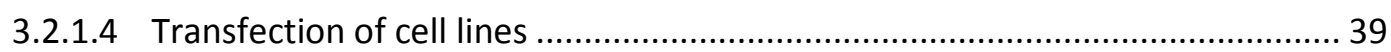

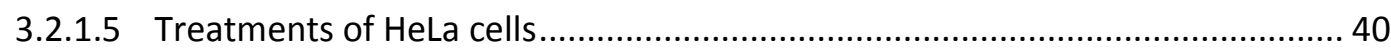

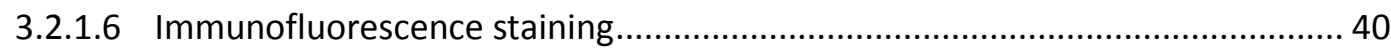

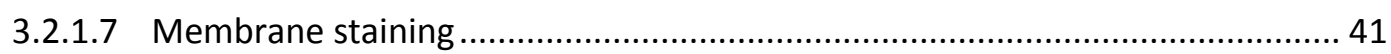

3.2.1.8 Analysis of TATS morphology of di-8-ANNEPS-stained mouse ventricular

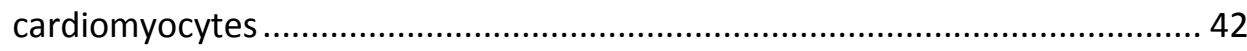

3.2.1.9 Flow cytometric analysis of readthrough using dual reporter assay ................. 42

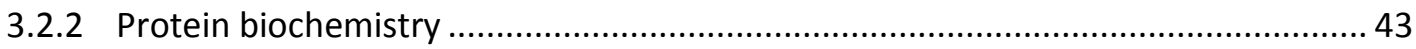

3.2.2.1 Isolation of proteins from cells for SDS- polyacrylamide gel electrophoresis

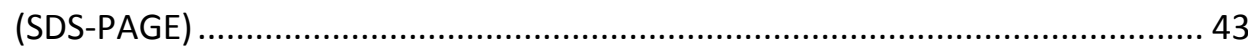

3.2.2.2. Thrombin and Endo $\mathrm{H}$ treatment of HeLa cell culture lysates ........................... 43

3.2.2.3 Isolation of proteins from rat ventricular heart tissue for SDS-PAGE................. 44

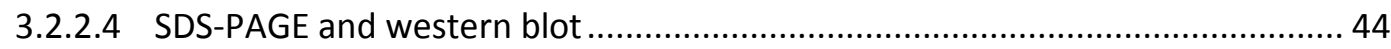

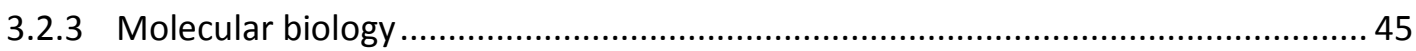

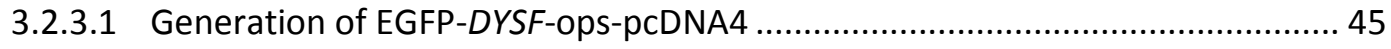

3.2.3.2 Generation of EGFP-L1431P-ops-pcDNA4 by Dpnl-mediated site-directed

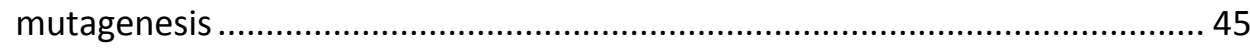

3.2.3.3 Amplification of DNA by polymerase chain reaction (PCR) …......................... 46

3.2.3.4 Restriction of DNA with restriction endonucleases .......................................... 46

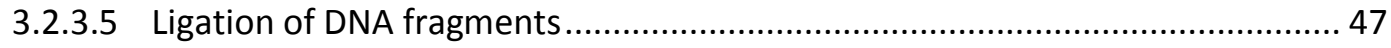

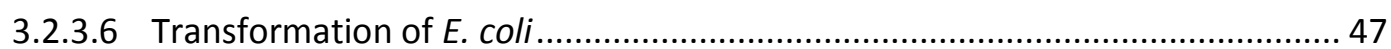

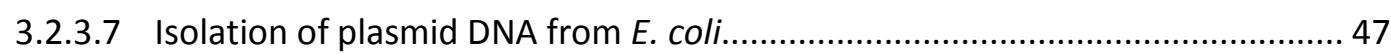

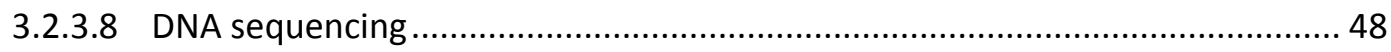

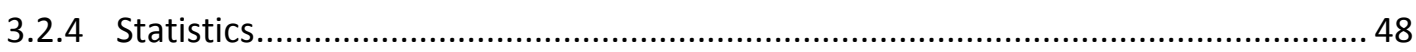

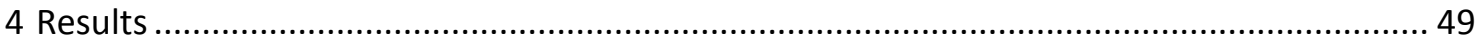

4.1 Dysferlin and BIN1 localize to different parts of the T-tubule system in C2C12 cells .... 49 
4.2 Abnormal development of the T-tubule system in LGMD2B patient myoblasts............ 50

4.3 Dysferlin is expressed at the cardiac T-tubule system during maturation ..................... 52

4.4 Dysferlin-deficiency leads to altered transverse-axial tubule system in adult cardiomyocytes

4.4.1 Dysferlin loss results in reorientated transverse-axial tubule system in cardiomyocytes 56

4.4.2 Structural parameters of skeletonized tubular membranes are changed in dysferlindeficient cardiomyocytes 58

4.5 Dysferlin gets inserted into the ER. 59

4.5.1 Efficiency of dysferlin insertion into the ER varies between mammalian cell lines. 61

4.5.2 Increased glycosylation of dysferlin mutant L1341P compared to wild-type in HeLa cells 63

4.6 Depletion of the TRC40 pathway component WRB has no effect on the localization or steady-state level of dysferlin 64

4.7 PBA increases steady-state level of dysferlin variants...................................................66

4.8 No effect of PBA on tubulation properties of wild-type dysferlin in HeLa cells 67

4.9 Dysferlin mutant R959W closely associates with the Golgi marker giantin in C2C12 myoblasts

4.10 Readthrough of DYSF patient nonsense codons can be differentially induced by G418 74

5 Discussion 78

5.1 Dysferlin and BIN1 function at different subcompartments of the tubule system during development 78

5.2 Early developmental abnormalities of the T-tubule system in patient myoblasts due to dysferlin loss 80

5.3 Dysferlin is also a key player of cardiac tubule system biogenesis............................... 81

5.4 First stop on the route of dysferlin: the Endoplasmic reticulum .................................. 83

5.5 4-Phenylbutyrate as potential therapeutic for the treatment of dysferlinopathy .......... 86

5.6 Therapeutic modulation of dysferlin expression by translational readthrough.............. 89

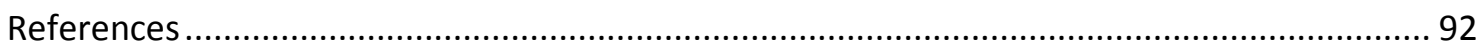

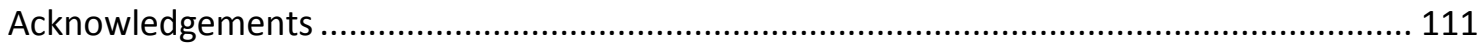

Curriculum vitae ...................................................................................... 114 


\section{Abstract}

Dysferlinopathies are a heterogeneous group of congenital muscle disorders characterized by late-onset muscular dystrophy and increased muscle prowess before onset of symptoms. Mutations in the DYSF gene encoding the protein dysferlin have been identified as the common genetic cause of this rare disease spectrum. However, little is known about the pathomechanism leading to muscle degeneration and therefore, no curative treatment is available. Dysferlin is a tail-anchored multi-C2 domain protein belonging to the ferlin protein family. For a long time, it has mainly been implicated in membrane repair. In recent years, new evidence uncovered an additional and fundamental role for dysferlin: the formation of the Ttubule system in skeletal muscle.

The aim of this study was to further elucidate the cellular role in skeletal and heart muscle and the trafficking of dysferlin. This would help to reveal the molecular pathomechanism of dysferlin-deficient muscular dystrophy and give the possibility to identify new targets for the development of therapeutic approaches.

The finding of an abnormal T-tubule system in developing dysferlinopathy patient myotubes suggests that dysferlin is essential during a very early stage of T-tubule biogenesis in skeletal muscle. Not only the T-tubule system in skeletal muscle, but also the cardiac tubular system of dysferlin-deficient mice is altered with loss and axialization of membrane tubules. This finding, together with the localization and increased expression of dysferlin at the developing T-tubule system in cardiomyocytes, support the role of dysferlin as a key player of cardiac T-tubule biogenesis. Furthermore, these findings may explain the pathology of dysferlin-deficiency in skeletal and heart muscle. The investigation of the cellular trafficking shows that mutated dysferlin is retained in the endoplasmic reticulum or Golgi network and provides evidence that functional dysferlin follows the secretory pathway to reach the plasma and T-tubule membrane. Treatment with the chemical chaperone 4-phenylbutyrate (PBA) increases the steady-state protein levels and partially rescues functional deficits of dysferlin mutants. Thus, PBA might be a potential therapeutic for the treatment of dysferlinopathy. Another therapeutic approach is the induction of translational readthrough by aminoglycosides in patients harboring nonsense DYSF mutations. The systematic analysis of readthrough induction for all recurrent DYSF nonsense mutations revealed a high variety of readthrough efficiency and might provide a suitable prediction for the treatability of dysferlinopathy patients. This gives the possibility to selectively treat patients with high therapeutic potential as aminoglycosides are associated with severe adverse effects. 


\section{List of figures}

Figure 1 | Triad structure and T-tubule system in the skeletal muscle.................................... 1

Figure 2 | Excitation-contraction coupling in skeletal myofibers. ............................................. 2

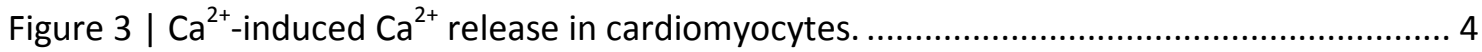

Figure 4 | Structural characteristics of C2 domain proteins. ............................................... 9

Figure 5 | Aminoglycoside-induced readthrough therapy of diseases caused by nonsense

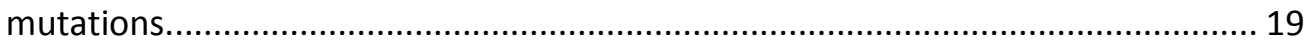

Figure 6 | Differential localization of dysferlin and BIN1 in developing myotubes. ................... 50

Figure 7 | Tubular membrane bundles in LGMD2B patient myotubes...................................... 51

Figure 8 | Dysferlin colocalizes with Cav1.2 in postnatal rat cardiomyocytes and dysferlin expression peaks after birth........................................................................... 54

Figure 9 | Altered morphology of tubular membrane network in ventricular cardiomyocytes of dysferlin-deficient mice.

Figure 10 | Altered directionality of transverse-axial tubule system in ventricular cardiomyocytes of dysferlin-deficient mice.

Figure 11 | Altered structural parameters of transverse-axial tubule system in ventricular cardiomyocytes of dysferlin-deficient mice.

Figure 12 | Use of the glycosylation tag opsin as reporter for protein integration into the ER. 59

Figure 13 | Site-specific Thrombin cleavage of dysferlin as prerequesite for glycosylation analysis.

Figure 14 | Differential glycosylation of dysferlin-ops in mammalian cell lines.

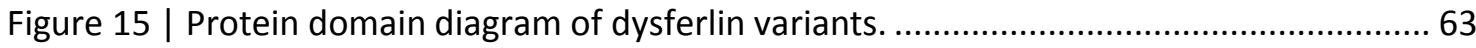

Figure 16 | Increased glycosylation of mutant L1341P compared to wild-type in HeLa cells. .. 64

Figure 17 | No effect of cardiac Wrb knockout on dysferlin localization and expression. 65

Figure 18 | Increased steady-state level of dysferlin WT and mutants R959W and L1341P upon PBA treatment.

Figure 19 | Wild-type dysferlin does neither colocalize with Golgi marker giantin, nor with ER marker PDI.

Figure 20 | Dysferlin mutant R959W colocalizes with giantin and PBA rescues tubulation deficiency of R959W mutant.

Figure 21 | Dysferlin mutant L1341P partially colocalizes with the ER marker PDI.

Figure 22 | While wild-type dysferlin localizes to the T-tubule system, mutant R959W closely associates with giantin in $\mathrm{C} 2 \mathrm{C} 12$ cells.

Figure 23 | Spectrum of nonsense mutations in the DYSF gene.

Figure 24 | Schematic representation of dual reporter for readthrough analysis in mammalian cells. 75

Figure 25 | Differential readthrough induction efficiancy of DYSF SCCs by G418. 


\section{List of tables}

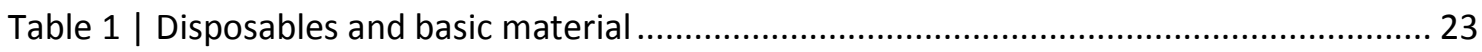

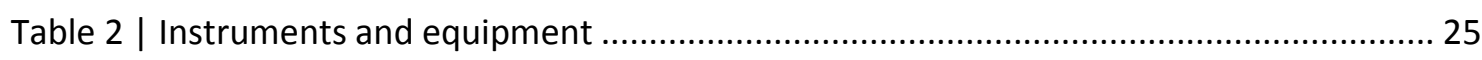

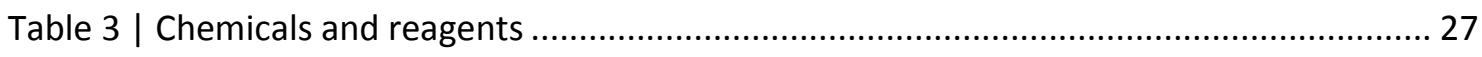

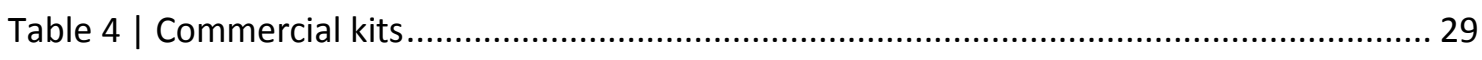

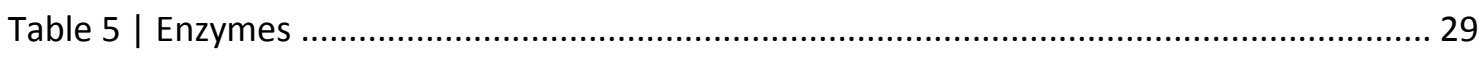

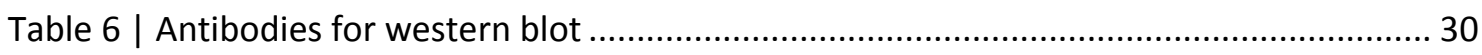

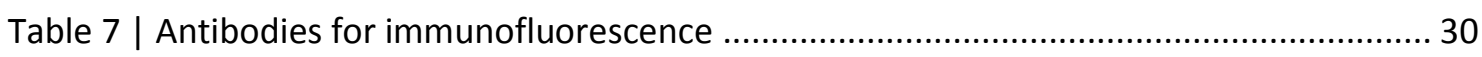

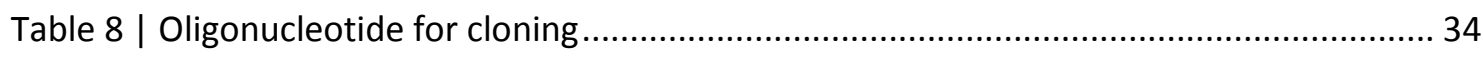

Table 9 | Oligonucleotides for Dpnl-mediated site-directed mutagenesis................................. 34

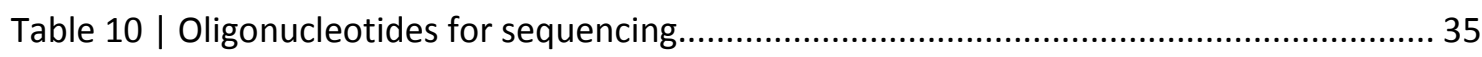

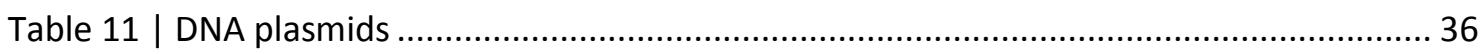

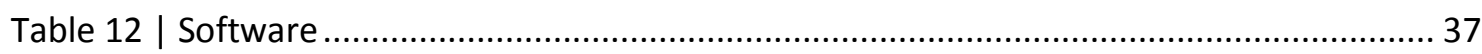

Table 13 | Protocol for preparation of stacking and resolving gels for SDS-PAGE.................... 44

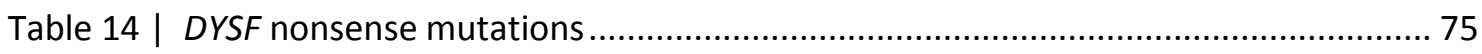




\section{List of abbreviations}

\begin{tabular}{|c|c|}
\hline$A$ & Adonosine \\
\hline AAV & Adeno-associated virus \\
\hline AON & Antisense oligonucleotides \\
\hline APS & Ammonium persulfate \\
\hline BIN1 & Protein bridging integrator 1 \\
\hline BSA & Bovine serum albumin \\
\hline C & Cytosine \\
\hline CAML & Calcium signal-modulating cyclophilin ligand \\
\hline CAV & Caveolin \\
\hline CFTR & Cystic fibrosis transmembrane conductance regulator \\
\hline $\mathrm{CH}_{3} \mathrm{CO}_{2} \mathrm{~K}$ & Potassium acetate \\
\hline CICR & $\mathrm{Ca}^{2+}$-induced $\mathrm{Ca}^{2+}$ release \\
\hline DAPI & 4',6-diamidino-2-phenylindole \\
\hline DGC & Dystrophin-glycoprotein complex \\
\hline DMEM & Dulbecco's Modified Eagle Medium \\
\hline DMSO & Dimethyl sulfoxide \\
\hline DTT & Dithiothreitol \\
\hline EDTA & Ethylenediaminetetraacetic acid \\
\hline EGTA & Ethylene glycol tetraacetic acid \\
\hline ELP2 & Elongator protein 2 \\
\hline FBS & Fetal bovine serum \\
\hline FER1L5 & Fer-1-like protein 5 \\
\hline G & Guanine \\
\hline GAPDH & Glyceraldehyde-3-phosphate dehydrogenase \\
\hline $\mathrm{HCl}$ & Hydrochloric acid \\
\hline HF & Heart failure \\
\hline HRP & Horseradish peroxidase \\
\hline Hsp70 & 70-kDa heat shock protein \\
\hline JPH & Junctophilin \\
\hline $\mathrm{KH}_{2} \mathrm{PO}_{4}$ & Monopotassium phosphate \\
\hline LB & Lysogeny broth \\
\hline MG53 & Mitsugumin 53 \\
\hline $\mathrm{Na}_{2} \mathrm{PO}_{4}$ & Disodium phosphate \\
\hline
\end{tabular}




\begin{tabular}{|c|c|}
\hline $\mathrm{NaCl}$ & Sodium chloride \\
\hline $\mathrm{NaHCO}_{3}$ & Sodium bicarbonate \\
\hline $\mathrm{NaN}_{3}$ & Sodium azide \\
\hline $\mathrm{NaOH}$ & Sodium hydroxide \\
\hline NP & Nonidet $^{\mathrm{TM}} \mathrm{P}$ \\
\hline PBA & 4-phenylbutyrate \\
\hline PFA & Paraformaldehyde \\
\hline $\mathrm{PI}$ & Phosphoinositide \\
\hline $\mathrm{PI}(4) \mathrm{P}$ & Phosphatidylinositol-4-phosphate \\
\hline $\mathrm{Pl}(4,5) \mathrm{P}_{2}$ & Phosphatidylinositol-4,5-bisphosphate \\
\hline PMSF & Phenylmethane sulfonyl fluoride \\
\hline RYR2 & Ryanodine receptor 2 \\
\hline SB & Sleeping Beauty \\
\hline SDS & Sodium dodecyl sulfate \\
\hline SH3 & Src homology 3 \\
\hline SICM & Scanning ion conductance microscopy \\
\hline SRP & Signal recognition particle \\
\hline STAT-3 & Signal transducer and activator of transcription-3 \\
\hline TA & Tail-anchored \\
\hline TAE & TRIS-acetate-EDTA \\
\hline TAT & trans-activator of transcription \\
\hline TATS & Transverse-axial tubule system \\
\hline TBS & Tris-buffered saline \\
\hline TEMED & $\mathrm{N}, \mathrm{N}, \mathrm{N}^{\prime}, \mathrm{N}^{\prime}$-Tetramethylethan-1,2-diamin \\
\hline TRC40 & Transmembrane domain recognition complex $40 \mathrm{kDa}$ \\
\hline T-tubule & Transverse tubule \\
\hline$U$ & Uracil \\
\hline WRB & Tryptophan Rich Basic protein \\
\hline
\end{tabular}




\section{Symbols and units}

\begin{tabular}{ll}
$\alpha$ & Alpha \\
$\beta$ & Beta \\
$\mathrm{K}$ & Kappa \\
$\%$ & Percent \\
${ }^{\circ} \mathrm{C}$ & Degree Celsius \\
$\mathrm{A}$ & Ampere \\
$\mathrm{Da}$ & Dalton \\
$\mathrm{g}$ & Gram \\
$\mathrm{h}$ & Hour \\
$\mathrm{k}$ & Kilo \\
$\mathrm{b}$ & Base \\
$\mathrm{L}$ & Liter \\
$\mathrm{m}$ & Milli (10-3) \\
$\mathrm{H}$ & Micro (10-6) \\
$\mathrm{M}$ & Molar (mol/L) \\
$\mathrm{min}$ & Minute \\
$\mathrm{sec}$ & Second \\
$\mathrm{n}$ & Nano (10-9) \\
$\mathrm{rpm}$ & Rounds per minute \\
\hline
\end{tabular}




\section{Introduction}

\subsection{Skeletal muscle anatomy and function}

The skeletal muscle fiber is a syncytium originating from fusion of myogenic precursor cells, myoblasts, into elongated multinucleated myotubes during myogenesis (Holtzer and Abbott, 1958). The highly organized complex of large tube-shaped cells is one of the prerequisites for optimal force development. Another requirement for precise muscle function is the temporal coupling of the motor neuron signal to the contraction of the myofiber. Muscle fibers possess an extensive membrane system, the transverse tubule system (T-tubule system) (Franziniarmstrong and Porter, 1964), composed of tube-shaped plasma membrane (sarcolemma) invaginations with a diameter of approximately $20-40 \mathrm{~nm}$ which transversally penetrate the whole fiber (Franzini-Armstrong et al., 1975). The T-tubules congregate with the terminal cisternae of the longitudinally orientated sarcoplasmic reticulum (SR) to form anatomical and functional structures called triads. One triad is composed of one T-tubule enclosed by two SR cisternae (Figure 1). The T-tubule and SR membranes are located in very close proximity with a gap of $12 \mathrm{~nm}$ (Boncompagni et al., 2006).

A

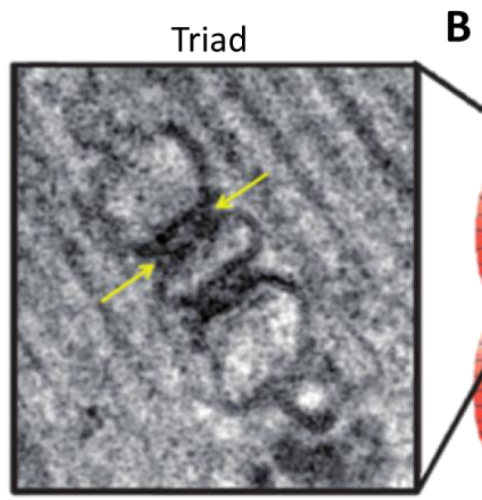

B

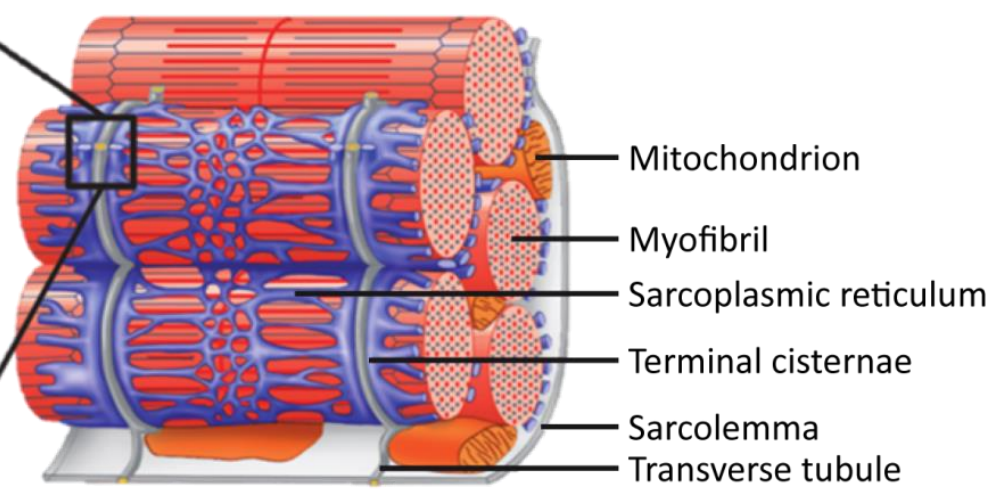

Figure 1 | Triad structure and T-tubule system in the skeletal muscle. (A) Electron micrograph of a triad structure. A central T-tubule is enclosed on both sides by one terminal cisterna of the SR. Arrows indicate electron-dense structures between the T-tubule and SR membrane representing the DHPRRyR1 complex. (B) Schematic representation of a skeletal muscle basic unit and surrounding membranes. T-tubules (gray) are transverse invaginations continuous with the plasma membrane. The SR network (blue) expands longitudinally along the muscle fiber. Adapted from Marieb \& Hoehn, 2007, (C) 2007 by Pearson Education, Inc.

The action potential, which is generated through electrochemical signal transduction, is not restricted to the sarcolemma but propagates along the T-tubule system into the interior of the muscle fiber to simultaneously excite the whole myofiber and to facilitate excitation- 
contraction coupling (EC coupling). In this process, depolarization of the T-tubule membrane leads to activation of the voltage-sensitive L-type $\mathrm{Ca}^{2+}$ channel (Dihydropyridine receptor, $\left.\mathrm{Ca}_{\mathrm{v}} 1.1\right)$ which is directly coupled to the $\mathrm{Ca}^{2+}$-releasing ryanodine receptor 1 (RyR1) of the SR membrane. Opening of RyR1 allows fast release of $\mathrm{Ca}^{2+}$ from the $\mathrm{SR}$, the main $\mathrm{Ca}^{2+}$ store of the muscle fiber, and muscle contraction (Ashcroft, 1991; Bezanilla et al., 1972) (Figure 2). When the coupling of these two receptors is disturbed for instance by an abnormally configured structure of T-tubule and SR membranes the process of EC coupling and directly $\mathrm{Ca}^{2+}$ homeostasis are affected (Tjondrokoesoemo et al., 2011).

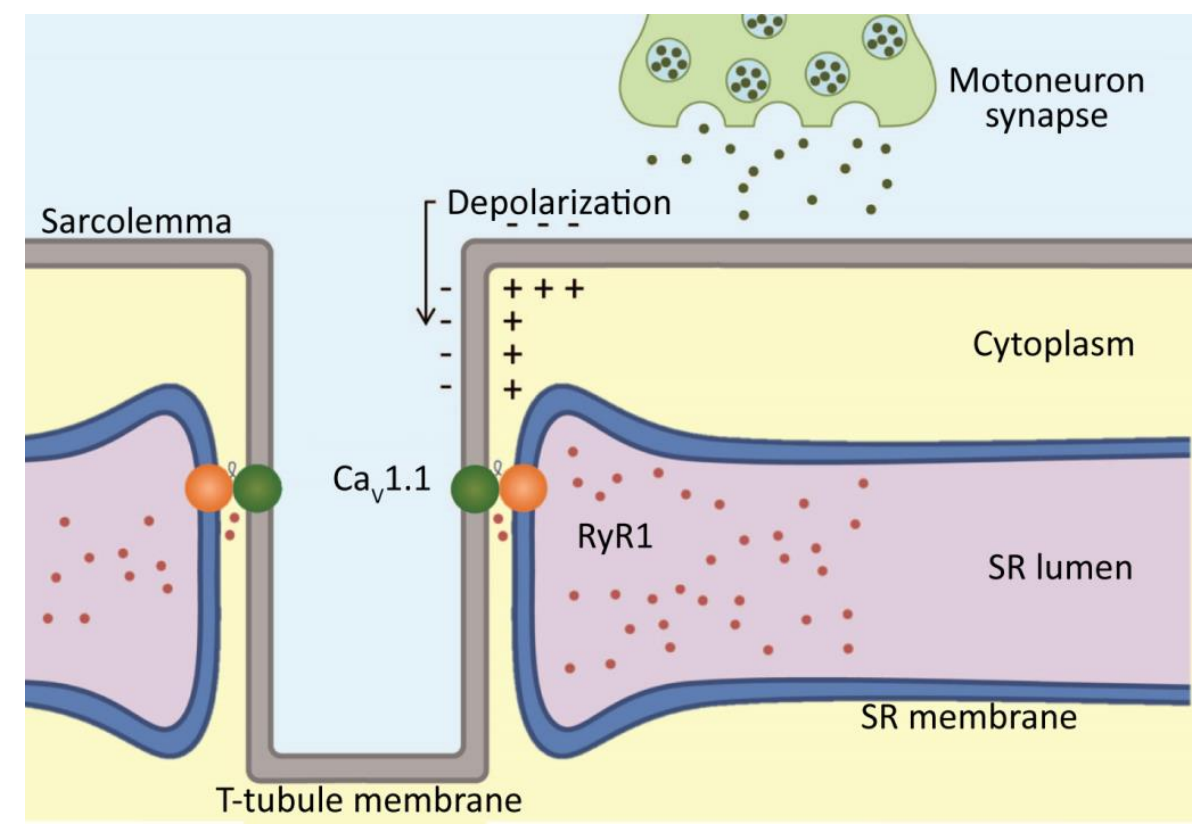

Figure 2 | Excitation-contraction coupling in skeletal myofibers. Scheme showing the connection between an electical action potential and the cytoplasmic $\mathrm{Ca}^{2+}$ increase at the triad, finally, leading to contraction of the skeletal myofiber. The neurotransmitter released by terminal synapses of motoneurons leads to depolarization of the myofiber sarcolemma. The action potential propagates along the membrane of the T-tubule system into the inner of the fiber and activates voltage-sentive $\mathrm{Ca}^{2+}$ channels of the skeletal muscle, Cav1.1. Conformational change of $\mathrm{Ca}_{\mathrm{V}} 1.1$ leads via direct interaction with the $\mathrm{Ca}^{2+}$ release channel RyR1 to its opening and massive influx of $\mathrm{Ca}^{2+}$ from the SR into the cytoplasm.

\subsection{Cardiac T-tubule system}

Besides the skeletal, also the heart muscle is described as striated due to the highly organized arrangement of sarcomeres, the contractile units of muscle cells. Still, there are morphological, functional and molecular differences between skeletal myofibers and cardiomyocytes. Heart cells do not form a multi-nucleated syncytium upon final differentiation 
but are mainly mono- or binucleated (Bensley et al., 2016). Ventricular cardiomyocytes possess a tubular membrane system which was initially thought to have exclusively a transverse orientation to the long axis of the myocyte (Lindner, 1957). These tubules occur periodically with regular spacing of approximately $2 \mu \mathrm{m}$ and are anchored along sarcomeric Zdiscs. They have a variable diameter of 200 to $400 \mathrm{~nm}$ (Fawcett and McNutt, 1969; Kostin et al., 1998; Savio-Galimberti et al., 2008; Soeller and Cannell, 1999; Wagner et al., 2012). In the 1970s, axially orientated membrane structures were detected for the first time in ventricular cardiomyocytes that interconnect transverse membranes within the cytoplasm (Sperelakis and Rubio, 1971) revealing a highly complex system of elongated membranes, called the transverse-axial tubule system (TATS) (Forbes et al., 1984). It has been estimated that the TATS is composed of $60 \%$ transverse and $40 \%$ axial membranes (Soeller and Cannell, 1999). Like in skeletal myofibers, also in cardiomyocytes membrane tubules are highly associated with the SR. Contrastingly, one transverse or axial tubule of the TATS is in close vicinity to only one terminal cisterna of the SR, an association called therefore cardiac dyad. The membranes of those two organelles are separated by a narrow cleft of approximately $15 \mathrm{~nm}$ (Cannell et al., 2006; Fawcett and McNutt, 1969; Nelson and Benson, 1963; Rostgaard and Behnke, 1965). The cardiac dyad is the contact site of voltage-gated $\mathrm{Ca}^{2+}$ channel $\mathrm{Ca}_{\mathrm{V}} 1.2$ located at transverse and axial mambranes of the TATS and the $\mathrm{Ca}^{2+}$ sense and release channel ryanodine receptor 2 (RyR2) at the membrane of the cardiac SR (Pinali et al., 2013; Swift et al., 2012). In cardiomyocytes contraction is initiated by a mechanism called $\mathrm{Ca}^{2+}$-induced $\mathrm{Ca}^{2+}$ release (CICR). The sarcolemma of cardiomyocytes gets depolarized through electrochemically propagation of the action potential from adjacent cells. Due to its continuity with the plasma membrane, also the membrane of the TATS gets depolarized leading to activation and opening of Cav1.2. An initial influx of $\mathrm{Ca}^{2+}$ from the extracellular space through Cav1.2 triggers the opening of RyR2 and consequently the massive release of $\mathrm{Ca}^{2+}$ from the $\mathrm{SR}$ into the cytoplasm finally inducing contraction (Fabiato, 1983; Stern, 1992) (Figure 3). 


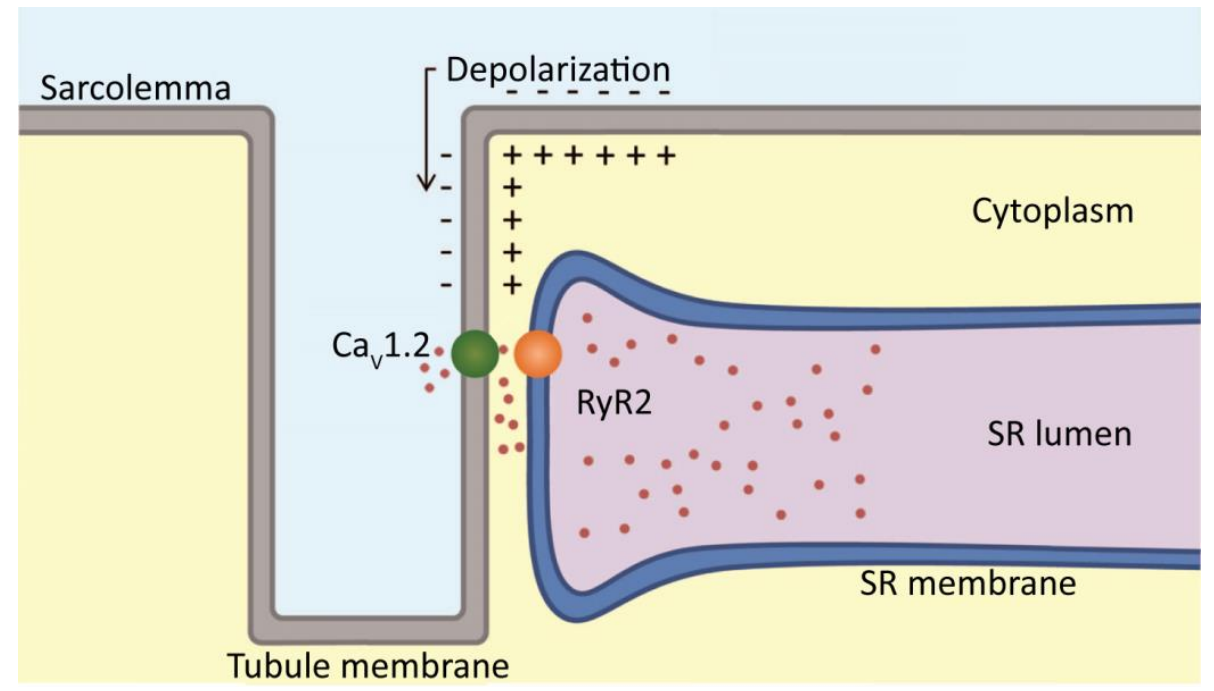

Figure 3 | Ca ${ }^{2+}$-induced $\mathrm{Ca}^{2+}$ release in cardiomyocytes. Scheme showing a cardiac dyad and the increase of cytoplasmic $\mathrm{Ca}^{2+}$ as result of electric stimulation in cardiomyocytes. The sarcolemma of a cardiomyocyte gets depolarized through electrical coupling with adjacent myocytes. The depolarization propagates along the membrane of the transverse-axial membrane system and leads to opening of the cardiac voltage-gated $\mathrm{Ca}^{2+}$ channel $\mathrm{Ca}_{\mathrm{V}} 1.2$. The moderate influx of $\mathrm{Ca}^{2+}$ from the extracellular space triggers opening of the cardiac $\mathrm{Ca}^{2+}$ sense and $\mathrm{Ca}^{2+}$ release channel RyR2 resulting in massive flow of $\mathrm{Ca}^{2+}$ from the SR into the cytoplasm of the cardiomyocyte.

\subsection{Other functions of tubule system}

Besides its direct importance for EC coupling, the T-tubule system functions in muscle fatigue, muscle differentiation, intracellular trafficking and plasma membrane repair. Experimental osmotic shock, for instance by treatment of single myofibers with glycerol, leads to tubule vacuolization with increase in tubule volume and partial detachment of T-tubules and tubulederived vacuoles from the sarcolemma. Vacuolization was also observed after fatigue stimulation by induced contraction of Xenopus laevis myofibers (Krolenko and Adamian, 2000; Krolenko et al., 1998; Lännergren et al., 1999). Vacuolization is reversible and highlights the plasticity of the T-tubule system, a characteristic which may be important for water balance, transport and recovery from fatigue of skeletal myofibers (Krolenko and Lucy, 2001; Krolenko et al., 1998). Furthermore, the T-tubule system seems to serve as a membrane reservoir for the repair of membrane ruptures. The process involves protein-assisted recruitment of tubulederived membranes to the sarcolemma wound (Fuson et al., 2014; Klinge et al., 2007; Lek et al., 2013). The TATS in cardiomyocytes possesses membrane folds creating a local slow diffusion zone for ions and thereby separating it from the bulk extracellular space. Through this specialized microanatomy, ion concentrations at the triads stay comparatively stable even 
upon concentration changes around the myocytes, decreasing the risk for arrhythmias (Hong et al., 2014).

\subsection{Biogenesis of the tubule system}

Until now, the process of T-tubule development is only poorly understood. Several models exist which amongst others describe the biogenesis of T-tubules as an endocytosis-like mechanism with tubules deriving from the plasma membrane (Ishikawa, 1968). Another model suggests the formation of tubules by addition of newly synthesized vesicles similar to the process of exocytosis (Schiaffino et al., 1977). Short tubules are first detected in the chicken skeletal muscle at embryonic day 14 , being continuous with the plasma membrane and showing a longitudinal orientation along the myotube at E15 (Flucher et al., 1993). Subsequently, at E16, a mainly longitudinal tubule network fills the whole myofiber. The SR develops and associates earlier with myofibrils then the tubule system. At E15 SR and tubule membrane attach to each other. The formation of the triads, at which from now on EC coupling occurs (Flucher et al., 1993), goes hand in hand with the translocation of Cav1.1 from the sarcolemma to membrane tubules (Romey et al., 1989). Much later during embryonic development, transverse branches are formed. The mature transverse structure of the Ttubule system is reached not earlier than several weeks after hatching (Flucher et al., 1993). Same is true for the biogenesis of the T-tubule system in mice. At birth, orientation of tubules is mainly longitudinal with some transverse connection. Final maturation is accomplished within the first 2 weeks of life (Franzini-Armstrong, 1991; Takekura et al., 2001). The exact molecular mechanism of T-tubule biogenesis is under investigation. Still, some proteins, including bridging integrator 1, junctophilin 2, caveolin 3 and dysferlin, have been directly implicated in this process.

\subsection{Caveolin 3}

Caveolins (CAVs) are the proteinaceous component and creators of flask-shaped plasma membrane invaginations with a size of 60 to $80 \mathrm{~nm}$, the caveolae. Caveolae specifically function in several processes, such as signal transduction and lipid regulation (Parton and Simons, 2007), but also are involved in the development of the tubule system as first proposed in 1968 (Ishikawa, 1968). One of the CAV proteins, CAV3, is mainly expressed in the striated muscle (Tang et al., 1996). CAV3 expression is specifically induced during differentiation of the skeletal myoblast cell line $\mathrm{C} 2 \mathrm{C} 12$, and CAV3 is localized to the developing T-tubule system as 
shown by colabeling with Cav1.1 (Parton et al., 1997; Tang et al., 1996). Depletion of CAV3 in mice is accompanied by alterations of the skeletal T-tubule system with dilation and longitudinal orientation of tubules (Galbiati et al., 2001). Mutations in the human CAV3 gene are associated with skeletal and cardiac muscle diseases: autosomal dominant limb-girdle muscular dystrophy type 1C (LGMD1C, OMIM \#607801), rippling muscle disease (OMIM \#606072), familial hypertrophic cardiomyopathy (OMIM \#192600) and long QT-syndrome (OMIM \#611818) (Betz et al., 2001; Hayashi et al., 2004; Minetti et al., 1998; Vatta et al., 2006).

\subsection{Junctophilin 2}

Junctophilins (JPHs) 1 and 2 in skeletal and heart muscle, respectively, have a C-terminal transmembrane domain which is anchored in the SR membrane and an N-terminal phospholipid binding domain with specific affinity for the membrane of the tubule system (Takeshima et al., 2000). The physical bridging of terminal SR membrane with T-tubule membrane by JPHs is a critical step during T-Tubule biogenesis as it occurs simultaneously with postnatal tubule maturation and strongly enhances EC coupling efficiency (Chen et al., 2013; Ziman et al., 2010). Cardiac-specific knockdown of JPH2 in mice is associated with the development of heart failure and reduced CICR due to improper dyad formation (van Oort et al., 2011). JPH1 deficiency in mice is lethal at birth. Muscles of embryos and neonatal mice show dramatic alterations in triad morphology, which is characterized by a reduced number of triads and by an increased junctional SR volume.

\section{$1.7 \quad$ BIN1}

The human BIN1 gene encompasses 20 exons which can be spliced into several tissue-specific isoforms of the protein bridging integrator 1 (BIN1, Amphiphysin 2). Isoform 8 is expressed only in the skeletal muscle and includes the muscle-specific exon 11 (Wechsler-Reya et al., 1997), whereas inclusion of exon 13 is specific for the cardiac form. The N-terminal part of BIN1 including an amphipathic helix and the BAR domain, is able to form a crescent-shaped dimer with itself or with the N-terminus of amphiphysin 1 (Peter et al., 2004; Wigge et al., 1997a). The muscle-specific exon 11 encodes a short sequence called phosphoinositide (PI) binding motif, which increases the binding affinity of BIN1 towards phospholipids (Fugier et al., 2011). An Src homology 3 (SH3) domain is part of all BIN1 isoforms (Ramjaun and McPherson, 1998) and binds peptides with proline-rich motifs (Yu, 1994). In isoform 8, the SH3 domain 
binds the BAR and PI domains intramolecularly and competes with the phospholipid phosphatidylinositol-4,5-bisphosphate $\left(\mathrm{PI}(4,5) \mathrm{P}_{2}\right)$. The presence of $\mathrm{PI}(4,5) \mathrm{P}_{2}$ and binding to $\mathrm{BAR}$ and $\mathrm{PI}$ domains induce a conformational change of BIN1 and the release of the SH3 domain from BAR and PI binding. Subsequently, the SH3 domain can interact with proteins exhibiting an adequate proline-rich motif such as the GTPase dynamin 2 on $\mathrm{PI}(4,5) \mathrm{P}_{2}$-enriched membranes (Kojima et al., 2004). Amphiphysins are reported to play a role during the process of endocytosis in neuronal and non-neuronal cells through interaction with proteins such as dynamin which are associated with clathrin-coated pits (Bauerfeind et al., 1997; David et al., 1996; Shupliakov, 1997; Wigge et al., 1997b). It is assumed that BIN1 mediates the recruitment of effector proteins to the site of membrane fission during the endocytic process (Taylor et al., 2011).

BIN1 is reported to be involved in T-tubule biogenesis. It localizes to the developing T-tubule system in skeletal and heart muscle (Hong et al., 2010; Lee et al., 2002). The protein induces the formation of membrane invaginations and cytosolic tubules that are continuous with the plasma membrane upon heterologous expression in $\mathrm{CHO}$ cells and myoblasts. The BIN1 protein directly tubulates liposomes in vitro (Lee et al., 2002). This function is considered as analogous to membrane reorganization events during development of the T-tubule system. A direct sculpting function of BIN1 for the cardiac TATS has been established in recent years. BIN1 shapes the tubule system and generates microfolds of the T-tubule membrane leading to low ion diffusion inside the tubule. The separation of these microdomains from the bulk extracellular space is possibly a mechanism to protect the heart from arrhythmias (Hong et al., 2014). By forming these folded membranes, BIN1 assembles Cav1.2 molecules to form $C_{v} 1.2$ clusters at the tubule membrane. Furthermore, BIN1 regulates $\mathrm{Ca}^{2+}$ channel trafficking and assembly by attracting and anchoring Cav1.2 molecules that are delivered via microtubulemediated transport from the Golgi network to the tubular membrane (Hong et al., 2010). Upon activation of $\beta$-adrenergic receptor signaling BIN1 recruits phosphorylated RyR2 into dyads, thereby increasing $\mathrm{Ca}^{2+}$ release (Fu et al., 2016). An abnormally formed T-tubule system has been detected in Drosophila melanogaster upon gene knockout (Razzaq et al., 2001), in adult mouse skeletal muscle fibers after BIN1 knockdown (Tjondrokoesoemo et al., 2011) and in human muscle biopsies of BIN1-deficient patients (Toussaint et al., 2011). Reduced expression of BIN1 is detected in heart failure leading to impaired trafficking and clustering of $C_{v} 1.2$ and RyR2 at cardiac dyads. Finally, contractility is reduced and arrhythmogenic risk is increased due to RyR2 uncoupling and $\mathrm{Ca}^{2+}$ leaks from the SR (Fu et al., 2016; Hong et al., 2012). BIN1 mutations are implicated in a rare congenital myopathy called autosomal 
recessive centronuclear myopathy (ARCNM, OMIM \#255200) characterized by early disease onset, a proximal slowly progressive skeletal muscle weakness and centralized nuclei (Böhm et al., 2010, 2013, 2014; Claeys et al., 2010; Nicot et al., 2007).

\subsection{Dysferlin}

The DYSF gene encodes the $230 \mathrm{kDa}$ protein dysferlin which belongs to the ferlin protein family (Anderson et al., 1999; Matsuda et al., 1999). The ferlins are named after their homology to the Caenorhabditis elegans protein Fer-1 that is essential for fusion of membranous organelles to the sperm plasma membrane during spermiogenesis (Achanzar and Ward, 1997). Human orthologs of dysferlin are myoferlin, otoferlin and Fer-1-like protein 5 (FER1L5). Otoferlin plays a role in exocytosis of synaptic vesicles in the inner ear hair cells and is crucial for $\mathrm{Ca}^{2+}$-dependent fusion of vesicles to the plasma membrane (Ramakrishnan et al., 2014). Mutations in the gene encoding otoferlin and leading to a nonfunctional or absent protein result in nonsyndromic deafness (Yasunaga et al., 2000). Myoferlin is highly expressed in myogenic precursor cells during differentiation and plays a crucial role during myoblastmyoblast and myoblast-myotube fusion (Doherty et al., 2005). Until now, no pathogenic mutations have been described for the genes encoding myoferlin and FER1L5. All ferlins are type II transmembrane proteins and have a similar domain structure. Besides a C-terminal transmembrane domain, a DysF sequence and ferlin domains, they possess multiple C2 domains (Davis et al., 2002) (Figure 4). C2 domains, like the proteinkinase C C2 domains, mediate $\mathrm{Ca}^{2+}$-dependent membrane binding via phospholipid interaction (Coussens et al., 1986). The ferlin C2 domains are diverse as each $C 2$ domain is more similar to its corresponding domain in paralogs than to the other C2 domains in the same ferlin (Washington and Ward, 2006). This indicates distinct domain functions within one protein. The C2A domain of dysferlin binds phosphatidylinositol-4-phosphate $(\mathrm{PI}(4) \mathrm{P})$ and $\mathrm{PI}(4,5) \mathrm{P}_{2}$, a phospholipid that is enriched in the membrane of the T-tubule system, in a $\mathrm{Ca}^{2+}$-dependent manner (Hidalgo et al., 1986; Therrien et al., 2009). 

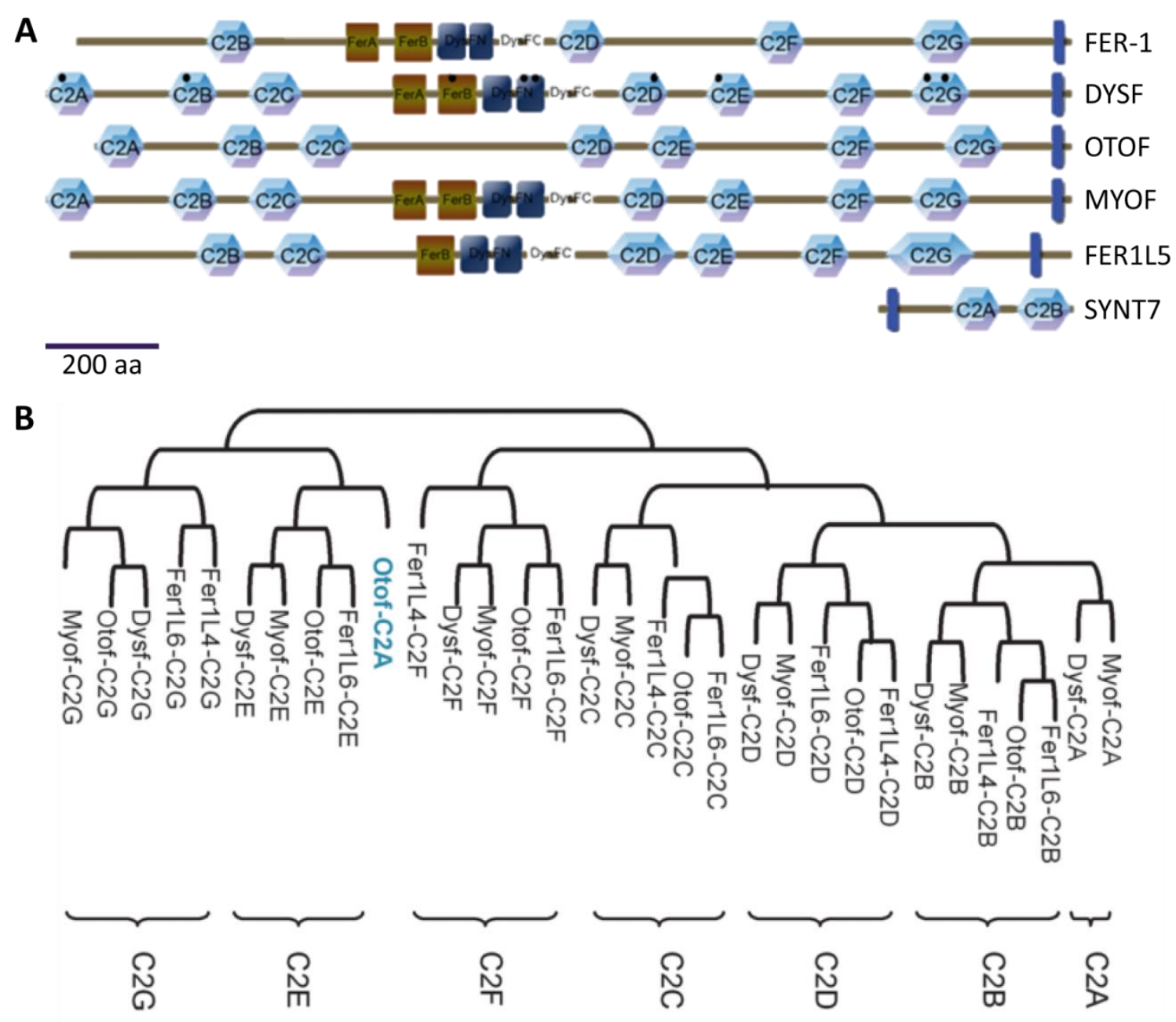

Figure 4 | Structural characteristics of C2 domain proteins. (A) Protein domain structure of Fer-1 and mammalian ferlin-like proteins showing high similarity. (B) Phylogenetic tree based on alignment of individual ferlin C2 domain sequences. Adapted from Han \& Campbell, 2007.

Dysferlin's single transmembrane domain is located at the extreme C-terminus (13 amino acids upstream of the C-terminus), characterizing dysferlin as a tail-anchored (TA) protein (Borgese et al., 2003a). The large N-terminal part is directed into the cytosol and the very short C-terminus is protruded into the extracellular space or organelle lumen (Kerr et al., 2013). Many integral membrane proteins initially pass the ER before being transported to the plasma or organelle membrane (Shao and Hegde, 2011). Due to the domain topology, TA proteins cannot be integrated into the membrane of the ER by the classical co-translational signal recognition particle (SRP)-dependent pathway involving the Sec61-complex (Borgese et al., 2003b; Kutay et al., 1993). As the transmembrane domain is located at the extreme Cterminus it emerges from the ribosome just prior to completion of translation. The mechanism for TA insertion includes both, a cytosolic component shielding the hydrophobic transmembrane domain from the aqueous environment, and an ER-associated component 
integrating the protein into the membrane (High and Abell, 2004). The conserved pathway required for the insertion of TA proteins involves the cytoplasmic chaperone ATPase transmembrane domain recognition complex $40 \mathrm{kDa}$ (TRC40/Asna-1) which posttranslationally interacts with the C-terminal hydrophobic stretch of the TA protein (Favaloro et al., 2008; Stefanovic and Hegde, 2007). TRC40 delivers the TA protein to the ER membrane-integrated receptor complex consisting of WRB (Tryptophan Rich Basic protein) and the mammalian specific CAML (Calcium signal-modulating cyclophilin ligand) (Vilardi et al., 2011; Yamamoto and Sakisaka, 2012) which leads to subsequent insertion into the ER. The nature of dysferlin as a TA protein suggests that it might be integrated into the ER before trafficking to its target membrane. Though, it is not known whether and how dysferlin enters the ER on its way through the cell. It is suggestive that the long $\mathrm{N}$-terminal stretch of dysferlin is interacting with chaperones during translation to ensure accurate folding of the protein. Also, the hydrophobic transmembrane domain emerging from the ribosome at the end of translation has to be shielded be chaperones to avoid aggregation.

\subsection{Dysferlin function}

The best characterized role of dysferlin is its function in membrane repair. The skeletal muscle is able to adapt to functional requirements like repetitive and continuous contractions. Therefore, the plasma membrane needs to be both, flexible and robust, as it is stressed by myofiber contractions. Still, small membrane ruptures, so called microlesions, can occur upon exceeded stress and have to be repaired immediately to protect the cell from massive $\mathrm{Ca}^{2+}$ influx and $\mathrm{Ca}^{2+}$-induced cell damage (Reviewed in (Tidball, 2011)). Upon entry of $\mathrm{Ca}^{2+}$ into the cell, several processes conglomerate in the accumulation of vesicles and other membraneous organelles to form a membrane patch which seals the ruptured plasma membrane by fusion of vesicles with each other and with the sarcolemma (Allen et al., 2010; McDade and Michele, 2014). Ultrastructural analysis of damaged dysferlin-deficient myofibers reveals disruption of the plasma membrane and subsarcolemmal accumulation of vesicles indicating diminished ability of vesicles to fuse and repair membrane lesions (Bansal et al., 2003; Cenacchi et al., 2005; Selcen et al., 2001). Direct disruption of the plasma membrane repair mechanism due to dysferlin-deficiency was reported for skeletal and heart muscle in mouse and human (Bansal et al., 2003; Han et al., 2007; Lostal et al., 2012; Philippi et al., 2012). In dysferlin-competent myofibers the membrane repair process is dependent on the orchestrated interaction of several proteins, of which dysferlin is a key player. Upon membrane rupture, initially, mitsugumin 53 (MG53) accumulates at injury sites in a $\mathrm{Ca}^{2+}$-independent manner (Cai et al., 
2009; Matsuda et al., 2012). Subsequently, dysferlin-containing vesicles arrive strongly $\mathrm{Ca}^{2+}$ dependently together with cytoplasmic annexin A6 at the membrane lesion and form a tight patch (McDade et al., 2014; Roostalu and Strähle, 2012). It has been shown that not the fulllength dysferlin is directly involved in membrane repair. Instead, dysferlin is $\mathrm{Ca}^{2+}$-dependently cleaved by calpains resulting in a so called mini-dysferlinC72 peptide that is decorating the accumulating injury-induced vesicles (Lek et al., 2013; Redpath et al., 2014) (Lek et al., 2013). Finally, vesicle fusion is induced by dysferlin-dependent recruitment of annexin A2 and A1 (Lennon et al., 2003).

In addition to membrane repair, dysferlin is involved in other processes of the myofiber that involve vesicle trafficking and fusion such as cytokine and receptor exocytosis (Chiu et al., 2009; Demonbreun et al., 2011). This function is supported by the observation that dysferlin's C2A and C2B domain interact with $\alpha$-tubulin and microtubules in the skeletal muscle (Azakir et al., 2010).

\subsection{Dysferlin's involvement in T-tubule biogenesis}

In addition to the above mentioned indications such as analogy to the membrane modeling Fer-1 and binding to $\mathrm{PI}(4,5,) \mathrm{P}_{2}$, further observations point to the involvement of dysferlin in the biogenesis of the T-tubule system in skeletal muscle. Dysferlin expression can be detected at the earliest stages of human development examined at 5 - 6 weeks of embryonic age, the stage when regional differentiation of the limbs can be detected (Anderson et al., 1999). Thereby, dysferlin localizes to the plasma membrane and especially the T-tubule system (Ampong et al., 2005; Anderson et al., 1999; Klinge et al., 2008). In differentiating myotubes dysferlin associates with the developing T-tubule network and is only recruited to plasma membrane lesions upon muscle fiber injury (Klinge et al., 2007). In addition to localization at the adult skeletal T-tubule system (Kerr et al., 2013), dysferlin shows localization at T-tubules in regenerating myofibers and only in later stages of regeneration it translocates to the sarcolemma (Klinge et al., 2010a). This lead to the suggestion that dysferlin is involved in Ttubule development of the skeletal muscle. Further evidence for this hypothesis was provided by the observation of a highly abnormally configured T-tubule system with dilated and longitudinally orientated tubules in predystrophic dysferlin-deficient mice (Klinge et al., 2010a) and increased sensitivity of the T-tubule system upon damage (Demonbreun et al., 2014; Kerr et al., 2013). Recent work of our group uncovers a direct shaping role of dysferlin during biogenesis of the skeletal T-tubule system (Hofhuis et al., 2017). Upon heterologous expression in non-muscle cells, dysferlin is able to do novo induce tubular structures. The 
depletion of these structures by cholesterol suggests that they are composed of membrane probably deriving from the plasma membrane. Additionally, dysferlin protein alone is capable of tubulating liposomes in vitro. Comparison of dysferlin and BIN1 revealed that the mechanism underlying tubulation is distinct. While BIN1-induced tubulation is dependent on the GTPase dynamin 2, dysferlin tubulates membranes independently of dynamin 2 . Furthermore, the recent work links dysferlin-induced tubulation necessarily to the phospholipid $\mathrm{PI}(4,5) \mathrm{P}_{2}$, which is enriched in the T-tubule membrane. The tubulation ability of dysferlin is abrogated by pathogenic mutations emphasizing that this function is physiologically relevant (Hofhuis et al., 2017).

\subsection{DYSF gene and mutations}

The DYSF gene is located on chromosome 2p13 and encompasses 55 exons (Liu et al., 1998). DYSF is conserved among mammals with a sequence similarity of $90 \%$ between the human and mouse gene (Vafiadaki et al., 2001). 80 recurrent mutations, occurring in at least three unrelated patients, are described for the DYSF gene (UMD-DYSF mutations database, http://www.umd.be/DYSF/W_DYSF/mutation.html). Mutations include mainly point mutations and small insertions or deletions and cover the entire coding region without any mutational hotspot regions. No genotype-phenotype correlation with respect to the distinct clinical manifestations exists (Klinge et al., 2008, 2010b; Krahn et al., 2009). Approximately a quarter of DYSF mutations comprise nonsense mutations that lead to the generation of a premature termination (stop) codon. Dysferlin mutations may lead to degradation of the altered mRNA through nonsense-mediated mRNA decay (Fujita et al., 2007) or mutant protein aggregation (Wenzel et al., 2006), thus causing total absence or reduction and altered localization of the protein, respectively. One patient has been identified with a truncated variant of dysferlin composed of the transmembrane domain, the last C2 domains and an outof-frame $\mathrm{N}$-terminal sequence. This patient showed late onset of disease and moderate progression compared to other dysferlin-deficient patients (Krahn et al., 2010).

\subsection{Dysferlinopathy}

Muscular dystrophies are a heterogeneous group of inherited muscle diseases characterized by progressive wasting and weakness of skeletal muscles. The age of disease onset is very variable spanning from late childhood to adolescence. Dystrophic muscle is designated by degeneration of muscle fibers, centrally located nuclei, increased fiber size variation and 
substitution of muscle tissue by fat and connective tissue (Flanigan, 2012). Dysferlin-deficient muscular dystrophy (Dysferlinopathy) is a rare disease (incidence 1/100,000 - 200,000,(Moore et al., 2006) caused by mutations in the DYSF gene and comprises mainly three clinically distinct skeletal muscle disorders: autosomal recessive limb-girdle muscular dystrophy type $2 \mathrm{~B}$ (LGMD2B, OMIM \#253601, (Bashir et al., 1998), Miyoshi myopathy (MM, OMIM \#254130(Liu et al., 1998) and distal anterior compartment myopathy (OMIM \#606768, (Illa et al., 2001). Until now, no curative treatment is available. Initial symptoms occur mostly in the first or second decade of life and involve muscle weakness and pain in the proximal or distal limb muscles for LGMD2B and MM, respectively. Additionally, a massive increase of serum creatine kinase levels is detectable indicating destruction of muscle tissue (Linssen et al., 1997; Mahjneh et al., 1996; Weiler et al., 1999). The diagnosis of dysferlinopathy is based on strongly reduced or absent expression of dysferlin protein in muscle biopsies and subsequent confirmation by genetic analysis. The disease course of dysferlin-deficiency is typically slowly progressive with propagation of the symptoms and dystrophic changes to other then primarily affected muscle groups, finally leading to affection of all limb-girdle muscles (Nguyen et al., 2007). In contrast to muscular dystrophies involving defects in the dystrophin-glycoprotein complex (DGC) with instability of the plasma membrane (Koenig et al., 1988), dysferlindeficient muscle maintains a functional DGC, indicating that dystrophic changes do not result from an instable plasma membrane structure but arise from a different pathomechanism (Bansal et al., 2003). Dysferlin-deficiency leads to disturbed myogenic differentiation (De Luna et al., 2007) and accumulation of subsarcolemmal vesicles (Cenacchi et al., 2005; Piccolo et al., 2000). Furthermore, a diminished membrane repair capacity of dysferlin-deficient muscle has been reported (Bansal et al., 2003; Hofhuis et al., 2017). Taking into consideration that dysferlinopathy patients are without symptoms in their first decades of life and that restoration of membrane repair is not sufficient to prevent the dystrophic phenotype (Lostal et al., 2012), it consequentially eliminates the possibility that the dystrophic changes are exclusively caused by a defective membrane repair system (Hofhuis et al., 2017). The function of dysferlin in formation of membrane tubules is linked to the development of the T-tubule system and is defective for pathological mutants leading to the conclusion that dysferlinopathy is caused by the inability of mutant dysferlin to properly form the T-tubule system in skeletal muscle (Hofhuis et al., 2017). Interestingly, dysferlin-deficient patients show a high level of fitness during childhood before onset of symptoms, an observation that is unique among all forms of muscular dystrophy (Klinge et al., 2010b). This phenotype could be reproduced by analyzing the performance of dysferlin-deficient mice in a voluntary running 
wheel experiment (Hofhuis et al., 2017). The explanation for increased muscle prowess upon dysferlin-deficiency might be an alteration in channel function due to deformation of the Ttubule system and redistribution of dysferlin-controlled $\mathrm{PI}(4,5) \mathrm{P}_{2}$ (Hofhuis et al., 2017).

\subsection{Dysferlin in the heart}

A lot of research has been performed to analyze the role of dysferlin and the effects of dysferlin-deficiency in skeletal muscle. Much less is known about the importance of dysferlin for the heart muscle. Dysferlin is mainly regarded as skeletal muscle disease because only in a few patients, diagnosed with dysferlinopathy, cardiac involvement is reported (Kuru et al., 2004). As in skeletal muscle, dysferlin is also involved in membrane repair of cardiomyocytes and exhibits a cytoprotective function in the model of ischemia/reperfusion injury (Han et al., 2007; Tzeng et al., 2014). The examination of mouse models for dysferlin-deficiency reveals that no or only a very mild cardiac phenotype is found under normal conditions (Chase et al., 2009; Rubi et al., 2015; Wenzel et al., 2007). In contrast, excessive strain such as ischemia/reperfusion injury, physical stress exercise or $\beta$-adrenergic activation by isoproterenol treatment of mice leads to signs of cardiac dysfunction (Chase et al., 2009; Han et al., 2007; Tzeng et al., 2014; Wei et al., 2015; Wenzel et al., 2007). These include the release of creatine kinase and Evens blue dye uptake as indications of membrane damage (Han et al., 2007; Tzeng et al., 2014), cardiac fibrosis, reduced fractional shortening (Wenzel et al., 2007), decreased stroke volume and relaxation velocity (Wei et al., 2015). Thus, systolic as well as diastolic cardiac functions are altered upon stress in dysferlin-deficient mice.

\subsection{Tubule system in heart failure}

Amongst the cardiovascular diseases, heart failure (HF) is one of the most frequent diseases leading to death. HF might be caused by chronic hypertension, acute myocardial infarction or ischemic heart disease and is more a secondary syndrome than a primary disease. HF is chronically progressive and described as condition in which heart function is decreased and insufficient to fulfil the metabolic demands of the body (Levy et al., 1996). HF is characterized by diminished cardiomyocyte contraction resulting from uncoupling of Cav1.2-RyR2 dyads and reduced systolic $\mathrm{Ca}^{2+}$ release (Gómez et al., 1997; Pieske et al., 1999). Several studies report that the cardiac TATS is altered in failing hearts and that disturbed $\mathrm{Ca}^{2+}$ handling might result from these morphological abnormalities. Confocal imaging of failing cardiomyocytes shows disruption and reduced density of membrane tubules, which can be directly linked to 
asynchronous EC coupling and reduced delayed $\mathrm{Ca}^{+2}$ release from the SR (Heinzel et al., 2008; Louch et al., 2004, 2006). In situ confocal visualization of whole hearts has the beneficial aspect that tissue integrity is preserved. Analysis of rat hearts from a pressure overload model shows that loss and redistribution of the T-tubule system starts early in compensated hypertrophy before progression to heart failure (Chen et al., 2015; Wei et al., 2010). Scanning ion conductance microscopy (SICM) provides information about the surface topology and reveals detachment of tubules from the sarcolemma in human and rat failing cardiomyocytes (Lyon et al., 2009). Detailed 3D analysis of a porcine myocardial infarction model shows loss of tubule structures in the peri-infarct zone and branching and axialization of remaining tubules (Pinali et al., 2017). Human failing cardiomyocytes show sheet-like rather than tubular invaginations of the sarcolemma and again decrease in T-tubule density. Additionally, $\mathrm{Ca}^{2+}$ release is delayed and asynchronous in cardiomyocytes from patients with HF (Seidel et al., 2017). Asynchronity might be due to uncoupling of T-tubules from the sarcomeres and leftbehind, so called, orphaned RyRs leading to uncontrolled $\mathrm{Ca}^{2+}$ handling as shown in spontaneously hypertensive rats developing HF (Song et al., 2006). Cannell and colleagues analyzed fixed myocardium from HF patients and found redistribution of TATS with dilated and mainly longitudinally orientated tubules (Cannell et al., 2006). Regularity of T-tubule alignment was analyzed by Wei and colleagues using Fourier transformation of confocal images and assessment of obtained power spectra (Song et al., 2006). Therefore, whole rat hearts were staining with the membrane dye FM 4-64 and analyzed by confocal microscopy. The T-tubule power index $\left(\mathrm{TT}_{\text {power }}\right)$ revealed global reorganization of the tubule system which correlated with disease progression (Wei et al., 2010).

\subsection{Therapeutic strategies for dysferlinopathy}

Several studies have investigated different therapeutic approaches for the treatment of dysferlinopathy. Until now, none of these approaches could be developed into a curative treatment.

\subsubsection{Immune modulation}

Muscle inflammation with infiltration of T-cells and macrophages as well as enhanced phagocytic activity of peripheral monocytes is a typical sign of dysferlinopathy (Gallardo et al., 2001; Nagaraju et al., 2008). Thus, several studies aimed to ameliorate disease progression through modulation of the immune system. No B-cell infiltration was detected in dysferlin- 
deficient muscle (Gallardo et al., 2001), still Lerario and colleagues observed a slight increase in muscle force after depletion B-cells with Rituximab@ in two dysferlinopathy patients, indicating that B-cells might be involved in the pathogenesis (Lerario et al., 2010). Inhibition of the Rho-kinase, which has a key signaling function in immune activation, using the substance fasudil was conducted in two mouse models of dysferlinopathy. Treatment resulted in suppressed immune response, but no or exacerbating muscular disease phenotype was observed (Rayavarapu et al., 2010). Another important signaling molecule of the inflammatory response, NF-KB, was inhibited by the treatment of dysferlin-deficient mice with celastrol for 4 months. The muscle inflammation was reduced without a beneficial effect on physical muscle function (Dillingham et al., 2015). Within the framework of a clinical trial immune suppression of dysferlinopathy patients was achieved by treatment with the glucocorticoid deflazacort. This lead to severe steroid-associated side effects and no improvement or even exacerbation of muscle strength (Walter et al., 2013). Consequently, immunosuppression in dysferlindeficient muscular dystrophy seems not to be a promising therapeutic approach.

\subsubsection{Influencing $\mathrm{Ca}^{2+}$ homeostasis}

Dysferlin associates with $\mathrm{Ca}^{2+}$ handling proteins in the membrane of T-tubules (Ampong et al., 2005) and contributes to the maintenance of $\mathrm{Ca}^{2+}$ homeostasis (Hofhuis et al., 2017; Kerr et al., 2013). Therefore, the alteration of $\mathrm{Ca}^{2+}$ handling was handled as therapeutic possibility to ameliorate disease progression. Dantrolene, which is binding to RyRs and thereby reducing $\mathrm{Ca}^{2+}$ release from the SR (Krause et al., 2004) was used to treat two patients with MM. Beside of a slight decrease of creatine kinase level, no positive effect was detected. Treatment of one patient had to be terminated prematurely because of suspected hepatopathy, a common side effect (Hattori et al., 2007; Montané et al., 2004). Furthermore, inhibition of Cav1.1 by diltiazem in dysferlin-deficient isolated myofibers and treated mice was reported to prevent contraction-induced membrane damage probably through reduced injury-induced $\mathrm{Ca}^{2+}$ influx and activation of $\mathrm{Ca}^{2+}$-mediated cytotoxicity. Diltiazem is approved for clinical use and might be a potential therapeutic for the treatment of dysferlinopathy (Kerr et al., 2013).

\subsubsection{Gene therapy}

Another field, which is extensively investigated as therapeutic strategy for dysferlin-deficient muscular dystrophy, is the modulation of dysferlin expression either through import of dysferlin coding genes or through restoration of endogenous dysferlin expression. These 
approaches have been analyzed at preclinical level and seem to be promising strategies for further clinical development (Barthélémy et al., 2011). Delivery of coding genes into genedeficient organisms is a gene therapeutic approach for the treatment of genetic diseases. Adeno-associated virus (AAV) is currently the best vector for this purpose. Though, the encapsulation capacity is limited to a size of $5 \mathrm{~kb}$ (Pryadkina et al., 2015) and classical AAVmeditated gene delivery of DYSF with about $6.2 \mathrm{~kb}$ is unfeasible. Therefore, different types of AAV-mediated gene delivery have been developed. Lostal and colleagues divided the DYSF cDNA sequence into two parts and cloned them into separate AAV vectors with appropriate splicing sequences. After combined intramuscular injection of both vector variants, the fulllength CDNA is generated by overlap of the two parts through homologous recombination. This method leads to expression of full-length dysferlin protein in the muscle leading to improvement of membrane capacity and locomotor activity as well as reduced dystrophic phenotype and necrotic fibers (Lostal et al., 2010). Safety concerns with regard to this method were addressed by Sondergaard and colleagues (Sondergaard et al., 2015). A comparison of gene transfer techniques for large genes revealed that the overlap strategy described above is the most effective approach in the generation of full-length dysferlin (Pryadkina et al., 2015). A dysferlinopathy patient with late onset and moderate disease progression was reported to express a so called minidysferlin, consisting of an out-of-frame $\mathrm{N}$-terminal domain, the last 2 C2 domains and the transmembrane domain (Krahn et al., 2010). Delivery of genes encoding truncated variants of dysferlin is technically more feasible then delivery of full-length dysferlin. Thus, the gene therapeutic delivery of minidysferlins is being investigated as approach to ameliorate the symptoms of patients with complete absence of the full-length protein. Several truncated dysferlin variants have been designed and analyzed for their functionality in a membrane wounding assay after AAV-mediated delivery showing that $\mathrm{C} 2 \mathrm{~B}, \mathrm{C} 2 \mathrm{C}, \mathrm{C} 2 \mathrm{E}$ and to a lesser extent C2D are not oblige for the membrane repair function (Azakir et al., 2012). Another gene delivery system that has been analyzed for therapy of dysferlin-deficiency is the Sleeping Beauty (SB) transposon system which is already used in clinical trials. It is composed of a synthetic non-viral vector and a transposase that can insert specific DNA fragments into vertebrate genomes. The advantage in comparison with AAV vectors is that DNA with more than $10 \mathrm{kB}$ can be integrated into the target genome. Full-length dysferlin cDNA was delivered into dysferlin-deficient myoblasts resulting in proper protein expression. Subsequently, dysferlin-expressing myoblasts were successfully transplanted into a skeletal muscle of dysferlin- and immune-deficient mice. 
Often, DYSF mutations lead to reading frame shifts or the generation of premature stop codons leading to truncated and dysfunctional proteins that are prone for degradation. In the exon skipping approach, mutated mRNA is targeted and the exon harboring a highly pathologic mutation is removed by alternative splicing. Though, only exons, which are not essential for protein function, can be targeted. The in-frame suppression of a certain exon or multiple adjacent exons is achieved by the application of antisense oligonucleotides (AON) (van Ommen et al., 2008). Currently, this approach seems to be promising for the treatment of Duchenne muscular dystrophy with mutations in the dystrophin-coding gene (Niks and Aartsma-Rus, 2017; van Ommen et al., 2008). A patient with late-onset mild dysferlinopathy due to a mutation leading to natural skipping of exon 32 has been reported. In this case, the loss of one DYSF exon leads to a mild phenotype suggesting that the function of dysferlin is not completely abrogated. This hints to the idea that DYSF exons may be dispensable or their lost causes only a mild disease phenotype (Sinnreich et al., 2006). Therapeutic exon skipping is optimal to target mutations that are homozygous to obtain maximal protein expression. Increase of wild-type dysferlin protein level to $10 \%$ in an originally dysferlin-deficient myofiber seems to be enough to partially ameliorate the disease phenotype. This suggests that the exon skipping approach might also be beneficial for heterozygous mutations if one allele is not targetable by this approach and normal dysferlin levels cannot be obtained (Aartsma-Rus et al., 2010; Sinnreich et al., 2006). AON-induced exon skipping in human myoblasts was efficient and led to rescue of myoblast fusion deficiency and disturbed membrane repair supporting this therapeutic approach (Barthélémy et al., 2015; Wein et al., 2010).

\subsubsection{Reallocation of mutated dysferlin}

Mutations in the DYSF gene might lead to alterations in protein structure and folding, ER homeostasis, trafficking and stability causing dysfunctionality and mislocalization of the protein (Fujita et al., 2007; Wenzel et al., 2006). Schoewel and colleagues developed dysferlinderived fluorescently-tagged peptides and introduced them through coupling to the cell penetrating peptide TAT (trans-activator of transcription from human immunodeficiency virus type 1) either into $\mathrm{C} 2 \mathrm{C} 12$ cells transfected with mutant dysferlin or primary patient myoblasts. This strategy resulted in reduced ER stress response, localization of mutant dysferlin the sarcolemma and rescue of membrane repair. 


\subsection{Translational readthrough}

One therapeutic approach for the treatment of genetic diseases caused by premature stop codons is the application of aminoglycosides, their derivatives or other small molecules which are able to induce translational readthrough of stop codons. Instead of translational termination the incorporation of an amino acid at the position of the premature stop codon takes place leading to continued translation until the original stop codon is reached and production of the full-length protein (Yang et al., 2016).

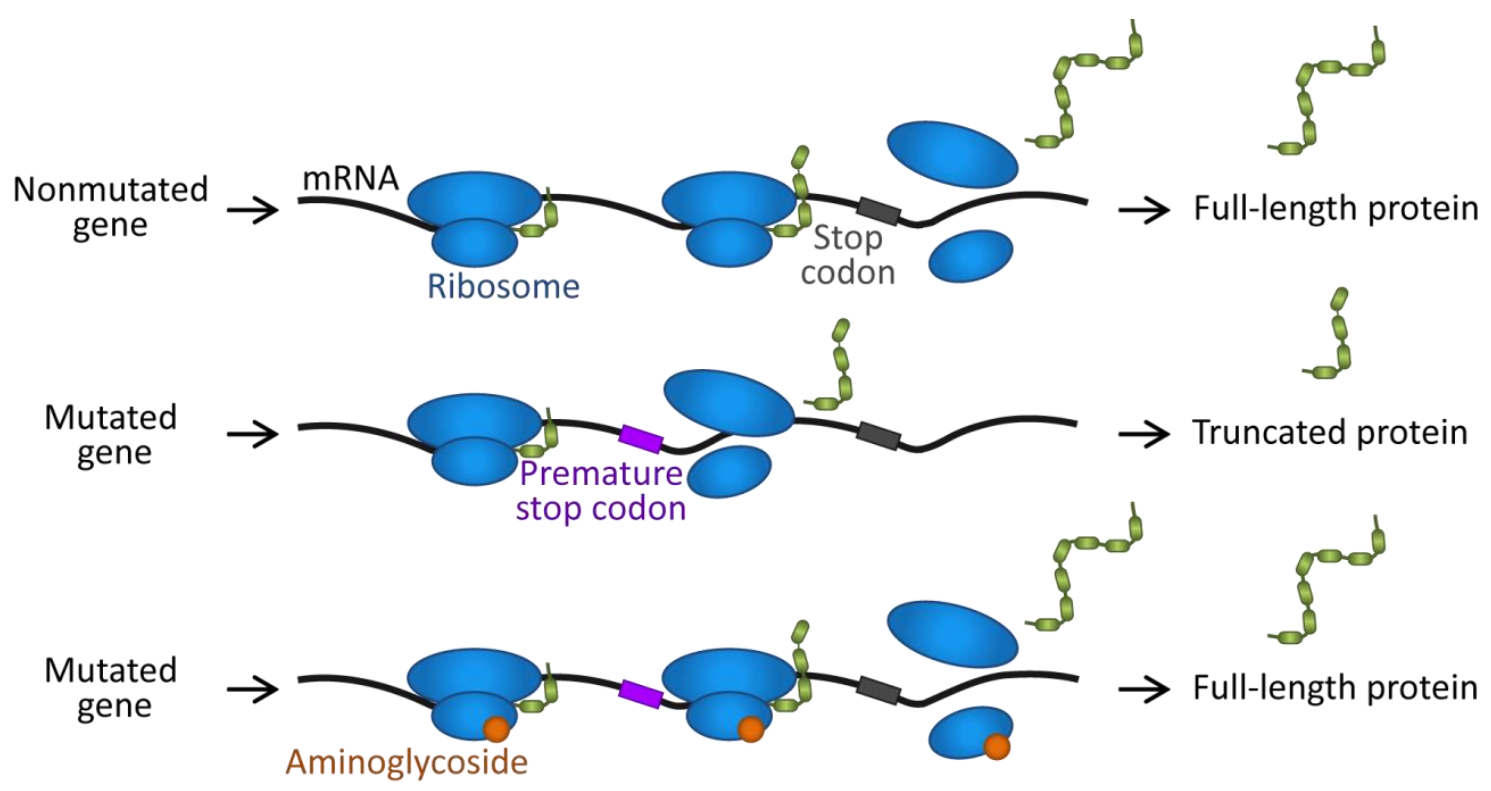

Figure 5 | Aminoglycoside-induced readthrough therapy of diseases caused by nonsense mutations. Translation of the mRNA encoded by a gene without premature stop codons leads to the generation of a functional full-length protein (top). Nonsense mutation causes the premature termination of translation and generation of a truncated, probably unfunctional and/or degradation-prone protein. Aminoglycosides induce translational readthrough of a premature termination codon, thereby leading to continuation of translation and the generation of a full-length protein with a probable exchanged amino acid at the position of the premature stop codon.

The concept of translational readthrough as a therapeutical approach for genetic diseases with premature stop codons was initially investigated for cystic fibrosis applying the aminoglycosides G418 (geneticin) and gentamicin (Bedwell et al., 1997; Howard et al., 1996). This approach is also under investigation for the treatment of Duchenne and Becker muscular dystrophy (Barton-Davis et al., 1999; Loufrani et al., 2004) as approximately $10 \%$ of patients harbor a nonsense mutation in the gene encoding dystrophin (UMD TREAT-NMD DMD mutations database, http://umd.be/TREAT_DMD/). However, these substances have a 
narrow therapeutic window and dosage has to be assessed very carefully upon systemic administration due to oto- and nephrotoxicity. Therefore, studies developing new readthrough inducing substances with less adverse effects are ongoing. 


\section{Aims of this work}

For a long time, dysferlin had been mainly described as mediator of muscle membrane repair (Bansal and Campbell, 2004; Cai et al., 2009; Lek et al., 2013). Though, a defective membrane repair caused by dysferlin-deficiency cannot be the only pathomechanism of dysferlindeficient muscular dystrophy (Bansal et al., 2003). This assumption is supported by the observation that the restoration of membrane repair in dysferlin-deficient myofibers does not impede disease progression (Krahn et al., 2010) and patients are asymptomatic and aboveaverage athletic until the second decade of life (Klinge et al., 2010b). In the recent years, new evidence supports an additional role of dysferlin during the biogenesis of the T-tubule system. The tubulation of membranes into elongated structures is proposed to be the primary cellular function of dysferlin. Mutations, which are found in dysferlinopathy patients, interfere with the tubulation capacity of dysferlin leading to the hypothesis that the inability of mutated dysferlin to tubulate membranes results in an abnormal T-tubule system and is the primary cause of muscular dysfunction (Hofhuis et al., 2017). Dysferlin localizes to the skeletal muscle T-tubule system and is essential for proper T-tubule formation in skeletal muscle (Klinge et al., 2010a), but the exact mechanism of dysferlin's T-tubule shaping function is unknown. Thus, the aims of this study were the following: The cellular fate of normal and mutated dysferlin should be investigated to get insight into the possible mechanisms of T-tubule formation and to understand the pathological events leading to muscular dysfunction. The effect of dysferlindeficiency should be further analyzed in a human model of early myogenesis to uncover the primary alterations resulting from the loss of dysferlin. Dysferlin is also highly expressed in the heart muscle and dysferlin-deficient mice show signs of cardiac dysfunction under stress conditions (Chase et al., 2009; Han et al., 2007; Tzeng et al., 2014; Wei et al., 2015; Wenzel et al., 2007). Thus, the involvement of dysferlin in the biogenesis of the cardiac T-tubule system and the effects of dysferlin loss on the morphology of this cellular compartment should be investigated. As little is known about the pathomechanism of dysferlinopathy, no curative treatment is available. Therefore, this thesis aimed to address two different approaches, the stabilization of mutated dysferlin and the induction of full-length protein expression by translational readthrough, as therapeutic options for the treatment of dysferlin-deficient muscular dystrophy. 


\section{$3 \quad$ Materials and Methods}

\subsection{Materials}

\subsubsection{Bacterial strains}

For cloning procedures and plasmid preparation the chemically competent Escherichia coli strain BioBlue (BIO-85036 $\geq 108 \mathrm{cfu} / \mu \mathrm{g}$ of pUC19, Bioline $\mathrm{GmbH}$ ) was used.

\subsubsection{Mammalian cell lines}

HeLa is a human epithelial cell line derived from a cervix adenocarcinoma.

HEK293 is a cell line derived from human embryonic kidney cells.

cOS-7 cells are adherent fibroblast-like cells from the kidney of the African green monkey.

CHO-K1 is an epithelial cell line derived from the ovary of the Chinese hamster.

C2C12 is a murine myoblast cell line clonally derived from leg muscles of an adult C3H mouse. This cell line is capable of differentiating into contractile myotubes and thereby expressing various skeletal muscle proteins. Therefore, $\mathrm{C} 2 \mathrm{C} 12$ cells are used in this study as model system for skeletal muscle differentiation.

\subsubsection{Human myoblasts}

Primary human myoblasts from LGMD patients and healthy controls were kindly provided by the Muscle Tissue Culture Collection (MTCC). I thank MTCC for providing the samples. The MTCC is part of the German network on muscular dystrophies (MD-NET, service structure S1, 01GM0601) and the German network for mitochondrial disorders (mito-NET, project D2, 01GM0862) funded by the German ministry of education and research (BMBF, Bonn, Germany). The MTCC is a partner of EuroBioBank (www.eurobiobank.org) and Translational Research in Europe for the Assessment and Treatment of Neuromuscular Disease (TREATNMD, www.treat-nmd.eu). 


\subsubsection{Animals}

\section{Dysf-gene deleted mice}

B6.129-Dysf ${ }^{\text {tm1Kcam }} / \mathrm{J}$ (Dysf-gene deleted) mice were kindly provided by Prof. Kate Bushby, Newcastle University, UK (Bansal et al., 2003)) with approval of the Mutant Mouse Regional Resource Centers (MMRRC), USA. Mice were housed under standard conditions and were treated in accordance with the European convention for the protection of vertebrate animals used for experimental and other scientific purposes.

\section{Rats}

Wistar rats were kindly provided by the central animal facility (Zentrale Tierexperimentelle Einrichtung, ZTE), University Medical Center Göttingen.

\subsubsection{General material and chemicals}

Table 1 | Disposables and basic material

\begin{tabular}{|c|c|c|}
\hline Materials & Product number & Manufacturer \\
\hline Gloves & 7696900 & Labsolute \\
\hline Reaction tubes, Biosphere ${ }^{\circledR}$ SafeSeal, $1.5 \mathrm{~mL}$ & 72.706 .200 & Sarstedt \\
\hline Reaction tubes, Multiply ${ }^{\circledR}$-Pro cup, $0.2 \mathrm{~mL}$ & 72.737 .002 & Sarstedt \\
\hline Reaction tubes, Safe-Lock, $2 \mathrm{~mL}$ & 30120094 & Eppendorf AG \\
\hline Conical tubes, $15 \mathrm{~mL}$, sterile & 62.554 .502 & Falcon \\
\hline Conical tubes, $50 \mathrm{~mL}$, sterile & 62.547 .254 & Falcon \\
\hline Pipette filter tips $10 \mu \mathrm{L}$ & 70.111 .4 .210 & Sarstedt \\
\hline Pipette filter tips $100 \mu \mathrm{L}$ & 70.760 .212 & Sarstedt \\
\hline Pipette filter tips $1250 \mu \mathrm{L}$, SurPhob SafeSeal ${ }^{\circledR}$ & VT0270 & $\begin{array}{l}\text { Biozym Scientific } \\
\text { GmbH }\end{array}$ \\
\hline Pipette tips $10 \mu \mathrm{L}$ & 70.113 & Sarstedt \\
\hline Pipette tips $200 \mu \mathrm{L}$ & 70.760 .002 & Sarstedt \\
\hline Serological pipettes, $2 \mathrm{~mL}$ & 86.1252 .001 & Sarstedt \\
\hline Serological pipettes, $5 \mathrm{~mL}$ & 86.1253 .001 & Sarstedt \\
\hline Serological pipettes, $10 \mathrm{~mL}$ & 86.1254 .001 & Sarstedt \\
\hline Serological pipettes, $25 \mathrm{~mL}$ & 86.1685 .001 & Sarstedt \\
\hline
\end{tabular}




\begin{tabular}{|c|c|c|}
\hline Pasteur pipettes & 7691060 & Labsolute \\
\hline Parafilm $^{\circledR}, \mathrm{M}$, laboratory film & PM996 & Bemis \\
\hline Filters, Minisart, pore size $0.2 \mu \mathrm{m}$ & $16534 \mathrm{~K}$ & Sigma Aldrich \\
\hline Scalpels & 02.001 .30 .021 & Feather Safety Razor \\
\hline Plates for cell culture, $35 \mathrm{~mm}$ & 83.3900 .300 & Sarstedt \\
\hline Plates for cell culture, $100 \mathrm{~mm}$ & 83.3902 .300 & Sarstedt \\
\hline Flasks for cell culture, $25 \mathrm{~cm}^{2}$ & 690175 & Greiner Bio-One \\
\hline Flasks for cell culture, $75 \mathrm{~cm}^{2}$ & 658175 & Greiner Bio-One \\
\hline Plates for cell culture, 6-well & 353046 & Falcon \\
\hline Plates for cell culture, 12-well & 665180 & Greiner Bio-One \\
\hline Plates for cell culture, 24-well & 662160 & Greiner Bio-One \\
\hline Cell flasks, Nunc ${ }^{\top \mathrm{M}}$ Lab-Tek $^{\circledast}$ Chamber Slides & 170920 & $\begin{array}{l}\text { Thermo Fisher } \\
\text { Scientific }\end{array}$ \\
\hline Cell dishes, $\mu$-Slide 4 Well, ibiTreat & 80426 & Ibidi \\
\hline $\begin{array}{l}\text { Cell dishes, } \mu \text {-dish, } 35 \mathrm{~mm} \text {, glass bottom, } \\
\text { ibiTreat }\end{array}$ & 81156 & Ibidi \\
\hline Cell strainer, $70 \mu \mathrm{M}$ & 542070 & Greiner Bio-One \\
\hline Cell scrapers & 83.183 & Sarstedt \\
\hline Cryo tubes, $1.8 \mathrm{~mL}$ & 368632 & Thermo Scientific \\
\hline Cryo $1^{\circ} \mathrm{C}$ freezing containers for cell culture & $5100-0001$ & Nalgene \\
\hline $\begin{array}{l}\text { Nitrocellulose blotting membrane, } \\
\text { Amersham }^{\mathrm{TM}} \text { Protran }^{\mathrm{TM}} 0.45 \mu \mathrm{m}\end{array}$ & 10600002 & GE Healthcare \\
\hline Blotting paper sheets & FT-2-520-580600 K & Sartorius AG \\
\hline Microplate, 96-well, flat bottom & 655101 & Greiner Bio-One \\
\hline Combitips advanced $^{\circledR}, 5 \mathrm{~mL}$ & 0030089.456 & Eppendorf AG \\
\hline Glass cover plates, $24-60 \mathrm{~mm}$ & CS2464100 & Menzel-Gläser \\
\hline Glass cover slips, 14 mm & CS14100 & Menzel-Gläser \\
\hline Glass microscope slides & $631-0411$ & Menzel-Gläser \\
\hline Tubes for flow cytometry, $5 \mathrm{~mL}$ & 352058 & Falcon \\
\hline Petri dishes, 92×16 mm & 82.1473 .001 & Sarstedt \\
\hline
\end{tabular}


Table 2 | Instruments and equipment

\begin{tabular}{|c|c|}
\hline Instrument & Manufacturer \\
\hline Pipette, manual, ErgoOne ${ }^{\circledR}, 2.5 \mu \mathrm{L}, 100 \mu \mathrm{L}, 200 \mu \mathrm{L}, 1000 \mu \mathrm{L}$ & $\begin{array}{l}\text { Starlab } \\
\text { International } \mathrm{GmbH}\end{array}$ \\
\hline Pipette, manual, Eppendorf Research ${ }^{\circledR}, 10 \mu \mathrm{L}$ & Eppendorf AG \\
\hline Pipette, manual, Pipetman ${ }^{\circledR}, 20 \mu \mathrm{L}$ & Gilson, Inc. \\
\hline Multipette ${ }^{\circledR}$ Plus & Eppendorf AG \\
\hline Centrifuge, Universal 320, rotor 1619 & $\begin{array}{l}\text { Andreas Hettich } \mathrm{GmbH} \& \\
\text { Co.KG }\end{array}$ \\
\hline Centrifuge, Mikro 200R, rotor 2424-B & $\begin{array}{l}\text { Andreas Hettich GmbH \& } \\
\text { Co.KG }\end{array}$ \\
\hline Centrifuge, 5417R & Eppendorf AG \\
\hline Centrifuge, 5424 & Eppendorf AG \\
\hline Centrifuge,mini, FugeOne ${ }^{\circledR}$ & Starlab GmbH \\
\hline Centrifuge, mini, Sprout & Biozym Scientific GmbH \\
\hline Thermo block, TB2m Biometra & Biometra $\mathrm{GmbH}$ \\
\hline Thermo block, Thermostat 5320 & Eppendorf AG \\
\hline Thermo block, Thermomixer compact & Eppendorf AG \\
\hline Thermocycler T3 & Biometra $\mathrm{GmbH}$ \\
\hline Thermocycler, labcycler & SensoQuest GmbH \\
\hline Magnetic stirrer with temperature control & $\begin{array}{l}\text { Heidolph Instruments } \\
\text { GmbH \& Co.KG }\end{array}$ \\
\hline Magnetic stirrer with temperature control, Combimag RCT & $\begin{array}{l}\text { IKA }{ }^{\circledR} \text {-Werke GmbH \& CO. } \\
\text { KG }\end{array}$ \\
\hline Vortex mixer, infrared & VELP Scientifica \\
\hline Vortex mixer, Genie $2^{\mathrm{TM}}$ & Bender \& Hobein $\mathrm{GmbH}$ \\
\hline Water bath & Memmert GmbH \\
\hline Weight balance & Sartorius AG \\
\hline Microwave oven & Panasonic \\
\hline Ice machine & $\begin{array}{l}\text { Ziegra Eismaschinen } \\
\mathrm{GmbH}\end{array}$ \\
\hline Cell culture sterile bench, HeraSafe & Heraeus \\
\hline
\end{tabular}




\begin{tabular}{|c|c|}
\hline Cull culture heating plate, Culture Temp ${ }^{\mathrm{TM}}$ & $\begin{array}{l}\text { Bel-Art Products, SP } \\
\text { Scienceware }\end{array}$ \\
\hline Cell culture incubator, HeraCell 150 & Heraeus \\
\hline Cell counting chamber, Neubauer & Brand GmbH + Co KG \\
\hline Homogenizer tissue ruptor & Qiagen \\
\hline Light microscope & Nikon ECLIPSE TS100 \\
\hline $\begin{array}{l}\text { Epifluorescence microscope, Axioimager M1, Plan Neofluar } \\
\text { 100x/1.3 oil lens }\end{array}$ & Carl Zeiss AG \\
\hline Camera for epifluorescence microscope, AxioCam HRm & Carl Zeiss AG \\
\hline $\begin{array}{l}\text { Confocal microscope, Inverted IX81, Uplansapo } 60 x / 1.35 \text { oil } \\
\text { objective }\end{array}$ & $\begin{array}{l}\text { Olympus Deutschland } \\
\text { GmbH }\end{array}$ \\
\hline Camera for confocal microscope, F-View II CCD & $\begin{array}{l}\text { Olympus Deutschland } \\
\text { GmbH }\end{array}$ \\
\hline Confocal microscope, LSM 710 NLO, 63x/1.4 NA oil objective & Carl Zeiss AG \\
\hline Spectrophotometer, ND-1000 & NanoDrop ${ }^{\mathrm{TM}}$ \\
\hline Power supply & Consort bvba \\
\hline Power supply, Standard PowerPack P25 & Biometra GmbH \\
\hline Agarose gel documentation system & BioDocAnalyze \\
\hline Incubator, shaking, for bacterial cultures & Memmert GmbH \\
\hline Microplate reader, BioTek Synergy Mx + power supply & BioTek $^{\circledast}$ Instruments \\
\hline Electrophoresis systems for SDS-PAGE, Mini-PROTEAN Tetra Cell & $\begin{array}{l}\text { Bio-Rad Laboratories } \\
\text { GmbH }\end{array}$ \\
\hline Electrophoresis systems for agarose gels & Analytik Jena \\
\hline Semi-dry blotting system, Biometra Fast Blot & Biometra GmbH \\
\hline Western blot documentation system, LAS-4000 & Fujifilm Europe GmbH \\
\hline Tube roller, SRT6, Stuart & Cole-Parmer \\
\hline Rocking platform & $\begin{array}{l}\text { GFL Gesellschaft für } \\
\text { Labortechnik mbH }\end{array}$ \\
\hline Rocking platform & Biometra GmbH \\
\hline
\end{tabular}


Table 3 | Chemicals and reagents

\begin{tabular}{|c|c|c|}
\hline Chemical/reagent & Product number & Manufacturer \\
\hline 2-Propanol & 1096341000 & Merck KGaA \\
\hline 4',6-diamidino-2-phenylindole (DAPI) & 32670 & Sigma-Aldrich Chemie GmbH \\
\hline 4-phenylbutyric acid (PBA) & P21005 & Sigma-Aldrich Chemie GmbH \\
\hline Acetic acid & 6755 & Carl Roth $\mathrm{GmbH}+$ Co. KG \\
\hline $\begin{array}{l}\text { Acrylamide solution, } 30 \% \text { with } 0.8 \% \\
\text { bisacrylamide }\end{array}$ & 3029.1 & Carl Roth $\mathrm{GmbH}+$ Co. KG \\
\hline Agarose & Bio-41025 & Bioline $\mathrm{GmbH}$ \\
\hline Ammonium persulfate (APS) & $113 \mathrm{H} 0315$ & Serva Electrophoresis GmbH \\
\hline Ampicillin Sodium Salt & A9518-25G & Sigma-Aldrich Chemie GmbH \\
\hline BCA Assay Reagent A & UP95424A & Interchim \\
\hline BCA Assay Reagent B & UP95425A & Interchim \\
\hline Bovine serum albumin (BSA), Fraktion V & 8076.2 & Carl Roth $\mathrm{GmbH}+$ Co. KG \\
\hline Bromophenol blue & $8122-5 g$ & Merck KGaA \\
\hline $\begin{array}{l}\text { cOmplete }{ }^{\mathrm{TM}} \text { Protease Inhibitor Cocktail } \\
\text { Tablets, EDTA-free }\end{array}$ & 04693116001 & $\begin{array}{l}\text { Roche Deutschland Holding } \\
\text { GmbH }\end{array}$ \\
\hline $\operatorname{DilC}_{16}(3)$ & D384 & Molecular Probes ${ }^{\circledR}$ \\
\hline Disodium phosphate $\left(\mathrm{Na}_{2} \mathrm{PO}_{4}\right)$ & T877 & Carl Roth $\mathrm{GmbH}+$ Co. KG \\
\hline Dithiothreitol (DTT) & 20710 & Serva Electrophoresis GmbH \\
\hline Dimethyl sulfoxide (DMSO) & 39757 & Serva Electrophoresis GmbH \\
\hline $\begin{array}{l}\text { Dulbecco's Modified Eagle Medium } \\
\text { (DMEM), } 1 \mathrm{~g} / \mathrm{L} \mathrm{D-glucose}\end{array}$ & F 0415 & Biochrom GmbH \\
\hline DMEM, 4.5 g/L D-glucose & F 0445 & Biochrom GmbH \\
\hline Ethanol & 1.00983 .2500 & Merck KGaA \\
\hline Ethylene glycol tetraacetic acid (EGTA) & 3054.2 & Carl Roth GmbH + Co. KG \\
\hline Ethylenediaminetetraacetic acid (EDTA) & CN06.1 & Carl Roth GmbH + Co. KG \\
\hline Fetal bovine serum (FBS), Gold & A15-151 & PAA Laboratories \\
\hline Geltrex & A-14133-02 & Gibco \\
\hline GeneRuler $^{\mathrm{TM}}$, DNA Ladder Mix & SM0331 & Fermentas Life Science \\
\hline Gentamicin & HN09.2 & Carl Roth GmbH + Co. KG \\
\hline
\end{tabular}




\begin{tabular}{|c|c|c|}
\hline GlutaMAX'M -I (100x) & $35050-061$ & Gibco \\
\hline Glycerol, anhydrous & A3552 & Applichem \\
\hline Horse serum & 26050088 & Gibco \\
\hline Hydrochloric acid (HCl) & 1003141000 & Merck KGaA \\
\hline $\begin{array}{l}\text { Laminin from Engelbreth-Holm-Swarm } \\
\text { murine sarcoma basement membrane }\end{array}$ & L2020 & Sigma-Aldrich Chemie GmbH \\
\hline Lysogeny broth (LB)-medium, powdered & X968.1 & Carl Roth GmbH + Co. KG \\
\hline LB-Agar (lurial/Miller), powdered & X969.1 & Carl Roth GmbH + Co. KG \\
\hline L-glutamine solution & G8540 & Sigma-Aldrich Chemie GmbH \\
\hline $\begin{array}{l}\text { Lumi-Light Plus Western Blotting } \\
\text { Substrate }\end{array}$ & 12015196001 & $\begin{array}{l}\text { Roche Deutschland Holding } \\
\text { GmbH }\end{array}$ \\
\hline Lumi-Light Western Blotting Substrate & 12015200001 & $\begin{array}{l}\text { Roche Deutschland Holding } \\
\text { GmbH }\end{array}$ \\
\hline Methanol & 8045 & J.T. Baker \\
\hline Milk powder & T145.3 & Carl Roth GmbH + Co. KG \\
\hline Monopotassium phosphate $\left(\mathrm{KH}_{2} \mathrm{PO}_{4}\right)$ & 3904 & Carl Roth GmbH + Co. KG \\
\hline Mowiol $^{\circledR}$ 4-88 Reagent & 475904 & Calbiochem $^{\circledR}$ \\
\hline $\begin{array}{l}\mathrm{N}, \mathrm{N}, \mathrm{N}^{\prime}, \mathrm{N}^{\prime} \text {-Tetramethylethan-1,2-diamin } \\
\text { (TEMED) }\end{array}$ & 2367.1 & Carl Roth GmbH + Co. KG \\
\hline Nonidet $^{\mathrm{TM}} \mathrm{P}$ (NP)-40 & 74385 & Fluka Analytical \\
\hline PageRuler ${ }^{\mathrm{TM}}$ Prestained Protein Ladder & 26616 & Thermo Fisher Scientific \\
\hline Paraformaldehyde (PFA), 4\% in PBS & $199431 \mathrm{LT}$ & Affymetrics \\
\hline PBS (Dulbecco's PBS) for cell culture & L0615-500 & Biowest \\
\hline Phenylmethane sulfonyl fluoride (PMSF) & A0999,0005 & Applichem \\
\hline Ponceau-S solution & P7170 & Sigma-Aldrich Chemie GmbH \\
\hline Potassium acetate $\left(\mathrm{CH}_{3} \mathrm{CO}_{2} \mathrm{~K}\right)$ & T874 & Carl Roth GmbH + Co. KG \\
\hline Saponin & 4185.1 & Carl Roth GmbH + Co. KG \\
\hline Skeletal Muscle Cell Growth Medium & $C-23060$ & PROMOCELL \\
\hline Sodium azide $\left(\mathrm{NaN}_{3}\right)$ & K305 & Carl Roth GmbH + Co. KG \\
\hline Sodium bicarbonate $\left(\mathrm{NaHCO}_{3}\right)$ & 0965 & Carl Roth GmbH + Co. KG \\
\hline Sodium cacodylate trihydrate & C4945 & Sigma-Aldrich Chemie GmbH \\
\hline
\end{tabular}




\begin{tabular}{|c|c|c|}
\hline Sodium chloride ( $\mathrm{NaCl})$ & 3957.1 & Carl Roth GmbH + Co. KG \\
\hline $\begin{array}{l}\text { Sodium dodecyl sulfate (SDS), } 20 \% \\
\text { solution }\end{array}$ & 1057 & Carl Roth GmbH + Co. KG \\
\hline Sodium hydroxide $(\mathrm{NaOH})$ & 6771.1 & Carl Roth GmbH + Co. KG \\
\hline Sucrose & 9378 & Sigma-Aldrich Chemie GmbH \\
\hline Tris & 5429.3 & Carl Roth GmbH + Co. KG \\
\hline Triton ${ }^{\circledR} \times 100$ & 3051 & Carl Roth GmbH + Co. KG \\
\hline $\begin{array}{l}\text { Tryptan blue, } 0.5 \%(\mathrm{w} / \mathrm{v}) \text { in } \\
\text { physiologocal saline }\end{array}$ & L2143 & Biochrom GmbH \\
\hline Tween $^{\circledR} 20$ & 8.22184 .0500 & Merck KGaA \\
\hline $\begin{array}{l}\text { VECTASHIELD Antifade Mounting } \\
\text { Medium with DAPI }\end{array}$ & $H-1200$ & Vector Laboratories \\
\hline$\beta$-Mercaptoethanol & M3148-25ml & Sigma-Aldrich Chemie $\mathrm{GmbH}$ \\
\hline
\end{tabular}

Table 4 | Commercial kits

\begin{tabular}{|c|c|c|}
\hline Kit & Product number & Manufacturer \\
\hline $\begin{array}{l}\text { BigDye Terminator v3.1 Cycle } \\
\text { Sequencing Kit }\end{array}$ & 4337455 & Thermo Fisher Scientific \\
\hline Effectene Transfection Reagent & 301427 & Qiagen \\
\hline NucleoSpin ${ }^{\circledR}$ Plasmid & 740588 & Macherey-Nagel GmbH \& Co. KG \\
\hline NucleoSpin ${ }^{\circledR}$ Gel and PCR Clean-up & 740609 & Macherey-Nagel GmbH \& Co. KG \\
\hline Viromer ${ }^{\circledR}$ Yellow & VY-01LB & Lipocalyx GmbH \\
\hline
\end{tabular}

\subsubsection{Enzymes}

Table 5 | Enzymes

\begin{tabular}{l|l|l} 
Enzyme & Product number & Manufacturer \\
\hline \hline Afel & R0652 & New England BioLabs ${ }^{\circledR}$ Inc. \\
\hline BamHI-HF & R3136 & New England BioLabs ${ }^{\circledR}$ Inc. \\
\hline Dpnl & R0176 & New England BioLabs ${ }^{\circledR}$ Inc. \\
\hline Endo H & P0702 & New England BioLabs ${ }^{\circledR}$ Inc.
\end{tabular}




\begin{tabular}{l|l|l} 
KAPA HiFi DNA Polymerase & 7958846001 & Kapa Biosystems \\
\hline Notl & R0189 & New England BioLabs ${ }^{\circledR}$ Inc. \\
\hline PRECISOR High-Fidelity DNA Polymerase & 1706 & BioCat GmbH \\
\hline RNAse A & 556746 & Calbiochem ${ }^{\circledR}$ \\
\hline T4 DNA Ligase & EL0014 & Thermo Fisher Scientific \\
\hline \begin{tabular}{l} 
Thrombin from bovine plasma \\
\hline $\begin{array}{l}\text { Trypsin/EDTA solution, 0.05\%/0.02\% } \\
\text { (w/v) }\end{array}$
\end{tabular} & T4648 & $\begin{array}{l}\text { Sigma-Aldrich Chemie } \\
\text { GmbH }\end{array}$ \\
\hline
\end{tabular}

\subsubsection{Antibodies}

Table 6 | Antibodies for western blot

\begin{tabular}{|c|c|c|c|c|}
\hline Antibody & Host species & Dilution & $\begin{array}{l}\text { Product } \\
\text { number }\end{array}$ & Manufacturer \\
\hline Anti-dysferlin & Mouse & $1: 500$ & NCL-Hamlet & $\begin{array}{l}\text { Novocastra } \\
\text { Laboratories }\end{array}$ \\
\hline Anti- $\alpha$-tubulin & Mouse & $1: 2,000$ & T9026 & $\begin{array}{l}\text { Sigma-Aldrich Chemie } \\
\text { GmbH }\end{array}$ \\
\hline $\begin{array}{l}\text { Anti-glyceraldehyde-3- } \\
\text { phosphate } \\
\text { dehydrogenase (GAPDH) }\end{array}$ & Mouse & $1: 10,000$ & G8795 & $\begin{array}{l}\text { Sigma-Aldrich Chemie } \\
\text { GmbH }\end{array}$ \\
\hline $\begin{array}{l}\text { Anti-opsin (supernatant } \\
\text { of hybridoma cells) }\end{array}$ & Mouse & $1: 100$ & & $\begin{array}{l}\text { Produced by Corinna } \\
\text { Dickel }\end{array}$ \\
\hline $\begin{array}{l}\text { Anti-mouse horseradish } \\
\text { peroxidase (HRP)-coupled }\end{array}$ & Donkey & $1: 10,000$ & 715035150 & $\begin{array}{l}\text { Jackson } \\
\text { ImmunoResearch Inc. }\end{array}$ \\
\hline
\end{tabular}

Table 7 | Antibodies for immunofluorescence

\begin{tabular}{l|l|l|l|l} 
Antibody & Host species & Dilution & $\begin{array}{l}\text { Product } \\
\text { number }\end{array}$ & Manufacturer \\
\hline \hline Anti-amphiphysin2 (BIN1) & Mouse & $1: 100$ & sc-13575 & $\begin{array}{l}\text { Santa Cruz } \\
\text { Biotechnology, Inc. }\end{array}$ \\
\hline Anti-dysferlin & Rabbit & $1: 300$ & ab124684 & Abcam \\
\hline Anti-dysferlin & Mouse & $1: 100$ & NCL-Hamlet & $\begin{array}{l}\text { Novocastra } \\
\text { Laboratories Ltd. }\end{array}$
\end{tabular}




\begin{tabular}{l|l|l|l|l}
\hline $\begin{array}{l}\text { Anti-L-type Ca } \\
\alpha 1 C / D / F / S \\
\text { ch-19) }\end{array}$ & Goat & $1: 100$ & sc-103588 & $\begin{array}{l}\text { Santa Cruz } \\
\text { Biotechnology, Inc. }\end{array}$ \\
\hline $\begin{array}{l}\text { Anti-mouse IgG-Alexa } \\
\text { Fluor } 488\end{array}$ & Goat & $1: 200$ & A-21053 & Life Technologies \\
\hline Anti-mouse IgG-Cy & Donkey & $1: 200$ & 715166150 & $\begin{array}{l}\text { Jackson } \\
\text { ImmunoResearch Inc. }\end{array}$ \\
\hline Anti-goat IgG-CyTM3 & Donkey & $1: 200$ & 705165147 & $\begin{array}{l}\text { Jackson } \\
\text { ImmunoResearch Inc. }\end{array}$ \\
\hline $\begin{array}{l}\text { Anti-rabbit IgG-Alexa } \\
\text { Fluor }\end{array}$ 488 & Donkey & $1: 200$ & 711545152 & $\begin{array}{l}\text { Jackson } \\
\text { ImmunoResearch Inc. }\end{array}$ \\
\hline
\end{tabular}

\subsubsection{Buffers and solutions}

PBS

$\begin{array}{ll}137 \mathrm{mM} & \mathrm{NaCl} \\ 2.7 \mathrm{mM} & \mathrm{KCl} \\ 8.1 \mathrm{mM} & \mathrm{Na}_{2} \mathrm{PO}_{4} \\ 1.8 & \mathrm{KH}_{2} \mathrm{PO}_{4} \\ \text { pH 7.4 } & \end{array}$

\section{Buffers for plasmid isolation}

P1

$\begin{array}{ll}50 \mathrm{mM} & \text { Tris/HCl, pH } 8.0 \\ 10 \mathrm{mM} & \text { EDTA } \\ 100 \mu \mathrm{g} / \mathrm{mL} & \text { RNAse A }\end{array}$

P2

$\begin{array}{ll}200 \mathrm{mM} & \mathrm{NaOH} \\ 1 \%(w / v) & \mathrm{SDS}\end{array}$

P3
$3 M$
$\mathrm{CH}_{3} \mathrm{CO}_{2} \mathrm{~K}, \mathrm{pH} 5.5$

\section{Cell lysis buffer}

$\begin{array}{ll}25 \mathrm{mM} & \text { Tris/HCl, pH } 7.4 \\ 150 \mathrm{mM} & \mathrm{NaCl} \\ 5 \mathrm{mM} & \text { EGTA } \\ 2 \mathrm{mM} & \text { EGTA, pH } 8.0 \\ 1 \%(\mathrm{v} / \mathrm{v}) & \mathrm{NP}-40 \\ 0.1 \%(\mathrm{w} / \mathrm{v}) & \mathrm{SDS}\end{array}$




\section{Homogenization buffer}

$\begin{array}{ll}250 \mathrm{mM} & \text { sucrose } \\ 6.2 \mathrm{mM} & \mathrm{NaN}_{3} \\ 10 \mathrm{mM} & \mathrm{NaHCO}_{3}, \mathrm{pH} 7.0 \\ 0.1 \mathrm{mM} & \mathrm{PMSF}^{\mathrm{m}} \\ 1 \times \text { cOmplete } & \text { Protease Inhibitor Cocktail }\end{array}$

Sucrose cacodylate buffer

$\begin{array}{ll}0.1 \mathrm{M} & \text { sucrose } \\ 0.1 \mathrm{M} & \text { sodium cacodylate } \\ \mathrm{pH} 7.4 & \end{array}$

SDS-PAGE sample buffer, $4 x$

$\begin{array}{ll}160 \mathrm{mM} & \text { Tris/HCl, pH } 6.8 \\ 8 \%(\mathrm{w} / \mathrm{v}) & \text { SDS } \\ 0.01 \%(\mathrm{w} / \mathrm{v}) & \text { bromophenol blue } \\ 20 \% & \beta \text {-mercaptoethanol } \\ 20 \%(\mathrm{v} / \mathrm{v}) & \text { glycerol }\end{array}$

\section{SDS-PAGE buffer}

$\begin{array}{ll}25 \mathrm{mM} & \text { Tris } \\ 1,92 \mathrm{M} & \text { glycine } \\ 1 \%(\mathrm{w} / \mathrm{v}) & \text { SDS }\end{array}$

Tris-buffered saline (TBS)

$\begin{array}{ll}50 \mathrm{mM} & \text { Tris/HCl, } \mathrm{pH} 7.6 \\ 150 & \mathrm{mM} \mathrm{NaCl}\end{array}$

Transfer buffer for semi-dry western blot

$\begin{array}{ll}25 \mathrm{mM} & \text { Tris } \\ 260 \mathrm{mM} & \text { glycine } \\ 20 \%(\mathrm{v} / \mathrm{v}) & \text { methanol }\end{array}$

\section{TRIS-Acetat-EDTA (TAE) buffer}

$\begin{array}{ll}40 \mathrm{mM} & \text { Tris/ } \mathrm{HCl}, \mathrm{pH} 8.0 \\ 0.1 \%(\mathrm{v} / \mathrm{v}) & \text { acetic acid } \\ 1 \mathrm{mM} & \text { EDTA }\end{array}$




\subsubsection{Mammalian cell culture medium}

COS-7 and CHO-K1 culture medium

DMEM, $4.5 \mathrm{~g} / \mathrm{L}$ D-glucose

$10 \%(v / v)$ FBS

$1 \%(\mathrm{v} / \mathrm{v})$ L-glutamine

HEK293 culture medium

DMEM, $4.5 \mathrm{~g} / \mathrm{L}$ D-glucose

$5 \%(v / v)$ FBS

$1 \%(v / v)$ L-glutamine

HeLa culture medium

DMEM, $1.0 \mathrm{~g} / \mathrm{L}$ D-glucose

$10 \%(v / v)$ FBS

$1 \%(v / v)$ L-glutamine

C2C12 culture medium

DMEM, $4.5 \mathrm{~g} / \mathrm{L}$ D-glucose

$15 \%(v / v)$ FBS

$1 \%(v / v)$ L-glutamine

C2C12 differentiation medium

DMEM, 4.5g/L D-glucose

$3 \%(v / v)$ horse serum

$1 \%(v / v)$ L-glutamine

Human myoblast culture medium

Skeletal Muscle Cell Growth Medium

$10 \%(v / v)$ FBS

1.5\% GlutaMAX ${ }^{\mathrm{TM}}-\mathrm{I}(100 \mathrm{x})$

$50 \mathrm{mg} / \mathrm{mL}$ gentamicin 


\section{Human myoblast differentiation medium}

DMEM, 4.5g/L D-glucose

$5 \%(v / v)$ horse serum

Freezing medium for cell lines

$$
\begin{aligned}
& \text { DMEM, } 4.5 \mathrm{~g} / \mathrm{L} \text { D-glucose } \\
& 20 \%(\mathrm{v} / \mathrm{v}) \text { FBS } \\
& 1 \%(\mathrm{v} / \mathrm{v}) \text { L-glutamine } \\
& 10 \%(\mathrm{v} / \mathrm{v}) \text { DMSO }
\end{aligned}
$$

Freezing medium for human myoblasts

DMEM, $4.5 \mathrm{~g} / \mathrm{L}$ D-glucose

$20 \%(v / v)$ FBS

$10 \%(v / v)$ DMSO

Sterile filtered

\subsubsection{Oligonucleotides}

Designed oligonucleotides were analyzed for melting temperature, self-dimerization, heterodimerization and hairpin structures using using OligoAnalyzer 3.1 (Integrated DNA Technologies, Inc).

Table 8 | Oligonucleotide for cloning

\begin{tabular}{l|l} 
Oligonucleotide & Sequence $\left(\mathbf{5}^{\prime} \mathbf{-} \mathbf{3}^{\prime}\right)$ \\
\hline \hline OST 587 & CCGCCCAGCATTGTGG \\
\hline pKB 17 & $\begin{array}{l}\text { GGTACGCGGCCGCGGATCCTTAGCCCGTCTTGTTGGAGAAAGGCACGTAGAAGTT } \\
\text { TGGGCCGCTGAAGGGTTCACCAGCTT }\end{array}$ \\
\hline
\end{tabular}

Table 9 | Oligonucleotides for Dpnl-mediated site-directed mutagenesis

\begin{tabular}{l|l} 
Oligonucleotide & Sequence (5'-3') \\
\hline \hline OST 581 & CCTGGCATGGGGCCCGCGGAACATGAAGAG \\
\hline OST 582 & CTCTTCATGTTCCGCGGGCCCCATGCCAGG
\end{tabular}




\begin{tabular}{l|l}
\multicolumn{2}{l}{ Table 10 | Oligonucleotides for sequencing } \\
Oligonucleotide & Sequence (5'-3') \\
\hline \hline IC 1 & GCT CAG CTG ACG GAT GAG C \\
\hline IC 2 & GAT CTC AGC CAA ATG GAA GC \\
\hline IC 3 & CTC TTC ATG GAA GTG ATG C \\
\hline IC 4 & GCA GCC AGA CAT CGA GC \\
\hline IC 5 & CAG CCA AGA AGT GCT CCT TGG \\
\hline OST 583 & CAAAGGGAGCCCGG \\
\hline OST 584 & GCAACCTGCTCCGGCC \\
\hline OST 585 & CAGGCTTCCCAGACCC \\
\hline OST 586 & GGGCACAACGGGCCTC \\
\hline OST 587 & CCGCCCAGCATTGTGG \\
\hline OST 603 & CAT CCC CTG CAC GCT GG \\
\hline BGH reverse & TAG AAG GCA CAG TCG AGG \\
\hline CMV promoter & CGCAAATGGCGGTAGGGT \\
\hline $\begin{array}{l}\text { Citrin } 3 \text { 'F1 (From Thomas Weber, } \\
\text { dept. of Otorhinolaryngology, UMG) }\end{array}$ & GCG TGC AGC TCG CCG ACC ACT ACC \\
\hline
\end{tabular}




\subsubsection{DNA plasmids}

Table 11 | DNA plasmids

\begin{tabular}{|c|c|}
\hline Plasmid name & Source/reference \\
\hline EGFP-DYSF-pcDNA4 & (Klinge et al., 2007) \\
\hline EGFP-DYSF-ops-pcDNA4 & this study \\
\hline EGFP-DYSF-L1341P-ops-pcDNA4 & this study \\
\hline EGFP-DYSF-L1341P-pcDNA4 & Irmgard Cierny \\
\hline EGFP-DYSF-R959W-pcDNA4 & Irmgard Cierny \\
\hline PST 1596, pcDNA3.1(+)_RFP_GFP_with MCS & Corinna Dickel \\
\hline PST 1902, PST1596_DYSF c.265C>T & Marco Schmidt \\
\hline PST 1990, PST1596_DYSF c.331C>T & Marco Schmidt \\
\hline PST 1922 , PST1596_DYSF c.610C>T & Corinna Dickel \\
\hline PST 1923, PST1596_DYSF c.691C>T & Corinna Dickel \\
\hline PST 1924, PST1596_DYSF c.1566C>G & Corinna Dickel \\
\hline PST 1925, PST1596_DYSF c.1717G>T & Corinna Dickel \\
\hline PST 1926, PST1596_DYSF c.1758C>T & Corinna Dickel \\
\hline PST 1927, PST1596_DYSF c.1813C>T & Corinna Dickel \\
\hline PST 1928, PST1596_DYSF c.1834C>T & Corinna Dickel \\
\hline PST 1929, PST1596_DYSF c.2494C>T & Corinna Dickel \\
\hline PST 1897, PST1596_DYSF c.3112C>T & Marco Schmidt \\
\hline PST 1903, PST1596_DYSF c.3516_3517delTT & Marco Schmidt \\
\hline PST 1930, PST1596_DYSF c.3805G>T & Corinna Dickel \\
\hline PST 1931, PST1596_DYSF c.3832C>T & Corinna Dickel \\
\hline PST 1899, PST1596_DYSF c.4194C>A & Marco Schmidt \\
\hline PST 1932, PST1596_DYSF c.4756C>T & Corinna Dickel \\
\hline PST 1933, PST1596_DYSF c.5713C>T & Corinna Dickel \\
\hline PST 1934, PST1596 DYSF c.5903G>A & Corinna Dickel \\
\hline
\end{tabular}




\subsubsection{Software}

Table 12 | Software

Software

Manufacturer/reference

\begin{tabular}{l|l}
\hline \hline Axiovision 4.8, epifluorescence microscope software & Carl Zeiss AG \\
\hline $\begin{array}{l}\text { Fluoview FV1000 FV10-ASW 2.0, confocal microscope } \\
\text { software }\end{array}$ & Olympus Deutschland GmbH \\
\hline ZEN 2009, confocal microscope software & Carl Zeiss AG \\
\hline Imaris x64, 7.4.0, microscopy image analysis software & Bitplane AG \\
\hline GraphPad Prism 4, graphing and statistics software & GraphPad Software, Inc. \\
\hline SAS ${ }^{\circledR}$ University Edition, statistics software & SAS Institute Software GmbH \\
\hline Fiji, image processing software & (Schindelin et al., 2012) \\
\hline ImageJ, image processing software & (Schneider et al., 2012) \\
\hline Analyze Skeleton, Fiji plugin & (Arganda-Carreras et al., 2010) \\
\hline Directionality, Fiji plugin & (Liu, 1991) \\
\hline JacoP, Fiji plugin & (Bolte and Cordelières, 2006) \\
\hline
\end{tabular}




\subsection{Methods}

\subsubsection{Cell biology}

\subsubsection{Cell culture}

\section{Culture of mammalian cell lines}

For freezing purposes, cells at confluency of approximately 70\% were washed with 1x PBS and detached by incubation with $0.5-1 \mathrm{~mL}$ trypsin/EDTA for $2 \mathrm{~min}$ at $37{ }^{\circ} \mathrm{C}$. Cells were resuspended in 10x volume of culture medium and centrifuged at $800 \mathrm{rpm}$ for $5 \mathrm{~min}$. The cell pellet was diluted in $1 \mathrm{~mL}$ freezing medium and transferred into cryo tubes, which were placed into freezing containers at $-80^{\circ} \mathrm{C}$ overnight (o.n.) to allow slow freezing. For long-term storage, cryo tubes were transferred to $-150^{\circ} \mathrm{C}$. For cultivation, cells were thawed in a water bath at 37 ${ }^{\circ} \mathrm{C}$ and transferred into $10 \mathrm{ml}$ culture medium. After centrifugation at $800 \mathrm{rpm}$ for $5 \mathrm{~min}$, cellpellets were resuspended in culture medium and seeded in culture flasks and cultivated at 37 ${ }^{\circ} \mathrm{C}$ in a $5 \% \mathrm{CO} / 95 \%$ humidity atmosphere. Depending on their confluency cells were split 1:5 to $1: 10$ every 3 to 5 days. Therefore, cells were detached with $1 \mathrm{~mL}$ trypsin/EDTA after washing with $1 \times$ PBS. Detached cells were resuspended in culture medium and seeded into new culture flasks.

\section{Culture of $\mathrm{C} 2 \mathrm{C} 12$ cells}

C2C12 were cultured in culture flasks and grown at low confluency (maximum 70\%) to avoid unintentional differentiation of cells. Differentiation of myoblasts into myotubes was induced at a cell confluency of $90 \%$. Therefore, the cultivation medium was replaced with differentiation medium after washing once with 1x PBS. C2C12 myoblasts were differentiated for 5 days. The medium was replaced by fresh differentiation medium every day.

\section{Culture of human myoblasts}

Primary human myoblasts were cultured in culture flasks and grown at low confluency (maximum 70\%) to avoid unintentional differentiation of cells. Differentiation of myoblasts into myotubes was induced at a cell confluency of $90 \%$. Therefore, the cultivation medium was replaced with differentiation medium after washing once with $1 \times$ PBS. Human myoblasts were differentiated for 7 days. The medium was replaced by fresh differentiation medium every day. 


\subsubsection{Isolation of ventricular cardiomyocytes from rats for immunofluorescence staining}

The isolation of ventricular rat cardiomyocytes was performed in cooperation with the group of Prof. Viacheslav Nikolaev, formerly department for Cardiology and Pneumology, University Medical Center Göttingen. Ventricular cardiomyocytes from rat hearts were isolated by retrograde perfusion according to the Langendorff technique (Bell et al., 2011). 11-, 14-, 17-, 20-, 23-day old or adult rats were anesthetized with isoflurane and sacrificed by cervical dislocation. The hearts were extracted quickly and connected to the perfusion system by putting the aorta onto the perfusion cannula. Hearts were perfused with $8 \mathrm{~mL} / \mathrm{min}$ at $37^{\circ} \mathrm{C}$. After initial perfusion with $\mathrm{Ca}^{2+}$-free buffer for $2 \mathrm{~min}$, hearts were digested with collagenase type II $(2 \mathrm{mg} / \mathrm{mL}$, approximately $300 \mathrm{U} / \mathrm{mg})$ in $40 \mu \mathrm{M}$ calcium chloride for 9 min at $37{ }^{\circ} \mathrm{C}$. Following perfusion, the ventricles were separated from the atria and minced in digestion buffer. The tissue was carefully resuspended with a $10 \mathrm{~mL}$ serological pipette and the digestion process was stopped by adding stop buffer before again resuspending. The cardiomyocytes were washed three times with stop buffer. Therefore, cells were allowed to sediment by gravity for 8 min at RT. The supernatant containing cell debris was discarded and cells were again resuspended in stop buffer. For immunofluorescence staining, cells were seeded on laminin-coated glass coverslips and incubated for $30 \mathrm{~min}$ at $37{ }^{\circ} \mathrm{C}$, before proceeding with the staining protocol. Laminin coating was performed by incubation of glass cover slips with $20 \mu \mathrm{g} / \mathrm{mL}$ laminin in PBS at $37{ }^{\circ} \mathrm{C}$ for $2 \mathrm{~h}$. Subsequently, cover slips were washed and allowed to dry at RT.

\subsubsection{Isolation of rat hearts for preparation of protein lysates}

11-week old rats were anesthetized by isoflurane and sacrificed by cervical dislocation. 14-, 17-, 20-, 23-week old rats and adult rats were euthanized by carbon dioxide inhalation and immediate opening of the thorax. The ventricular part of the heart was separated from the atrial part, transferred into reaction tubes and frozen in liquid nitrogen. Ventricular heart tissues were stored at $-80{ }^{\circ} \mathrm{C}$ until preparation of protein lysates.

\subsubsection{Transfection of cell lines}

HeLa, HEK293, COS-7 and CHO-K1 cells were transfected with plasmid DNA using Effectene Transfection Reagent according to manufacturer's instructions. $48 \mathrm{~h}$ after transfection, cells 
were either harvested for the isolation of proteins or fixed for immunofluorescence staining. C2C12 cells were transfected with plasmid DNA using Viromer ${ }^{\circledR}$ YELLOW transfection reagent according to manufacturer's instructions. $72 \mathrm{~h}$ after transfection, cells were harvested for the isolation of proteins.

\subsubsection{Treatments of HeLa cells}

\section{PBA treatment}

For stabilization experiments, HeLa cells were treated with $5 \mathrm{mM}$ PBA for $24 \mathrm{~h}$. Therefore, the medium was replaced $24 \mathrm{~h}$ after transfection and culture medium containing PBA was added for another $24 \mathrm{~h}$. Transfected and PBA-treated cells were used for analysis of protein steadystate level and localization.

\section{G418 treatment}

For readthrough analysis, HeLa cells were transfected with DNA plasmids encoding dual fluorescence reporters. $6 \mathrm{~h}$ after transfection, the medium was changed to culture medium containing $100 \mu \mathrm{g} / \mathrm{mL}$ of $\mathrm{G} 418$ and incubated for another $18 \mathrm{~h} .24 \mathrm{~h}$ after transfection, cells were harvested for flow cytometric analysis.

\subsubsection{Immunofluorescence staining}

\section{Immunofluorescence staining of cell lines}

For immunofluorescence staining, HeLa cells were seeded on glass coverslips in multi-well plates and $\mathrm{C} 2 \mathrm{C} 12$ cells were seeded in NuncTM Lab-Tek ${ }^{\circledR}$ Chamber Slides. $48 \mathrm{~h}$ after transfection, cells were washed once with PBS, fixed with 4\% PFA by incubation for $20 \mathrm{~min}$ at RT and washed once with blocking solution (3\% horse serum and $0.5 \%$ saponin in PBS). Following incubation in blocking solution for $30 \mathrm{~min}$ at RT, cells were incubated with the primary antibody diluted in blocking solution for $1 \mathrm{~h}$ at RT in a moist chamber. Cells were washed three times for 5 min with PBS and incubated with the secondary antibody as outlined above. Following washing three times for $5 \mathrm{~min}$, cells were mounted with mowiol containing DAPI $(1: 2,000)$. Cover slips were transferred on microscope slides. NuncTM Lab-Tek ${ }^{\circledR}$ Chamber $^{2}$ Slide bottoms were covered with glass cover plates. Immunofluorescence samples were allowed to cure at RT o.n. and were long-term stored at $4{ }^{\circ} \mathrm{C}$. Cells were visualized by epifluorescence or confocal laser scanning (Inverted IX81 Olympus) microscopy using 100x or $63 x$ oil objectives, respectively. 


\section{Immunofluorescence staining of mouse ventricular cardiomyocytes}

Langendorff-isolated ventricular cardiomyocytes from 8 week-old cardiomyocyte-specific tamoxifen inducible WRB knockout mice (MerCreMer - (Cre-) and MerCreMer + (Cre-, knockout)) were provided by Dr. Jhon Rivera-Monroy, department of Molecular Biology, University Medical Center Göttingen (For isolation protocol see Rivera-Monroy et al., 2016). The staining of cardiomyocytes were performed were carefully to avoid detachment of the cells. Cardiomyocytes were fixed with 4\% PFA for $5 \mathrm{~min}$ at RT and washed twice with PBS before blocking with 10\% FBS in PBS for 60 min at RT. Primary antibody was diluted in 5\% FBS/PBS and incubated in a moist chamber at o.n. at $4{ }^{\circ} \mathrm{C}$. After washing once for 5 min with PBS, incubation with the secondary antibody was performed for $1 \mathrm{~h}$ at RT in the dark in a moist chamber. Cells were washed twice for 5 min with PBS, briefly washed with water and mounted with mowiol containing DAPI $(1: 2,000)$. Immunofluorescence samples were allowed to cure at RT o.n. and were long-term stored at $4{ }^{\circ} \mathrm{C}$. Cells were visualized by confocal laser scanning microscopy using a $63 x$ oil objective. Dysferlin expression level was analyzed on the basis of confocal immunofluorescence images and calculated as corrected total cell fluorescence (CTCF) by subtracting the background multiplied with the cell area from the integrated cell intensity.

\section{Immunofluorescence staining of rat ventricular cardiomyocytes}

Langendorff-isolated ventricular rat cardiomyocytes were fixed in 4\% PFA for $5 \mathrm{~min}$ at RT and blocked in $5 \%$ horse serum and $0.2 \%$ Triton ${ }^{\circledast}$ X 100 in PBS for $1 \mathrm{~h}$ at RT. Primary antibody was diluted in the blocking solution and incubated in a moist chamber o.n. at $4{ }^{\circ} \mathrm{C}$. After washing twice shorty and once for 10 min with blocking solution, cells were incubated with secondary fluorescently-labeled antibody for $4 \mathrm{~h}$ at RT in a moist chamber. Cells were washed as described above with PBS and mounted with VECTASHIELD ${ }^{\circledR}$ containing DAPI. After burdening o.n. at RT, cells were visualized by confocal laser scanning microscopy (Inverted IX81 Olympus).

\subsubsection{Membrane staining}

\section{Membrane staining of human myoblasts with DilC16(3)}

Undifferentiated human myoblasts were seeded in $\mu$-Slide 4 Well cell dishes. After differentiation of 7 days, cells were washed with sucrose cacodylate buffer and incubated with DilC16(3) diluted to $12.5 \mu \mathrm{g} / \mathrm{mL}$ in sucrose cacodylate buffer for $10 \mathrm{~min}$ at RT. Cells were visualized by confocal laser scanning microscopy (Inverted IX81 Olympus). 


\section{Membrane staining of mouse ventricular cardiomyocytes with di-8-ANEPPS}

The isolation of ventricular cardiomyocytes from Dysf gene-deleted and control mice was performed by Ines Müller, group of Prof. Niels Voigt, institute of Pharmacology and Toxicology, University Medical Center Göttingen. Ventricular cardiomyocytes from mouse hearts were isolated by retrograde perfusion according to the Langendorff technique (Bell et al., 2011). For membrane staining, cells were gently resuspended in stop buffer containing 50 $\mu \mathrm{M}$ di-8-ANEPPS. Immediately, cells were seeded in laminin-coated microscopy cell dishes ( $\mu$ dish, $35 \mathrm{~mm}$, glass bottom, ibiTreat) and incubated for $30 \mathrm{~min}$ at RT in the dark. Laminin coating was performed by covering the bottom of the microscopy cell dishes with $20 \mu \mathrm{g} / \mathrm{mL}$ of laminin in PBS and incubation at $37^{\circ} \mathrm{C}$ for $1 \mathrm{~h}$. Subsequently, cover slips were washed and allowed to dry at RT. After the staining, the di-8-ANEPPS solution was removed carefully to not detach the cells from the bottom. After washing once with stop buffer, cells were overlayed with stop buffer and imaged by confocal laser scanning microscopy (LSM 710 NLO equipped with a 63x/1.4 NA oil objective). For the imaging protocol see (Wagner et al., 2014).

\subsubsection{Analysis of TATS morphology of di-8-ANNEPS-stained mouse ventricular cardiomyocytes}

The confocal images of di-8-ANEPPS-stained ventricular cardiomyocytes from Dysf genedeleted and control mice were processed and analyzed as described by Wagner and colleagues (Wagner et al., 2014) with minor changes: For background subtraction, the rolling ball radius was set to 15 . The amount of axial and transversal structures was calculated as the sum of structures with an orientation of $-5^{\circ}$ to $+5^{\circ}$ (axial) and $+85^{\circ}$ to $+95^{\circ}$ (transversal).

\subsubsection{Flow cytometric analysis of readthrough using dual reporter assay}

For the analysis of readthrough of stop codon contexts (stop codon +/- 10 nucleotides upstream and downstream) from all DYSF nonsense mutations, a dual fluorescent reporter was used and coupled to flow cytometric analysis of fluorescence. The dual reporter consists of an N-terminal TagRFP and a C-terminal EGFP tag flanking the stop codon context. A construct without a stop codon between the fluorescent tags served as $100 \%$ readthrough control. HeLa cells were transfected with the dual reporter and readthrough was either not induced (basal readthrough) or induced by the treatment with G418. $24 \mathrm{~h}$ after transfection, cells were harvested by trypsin/EDTA and centrifugation. The cell pellet was resuspended in $700 \mu \mathrm{L}$ PBS containing 10\% FCS and cells were filtered through a cell strainer. The cells were 
analyzed by flow cytometry using a LSRII (Becton Dickinson) flow cytometer equipped with $488 \mathrm{~nm}$ and $561 \mathrm{~nm}$ lasers. Living cells were selected by gating according to side scatter (SSCA, corresponds to cell granularity) and forward scatter (FSC-A, corresponds to cell size). Additionally, cells were gated according to TagRFP and EGFP fluorescence intensity by setting a threshold which excludes non-transfected cells. Finally, the readthrough was calculated as the EGFP over TagRFP fluorescence ratio normalized to the untreated $100 \%$ readthrough control.

\subsubsection{Protein biochemistry}

\subsubsection{Isolation of proteins from cells for SDS- polyacrylamide gel electrophoresis (SDS-PAGE)}

Whole cell protein lysates were obtained from confluent cell cultures. After washing once with PBS, $1 \mathrm{~mL}$ PBS was added. Cells were detached by cell scrapers and transferred into reaction tubes. After centrifugation at $2000 \mathrm{rpm}$ for $5 \mathrm{~min}$, cell pellets were resuspended in cell lysis buffer and incubated for $20 \mathrm{~min}$ on ice. The cell debris was separated from the protein lysate by centrifugation at $14,000 \mathrm{rpm}$ for $20 \mathrm{~min}$ at $4{ }^{\circ} \mathrm{C}$. The protein lysate was transferred into a new reaction tube and either protein concentration was measured or protein lysates were frozen. Cell lysates were kept for short-term storage at $-20^{\circ} \mathrm{C}$ and for long-term storage at -80 ${ }^{\circ} \mathrm{C}$. Protein concentrations were assessed by BCA assay according to manufacturer's instructions. Protein lysates with appropriate amount of protein were mixed with 4x SDS-PAGE sample buffer to obtain $1 \mathrm{x}$ concentration. The samples were boiled either at $70{ }^{\circ} \mathrm{C}$ for detection of full-length dysferlin or $95{ }^{\circ} \mathrm{C}$ for detection of truncated dysferlin and stored at -20 ${ }^{\circ} \mathrm{C}$ prior to SDS-PAGE.

\subsubsection{Thrombin and Endo $H$ treatment of HeLa cell culture lysates}

For cleavage of full-length dysferlin, cell lysates with appropriate protein amount were mixed with $20 \mu \mathrm{L}$ of protease thrombin (stock: $100 \mathrm{NIH}$ units $/ \mathrm{mL}$ in $0.1 \% \mathrm{BSA} / 50 \mathrm{mM}$ Tris/ $\mathrm{HCl}, \mathrm{pH}$ 6.8) and incubated for $1 \mathrm{~h}$ at $37^{\circ} \mathrm{C}$. Subsequently, removal of $\mathrm{N}$-glycosylation modifications was performed by treatment of cell lysates with the endoglycosidase Endo $\mathrm{H}$ using the supplemented buffers according to manufacturer's instructions. Shorty, proteins were denatured for $10 \mathrm{~min}$ at $95^{\circ} \mathrm{C}$ prior to Endo $\mathrm{H}$ cleavage for $1 \mathrm{~h}$ at $37^{\circ} \mathrm{C}$. 


\subsubsection{Isolation of proteins from rat ventricular heart tissue for SDS-PAGE}

Ventricular heart tissue from rats of different age was used for the preparation of protein lysates. Therefore, the tissue was weighted and $1.5 \mathrm{~mL}$ homogenization buffer per $100 \mathrm{mg}$ tissue was added. The cardiac tissue was homogenized 5 times for $5 \mathrm{sec}$ on ice. The homogenate was centrifuged two times at $1,300 \times \mathrm{g}$ for $10 \mathrm{~min}$ at $4{ }^{\circ} \mathrm{C}$ and in between centrifugation steps the supernatant was transferred into a new reaction tube. The final protein lysate was stored at $-80{ }^{\circ} \mathrm{C}$ or immediately used for the determination of protein concentration by BCA assay according to manufacturer's instructions. SDS-PAGE samples were prepared by pooling $10 \mu \mathrm{g}$ of protein from each rat of the same age and mixing the proteins with $4 x$ SDS-PAGE sample buffer to obtain $1 x$ concentration. The samples were boiled at $90^{\circ} \mathrm{C}$ and stored at $-20^{\circ} \mathrm{C}$ prior to SDS-PAGE.

\subsubsection{SDS-PAGE and western blot}

SDS-PAGE was used for the separation of protein samples according to the molecular weight of proteins. For efficient separation, a 5\% acrylamide stacking gel and, depending on the size of proteins to be detected, a resolving gel of $8-15 \%$ acrylamide concentration was used. Volume of stacking and resolving gel was adjusted to the gel size (small/large gels). Subsequently, western blot was performed to determine the protein level of specific proteins. The molecular weight of the separated proteins was determined by comparison with a prestained protein ladder.

Table 13 | Protocol for preparation of stacking and resolving gels for SDS-PAGE

\begin{tabular}{l|l|l|l} 
Component & $\mathbf{5 \%}$ stacking gel & $\mathbf{8 \%}$ resolving gel & $\mathbf{1 5 \%}$ resolving gel \\
\hline \hline Total volume & $2 \mathrm{~mL}$ & $5 \mathrm{~mL}$ & $5 \mathrm{~mL}$ \\
\hline Water & $1.4 \mathrm{~mL}$ & $2.3 \mathrm{~mL}$ & $1.1 \mathrm{~mL}$ \\
\hline $30 \%$ acrylamide solution & $330 \mu \mathrm{L}$ & $1.3 \mathrm{~mL}$ & $2.5 \mathrm{~mL}$ \\
\hline $1.0 \mathrm{M}$ Tris, pH 6.8 & $250 \mu \mathrm{L}$ & $/$ & $/$ \\
\hline $1.5 \mathrm{M}$ Tris, pH 8.8 & $/$ & $1.3 \mathrm{~mL}$ & $1.3 \mathrm{~mL}$ \\
\hline $10 \%$ SDS & $20 \mu \mathrm{L}$ & $50 \mu \mathrm{L}$ & $50 \mu \mathrm{L}$ \\
\hline $10 \%$ APS & $20 \mu \mathrm{L}$ & $50 \mu \mathrm{L}$ & $50 \mu \mathrm{L}$ \\
\hline TEMED & $4 \mu \mathrm{L}$ & $6 \mu \mathrm{L}$ & $4 \mu \mathrm{L}$
\end{tabular}


Proteins were concentrated in the stacking gel at $15 \mathrm{~mA} / 25 \mathrm{~mA}$ (for small and large gels, respectively), followed by separation at $25 \mathrm{~mA} / 45 \mathrm{~mA}$.

Following SDS-PAGE, proteins were electrotransferred to a nitrocellulose membrane. Therefore, a sandwich consisting of 3 layers of blotting paper, membrane, gel, 3 layers of blotting paper was prepared. The sandwich was placed into the semi-dry blotting system with the membrane facing the anode and soaked with transfer buffer. Blotting was performed at $1.25 \mathrm{~mA}$ per $\mathrm{cm}^{2}$ of sanchwich area for $1.5 \mathrm{~h}$. Transferred total proteins were visualized by Ponceau-S staining.

For immunostaining the membranes were previously blocked for $1 \mathrm{~h}$ with $5 \%$ milk, $1 \%$ Tween ${ }^{\circledR}$ 20 in TBS (TBS-T) to avoid unspecific binding of the primary antibody which was incubated o.n. at $4{ }^{\circ} \mathrm{C}$. The membranes were washed 3 times for 5 min with TBS-T and incubated with horseradish peroxidase (HRP)-coupled secondary antibody diluted in 5\% milk/TBS-T for $1 \mathrm{~h}$ at RT. After washing 3 times for 5 min with TBS-T, proteins bound to antibody-complexes were visualized by enhanced chemiluminescence (Lumi-Light Western Blotting Substrate) using a western blot documentation system LAS-4000. Protein signal was quantified using Fiji software.

\subsubsection{Molecular biology}

\subsubsection{Generation of EGFP-DYSF-ops-pcDNA4}

The plasmid containing an ops-tagged DYSF cDNA sequence was generated by the amplification of a C-terminal fragment of the DYSF sequence containing the opsin tag sequence, which was incorporated into the reverse primer, and cloning of the amplicon into the preexisting plasmid EGFP-DYSF-pcDNA4.

\subsubsection{Generation of EGFP-L1431P-ops-pcDNA4 by Dpnl-mediated site-directed mutagenesis}

The pathogenic mutation L1341P was introduced into the plasmid EGFP-DYSF-ops-pcDNA4 by site-directed mutagenesis and subsequent Dpnl digestion. Therefore, KAPA HiFi DNA polymerase and primers OST 581 and OST 582 were used. For the mutagenesis reaction, $10 \mathrm{ng}$ of template DNA were mixed with $5 \mu \mathrm{L}$ GC buffer, $0.75 \mu \mathrm{L}$ of dNTP mix (3.75 mM), $0.75 \mu \mathrm{L}$ per 
primer $(10 \mu \mathrm{M})$ and $0.5 \mu \mathrm{L}$ KAPA HiFi DNA polymerase in a total volume of $25 \mu \mathrm{L}$. The reaction was performed applying the following program:

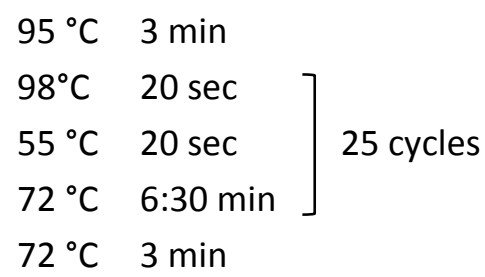

Subsequently, the template DNA was removed by digestion of the total reaction mixture with $1 \mu \mathrm{L}$ of Dpnl for $1: 30 \mathrm{~h}$ at $37^{\circ} \mathrm{C}$.

\subsubsection{Amplification of DNA by polymerase chain reaction (PCR)}

The amplification of the C-terminal DYSF fragment and coupling to the opsin tag sequence was performed by PCR using PRECISOR High-Fidelity DNA Polymerase. EGFP-DYSF-pcDNA4 was used as template. Primers OST587 and pKB17 were used for the amplification. Coupling of DYSF to opsin tag was achieved by incorporation of the opsin tag sequence into the reverse primer pKB17 and removal of the DYSF stop codon. For the PCR, 10 ng of template DNA were mixed with $10 \mu \mathrm{L}$ of $\mathrm{GC}$ buffer, $2.7 \mu \mathrm{L}$ of dNTP mix (3.75 mM), $1 \mu \mathrm{L}$ per primer $(10 \mu \mathrm{M})$ and 1 $\mu \mathrm{L}$ of polymerase in a total volume of $50 \mu \mathrm{L}$. The amplification was performed applying the following PCR program:

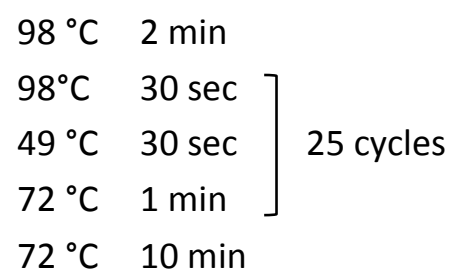

\subsubsection{Restriction of DNA with restriction endonucleases}

DNA fragments and plasmids were cleaved using restriction endonucleases from New England BioLabs ${ }^{\circledast}$ Inc. according to manufacturer's instructions. For cloning of EGFP-DYSF-ops-pcDNA4 enzymes Afel and Notl in CutSmart ${ }^{\circledR}$ buffer were used. For test digestion of clones, BamHI-HF ${ }^{\circledR}$ in CutSmart ${ }^{\circledR}$ buffer was used. DNA fragment were separated by agarose gel electrophoresis and extracted by NucleoSpin ${ }^{\circledR}$ Gel and PCR Clean-up. 


\subsubsection{Ligation of DNA fragments}

For cloning of EGFP-DYSF-ops-pcDNA4 the digested amplicon and plasmid EGFP-DYSF-pcDNA4 were ligated using T4 DNA Ligase. Ligation was carried out by mixing $50 \mathrm{ng}$ of digested plasmid DNA with three-fold molar mass of digested amplicon with $1 \mu \mathrm{l}$ of T4-ligase and $2 \mu \mathrm{l} 10 \mathrm{x}$ ligase buffer in a total reaction volume of $20 \mu \mathrm{L}$. The ligation mixture was incubated at RT for $30 \mathrm{~min}$ and subsequently used for transformation of competent $E$. coli.

\subsubsection{Transformation of $E$. coli}

Plasmid DNA was introduced in E. coli bacteria using heat shock. For cloning purposes, $1 \mu \mathrm{l}$ ligation reaction was added to $10 \mu \mathrm{l}$ of competent $E$. coli bacterial solution. For transformation of mutagenized DNA, $2 \mu \mathrm{L}$ of mutagenesis mixture was added to $20 \mu \mathrm{L}$ of competent $E$. coli bacterial solution. Following $20 \mathrm{~min}$ of incubation on ice, the transformation mix was set to $42^{\circ} \mathrm{C}$ for $70 \mathrm{~s}$. Subsequently, the solution was cooled down on ice for $2 \mathrm{~min}$ and $400 \mu \mathrm{l}$ of LB medium were added. After incubation at $37{ }^{\circ} \mathrm{C}$ and $300 \mathrm{rpm}$ for $1 \mathrm{~h}$, the mixture was plated on LB agar plates containing $100 \mu \mathrm{g} / \mathrm{mL}$ ampicillin and cultivated o.n. at $37^{\circ} \mathrm{C}$. Single colonies were picked and and small bacterial cultures were prepared by inoculation of $3 \mathrm{~mL} \mathrm{LB}$ medium containing $100 \mu \mathrm{g} / \mathrm{mL}$ ampicillin and o.n. incubation at $37^{\circ} \mathrm{C}$ and $200 \mathrm{rpm}$.

\subsubsection{Isolation of plasmid DNA from $E$. coli}

\section{Isolation of plasmid DNA from small $E$. coli cultures}

Plasmid DNA was isolated from $3 \mathrm{~mL}$ o.n. E. coli cultures. Therefore, bacteria were harvested at $8000 \mathrm{rpm}$ for $1 \mathrm{~min}$. The pellet was resuspended in $200 \mu \mathrm{L}$ of buffer P1 and $300 \mu \mathrm{L}$ buffer of P2 was added and the samples were inverted and incubated for $5 \mathrm{~min}$ at room temperature. $300 \mu \mathrm{L}$ of buffer P3 was added, the samples were inverted and centrifuged for $10 \mathrm{~min}$ at $14,000 \mathrm{rpm}$. The supernatant was transferred into a new reaction tube and the DNA was precipitated with 0.7 volumes of isopropanol and $20 \mathrm{~min}$ centrifugation at 14,000 rpm. The pellet was washed with $70 \%$ ethanol, dried for $10 \mathrm{~min}$ at $37^{\circ} \mathrm{C}$ and resuspended in $30 \mu \mathrm{L} \mathrm{dH_{2 }} \mathrm{O}$.

Large bacterial cultures were prepared by inoculation of $100 \mathrm{~mL}$ LB medium with $100 \mu \mathrm{L}$ of small o.n. bacterial culture and incubation o.n. at $37^{\circ} \mathrm{C}$ and $200 \mathrm{rpm}$ 


\section{Isolation of plasmid DNA from large $E$. coli cultures}

Plasmid DNA was isolated from $100 \mathrm{~mL}$ o.n. E. coli cultures. Bacteria were harvested by $20 \mathrm{~min}$ centrifugation at $3,000 \mathrm{rpm}$ and isolation of DNA was performed according to the manufacturer's instructions using the NucleoSpin ${ }^{\circledast}$ Plasmid kit. DNA was eluted from columns with $\mathrm{dH}_{2} \mathrm{O}$.

\subsubsection{DNA sequencing}

For DNA sequencing (Sanger method) the BigDye Terminator v3.1 Cycle Sequencing Kit according to manufacturer's instructions was used. $300 \mathrm{ng}$ of DNA were mixed with $0.5 \mu \mathrm{L}$ sequencing primer $(10 \mu \mathrm{M}), 2 \mu \mathrm{L}$ BigDye $5 x$ buffer and $1 \mu \mathrm{L}$ BigDye ${ }^{\circledR}$ Terminator v3.1 Ready Reaction Mix in a total volume of $10 \mu \mathrm{L}$. The reaction was performed as follows:

$96^{\circ} \mathrm{C} \quad 10 \mathrm{sec}$

$60^{\circ} \mathrm{C} \quad 4 \mathrm{~min}, 24$ cycles

For purification of the cycle sequencing product $220 \mu \mathrm{L}$ of $100 \%$ ethanol, $120 \mu \mathrm{L}$ of $\mathrm{dH}_{2} \mathrm{O}$ and $10 \mu \mathrm{L}$ of $3 \mathrm{M}$ sodium acetate ( $\mathrm{pH}$ 4.6) were added. The mix was vortexed and incubated for 15 min at RT before centrifugation for $20 \mathrm{~min}$ at $14,000 \mathrm{rpm}$. The pellet was washed with $70 \%$ ethanol, dried and resuspended in $10 \mu \mathrm{L}$ formamide. DNA sequencing was performed by Andreas Ohlenbusch, department for Child and Adolescent Medicine, University Medical Center Göttingen.

\subsubsection{Statistics}

Experimental data is presented as mean \pm SEM. Statistical analysis was performed using Microsoft Excel 2010, GraphPad Prism 4 or SAS ${ }^{\circledR}$ software by student's t-test assuming normal distribution or two-way ANOVA for repeated measurements with Bonferroni's post hoc multiple comparison test. If $\mathrm{P}$-values are smaller than 0.05 , significance is assumed. 


\section{$4 \quad$ Results}

\subsection{Dysferlin and BIN1 localize to different parts of the T-tubule system in C2C12 cells}

Previous work of our group demonstrated that dysferlin is able to induce tubular structures upon heterologous expression in non-muscle cells and that these induced structures are newly formed membrane tubules (Hofhuis et al., 2017). This and other observations such as dysferlin binding to $\mathrm{PI}(4,5) \mathrm{P}_{2}$ (Hofhuis et al., 2017; Therrien et al., 2009), an abnormally configured Ttubule system upon dysferlin-deficiency (Klinge et al., 2010a) and localization of dysferlin to the developing and regenerating T-tubule system (Klinge et al., 2007, 2010a) lead to the hypothesis that dysferlin is involved in membrane remodeling and biogenesis of the T-tubule system in skeletal muscle. The BAR domain protein BIN1 may function in a similar fashion. BIN1 induces formation of membrane tubules (Lee et al., 2002), a function which is dependent on $\mathrm{PI}(4,5) \mathrm{P}_{2}$ binding (Fugier et al., 2011), and BIN1-deficiency also leads to muscle disease (Nicot et al., 2007). It seems that the tubulation properties of both, BIN1 and dysferlin, observed in in vitro and cell experiments, might be the basis for their membrane organizing function during myogenic differentiation. To characterize dysferlin and BIN1 during T-tubule development, both proteins were immunolabeled in $\mathrm{C} 2 \mathrm{C} 12$ cells, a murine myoblast cell line which is differentiated into myotubes, and thereby used as model system for muscle development and T-tubule biogenesis. As previously reported, endogenous dysferlin and BIN1 localize to vesicular and tubular structures constituting membranes of the developing T-tubule system. Thereby, they partially colocalize especially at the tubular compartment (Klinge et al., 2007). Confocal microscopy of colabeled C2C12 myotubes reveals that a fairly large amount of dysferlin and BIN1 is not colocalizing but is expressed at distinct cellular areas. Dysferlin is mainly located at central and perinuclear areas forming a longitudinal tubule network. In contrast, BIN1 is rather distal localizing to the sarcolemma and longitudinal membrane structures in the proximity of the sarcolemma (Figure 6, A and B). A 3D-volume model of a myocyte shows that the inner cell area is mainly composed of dysferlin-labeled membranes and the outer area is like a shell which is dominated by BIN1. Furthermore, a layer in between the two described areas is characterized by membrane structures at which dysferlin and BIN1 proteins colocalize (Figure 6, C). 


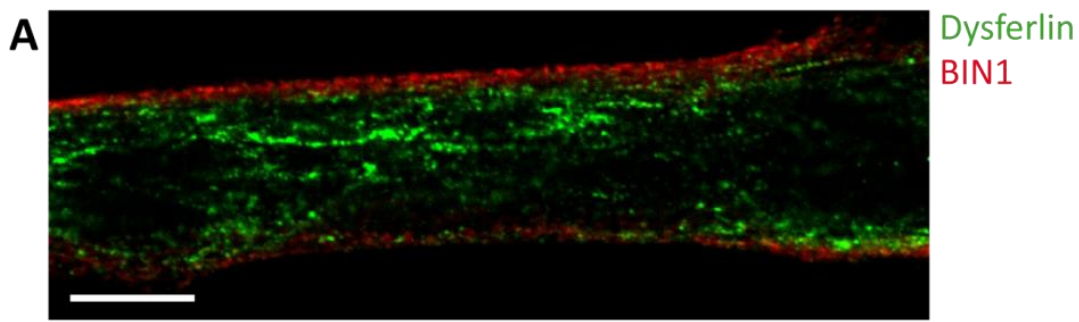

B

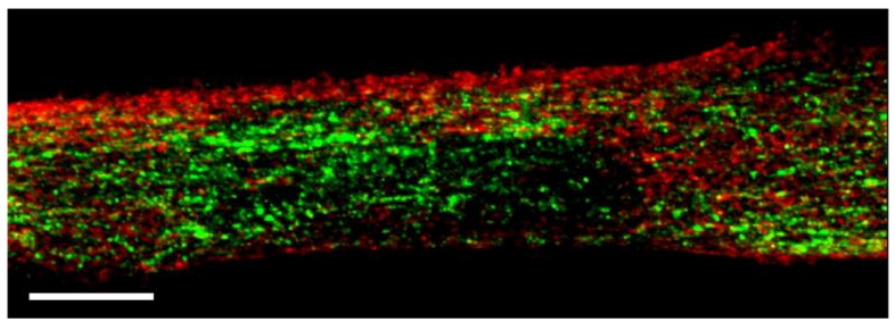

C
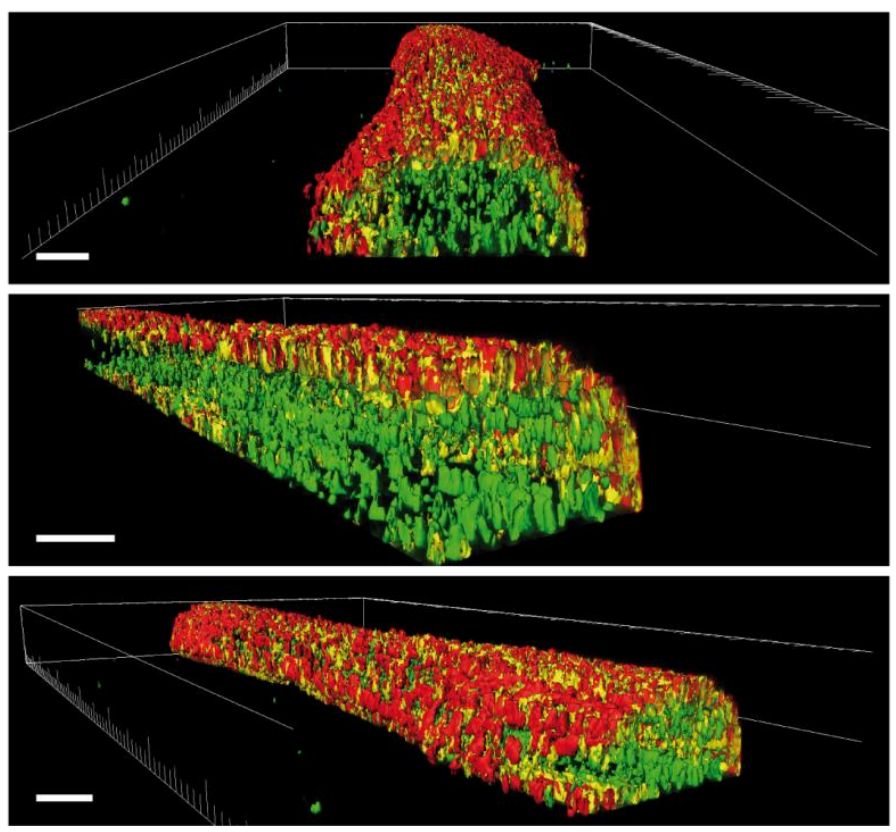

Figure 6 | Differential localization of dysferlin and BIN1 in developing myotubes. C2C12 myotubes were differentiated for 5 days and co-labeled with antibodies against endogenous dysferlin (green) and BIN1 (red). Immunofluorescence samples were visualized by confocal microscopy. (A) Confocal image of a single plane of a C2C12 myotube. (B) Single slices of a confocal image stack were combined generating an overlay of the myotube (Software Imaris). (C) Confocal image stack was converted into a 3D-volume model of the labeled structures (Software Imaris). Scale bars $10 \mu \mathrm{m}$.

\subsection{Abnormal development of the T-tubule system in LGMD2B patient myoblasts}

As previously reported by our group, dysferlin-deficiency does not only lead to a typically dystrophic muscle phenotype and an impaired membrane repair (Bansal et al., 2003), but also disturbs the T-tubule structure (Klinge et al., 2010a). Labeling of T-tubules from skeletal muscles of dysferlin-null mice with calcium potassium ferrocyanide and electron microscopic 
analysis of the muscle tissue reveal irregularity and dilatation of this membrane organelle (Klinge et al., 2010a), features that are even enhanced upon notexin-induced muscle regeneration (Hofhuis et al., 2017). These results indirectly suggest an important role of dysferlin for proper biogenesis of the T-tubule system as they originate from the examination of adult mouse muscles. To analyze the effects of dysferlin-loss more directly, myoblasts from a LGMD2B patient harboring a splice site mutation in the DYSF gene (c.1939-6T>A) were analyzed. Myoblasts can be differentiated in culture, a process during which the cells fuse to form multinucleated myotubes and develop a premature T-tubule system. Thereby the cells serve as model system for T-tubulogenesis. Human myoblasts were differentiated by serum deprivation for 7 days in culture and subsequently analyzed. The homozygous mutation leads to a nearly complete loss of dysferlin protein expression as detected by western blot of differentiated myoblast lysates (Figure 7, A).

B
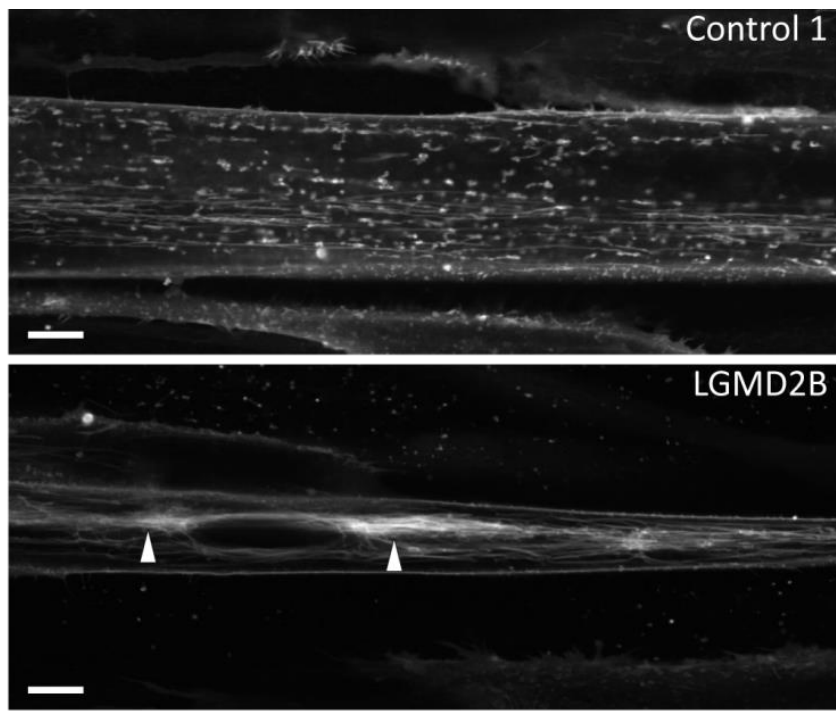

A

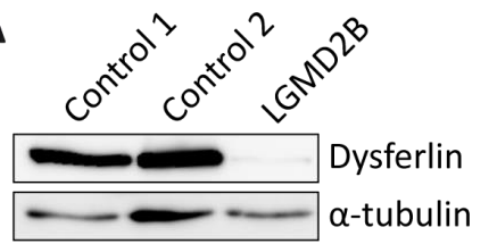

C

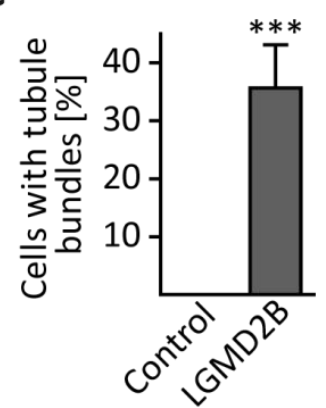

Figure 7 | Tubular membrane bundles in LGMD2B patient myotubes. (A) Dysferlin expression was analyzed via western blot using $30 \mu \mathrm{g}$ whole cell lysate obtained from human control and dysferlindeficient (LGMD2B) myotubes after a differentiation time of 7 days. Dysferlin was detected by antidysferlin (NCL-Hamlet) antibody. $\alpha$-tubulin served as loading control. (B) Representative images of human control and dysferlin-deficient (LGMD2B) myotubes after 7 days of differentiation stained with the dye DilC16(3) $\left(12.5 \mathrm{\mu g} / \mathrm{mL}\right.$ in sucrose cacodylate buffer) for $10 \mathrm{~min}$ at $37{ }^{\circ} \mathrm{C}$ to visualize the membrane system. Cells were imaged by confocal microscopy. Arrowheads indicate tubular membrane bundles. Scale bars $10 \mu \mathrm{m}$. (C) Quantification of cells with tubular membrane bundles as indicated in (B). $\mathrm{N}=3$ (15-24 cells/experiment) +/- SEM, $* * *=\mathrm{P} \leq 0.001$ (Student's t-test).

The membrane system of living cells was stained with the lipophilic red-fluorescent dye DilC $_{16}(3)$ and visualized by confocal microscopy. DilC ${ }_{16}(3)$ stained the sarcolemma, but also vesicular and longitudinal tubular membranes inside the cells (Figure 7, B). In contrast to the 
control fibers, compact tubular membrane bundles were observed in $36 \%$ of dysferlindeficient fibers (Figure 7, B and C). These dense formations were located mainly in the transverse center and often in the perinuclear region of the myotubes. The compact membrane bundles which were observed only in dysferlin-deficient myotubes might be the result of an abnormal formation of the T-tubule system due to absence of dysferlin.

\subsection{Dysferlin is expressed at the cardiac T-tubule system during maturation}

Results showing that dysferlin localizes to the sarcolemma and the T-tubule system (Ampong et al., 2005; Anderson et al., 1999; Chase et al., 2009; Klinge et al., 2010a) demonstrate the importance of this protein for this organelle in skeletal muscle. Abnormal configuration of the adult (Klinge et al., 2010a) and developing (Figure 7) T-tubule system upon dysferlin-deficiency gives insight into the pathophysiological mechanisms of muscular dystrophy due to dysferlin loss. Dysferlinopathy is mainly described as skeletal muscle disease but there are reports suggesting that the heart muscle is also affected by dysferlin-deficiency. Thus, the question arises whether dysferlin is not only essential for the biogenesis of the transverse membrane system in skeletal muscle but also plays a role in the development of the cardiac T-tubules. To answer this question, a time course experiment was performed analyzing dysferlin expression in the rat heart at different time points during the first three weeks of life, the time window of cardiac T-tubule maturation (Han et al., 2013; Reynolds et al., 2013). Single ventricular cardiomyocytes of $11,14,17,20$, and 23 days old rats and of adult rats were isolated by Langendorff-perfusion (Bell et al., 2011) and endogenous dysferlin as well as Cav1.2 as Ttubule marker were immunolabeled. The cells were visualized by confocal microscopy. At the beginning of the analyzed time period (P11 - P14) cardiomyocytes were comparably small with roundish edges. No Cav1.2-labeled structures resembling the T-tubule system were detectable, instead Cav1.2 is localizing to the sarcolemma at P14. Over time, cardiomyocytes enlarged and developed characteristic sharp edges. Cav1.2 expression increased and localized to transverse elements of the maturating T-tubule system. Simultaneously, the dysferlin signal showed a similar expression pattern as the T-tubule marker Cav1.2 (Figure 8, A). To quantify expression of dysferlin at the T-tubule system, colocalization with $\mathrm{Ca}_{\mathrm{v}} 1.2$ was assessed by Mander's M1 and M2 coefficients (Figure 8, B). Thereby, M1 corresponds to the dysferlin signal that is overlapping with Cav1.2 signal normalized to the total dysferlin labeling ( $\mathrm{M} 2$ vice versa). At P11 M1 and M2 values are only 0.14 indicating very low colocalization of dysferlin and 
Cav1.2. Over time (P11 - P23), both, M1 and M2 coefficients increase and respective values stay similar. Adult cardiomyocytes show the highest M1 and M2 colocalization coefficients of 0.64 and 0.55 , respectively. These values show that the proportion of dysferlin signal overlapping with $\mathrm{Ca}_{\vee} 1.2$ is higher than the Cav1.2 signal overlapping with dysferlin. To further characterize dysferlin expression in developing cardiomyocytes, the protein level was assessed by western blot (Figure 8, C). Therefore, hearts were isolated from 11-, 14-, 17-, 20-, 23-day old or adult rats and homogenates of the ventricular muscle tissue were prepared. Dysferlin was detected by anti-dysferlin (NCL-Hamlet) antibody. GAPDH served as loading control. Western blot signal was densitometrically quantified (Figure 8, D) and shows a 7-fold increase in dysferlin protein level from P11 to P20. After the peak at P20, dysferlin expression decreases again. Analysis of dysferlin in maturating rat cardiomyocytes shows peaked expression at P17 P20 and localization to the developing T-tubule system. 
A
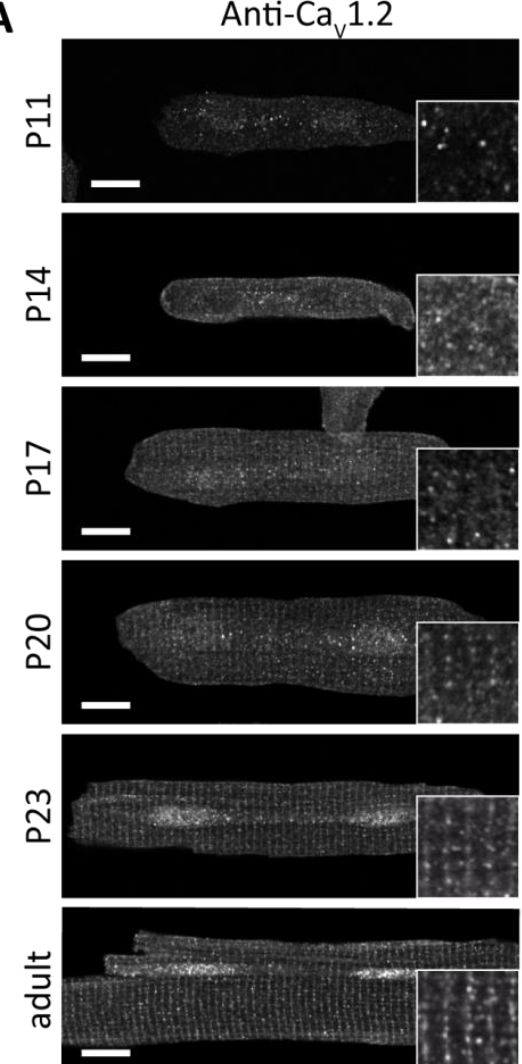

B

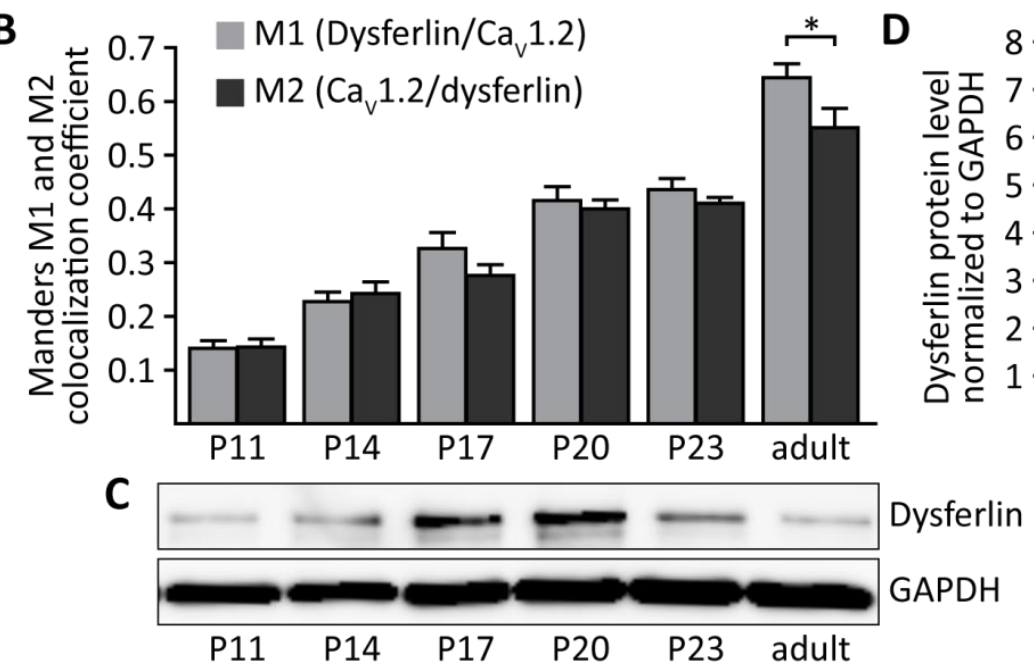

Anti-dysferlin
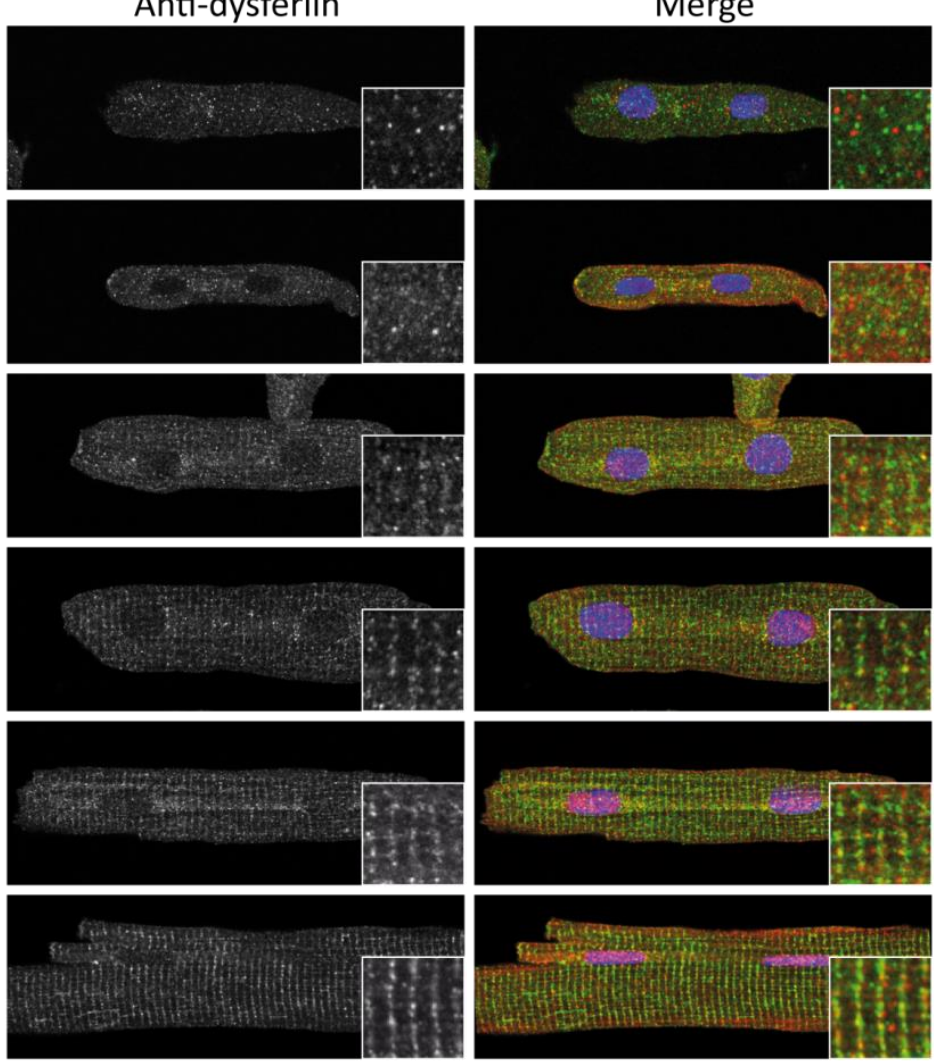

Figure 8 | Dysferlin colocalizes with Cav1.2 in postnatal rat cardiomyocytes and dysferlin expression peaks after birth. $\mathrm{P}=$ days after birth. (A) Rat cardiomyocytes were Langendorff-isolated at the indicated time points and dysferlin localization was analyzed by confocal microscopy. Representative images of rat cardiomyocytes immunolabeled with anti-dyferlin (NCL-Hamlet, green) and anti-Cav1.2 (red) as Ttubule marker. Scale bars $10 \mu \mathrm{m}$. (B) Colocalization of dysferlin and Cav1.2 was analyzed using the JACoP plugin of ImageJ and calculating the Manders coefficient. M1=(sum of green pixels colocalizing with red)/total green pixels. $\mathrm{M} 2=$ (sum of red pixels colocalizing with green)/total red pixels. $\mathrm{N}=1-3$ rats (5-8 cells/rat) +/- SEM (Student's t-test). (C) Rat hearts were isolated at the indicated time points and ventricular tissue was used for western blot analysis. Dysferlin was deteted by anti-dyferlin (NCLHamlet), anti-GAPDH served as loading control. A representative western blot is depicted. (D) 
Quantification of dysferlin expression based on western blots. Dysferlin level was normalized to GAPDH and related to $\mathrm{P} 11$. $\mathrm{N}=3+/-\mathrm{SEM}$.

\subsection{Dysferlin-deficiency leads to altered transverse-axial tubule system in adult cardiomyocytes}

Dysferlin localizes to the developing T-tubule system in rat cardiomyocytes and dysferlin expression peaks in a narrow time frame during which maturation of the tubular membrane system takes place (Figure 8). Consequently, the effect of dysferlin loss on the morphology of this membrane system should be analyzed. Therefore, ventricular cardiomyocytes of control $\left(D y s f^{\prime /+}\right.$ ) and dysferlin-deficient (Dysf $f^{/}$) adult mice were Langendorff-isolated (Bell et al., 2011) and living cells were stained with the red-fluorescent lipophilic membrane dye di-8-ANEPPS (Wagner et al., 2014). Cell integrity criteria such as transverse striation, sharp cell edges and lack of membrane blebs were applied to guarantee that only cells that withstood the isolation procedure without apparent damage were used for subsequent acquisition of the labeled membrane system (Figure 9, top).
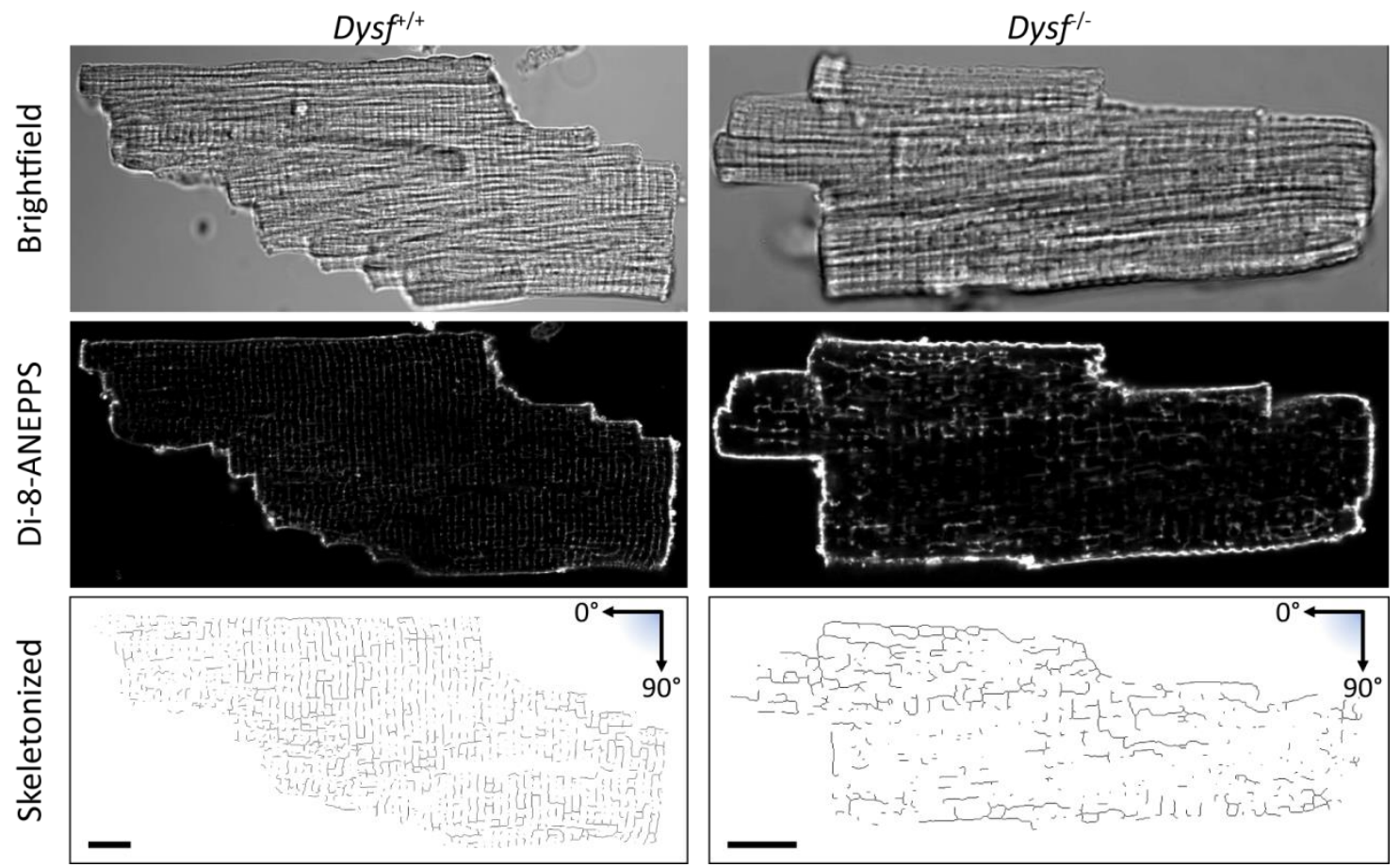

Figure 9 | Altered morphology of tubular membrane network in ventricular cardiomyocytes of dysferlin-deficient mice. Ventricular cardiomyocytes were isolated from control (Dysf ${ }^{+/+}$) and dysferlindeficient $\left(\right.$ Dysf $^{-1}$ ) mice by Langendorff-perfusion. The membrane system was stained with di-8-ANEPPS for $30 \mathrm{~min}$ at RT and cells were imaged by confocal microscopy. Using the software ImageJ, the confocal image signal was skeletonized for subsequent detailed analysis of membrane structures. Representative brightfield, di-8-ANEPPS and skeletonized images are depicted. Scale bars $10 \mu \mathrm{m}$. 
The fluorescent signal of the dye was visualized by confocal microscopy (Figure 9, middle). Di-8ANEPPS stains the sarcolemma and cytoplasmic membrane structures. The intracellular membranes have a predominantly axial $\left(0^{\circ}\right)$ or transverse $\left(90^{\circ}\right)$ orientation. The images of the di-8-ANEPPS-labeled transverse-axial membrane system reveal an altered morphology in Dysf ${ }^{1}$-cardiomyocytes compared to dysferlin-competent cells. In order to be able to quantify the visually noticeable alterations, the images were skeletonized using an ImageJ plugin (Figure 9).

\subsubsection{Dysferlin loss results in reorientated transverse-axial tubule system in cardiomyocytes}

The intracellular membrane system in cardiomyocytes has transversely- and axially-orientated portions which are both important for a proper cell function (Kirk et al., 2003; Ohler et al., 2010). Di-8-ANEPPS-staining of adult dysferlin-deficient and control cardiomyocytes reveals apparent morphological alterations (Figure 9). The dimension of morphological changes was assessed by quantifying the amount of structures for each direction $\left(-45^{\circ}-134^{\circ}\right)$ based on the skeletonized images of di-8-ANEPPS-labeled cells (Wagner et al., 2014) Figure 9). The quantification is depicted as histogram with the amount of structures plotted against the structure direction and reveals a bimodal distribution, both, for $D y s f^{+/+}$and $D y s f^{/-}$ cardiomyocytes (Figure 10, A). However, the proportion of structures with transverse $\left(90^{\circ}+/-\right.$ $\left.5^{\circ}\right)$ or axial $\left(0^{\circ}+/-5^{\circ}\right)$ orientation is significantly changed in dysferlin-deficient cells compared to controls (Figure 10, B). Dysferlin-competent cardiomyocytes have $13.4 \%$ axially and $16.0 \%$ transversely orientated structures. In dysferlin-deficient cells the distribution is changed to $20.1 \%$ and $8.8 \%$ axial and transverse orientation, respectively (Figure 10, C). Thus, dysferlindeficiency leads to an extensive shift in directionality of the T-tubues in adult cardiomyocytes. 

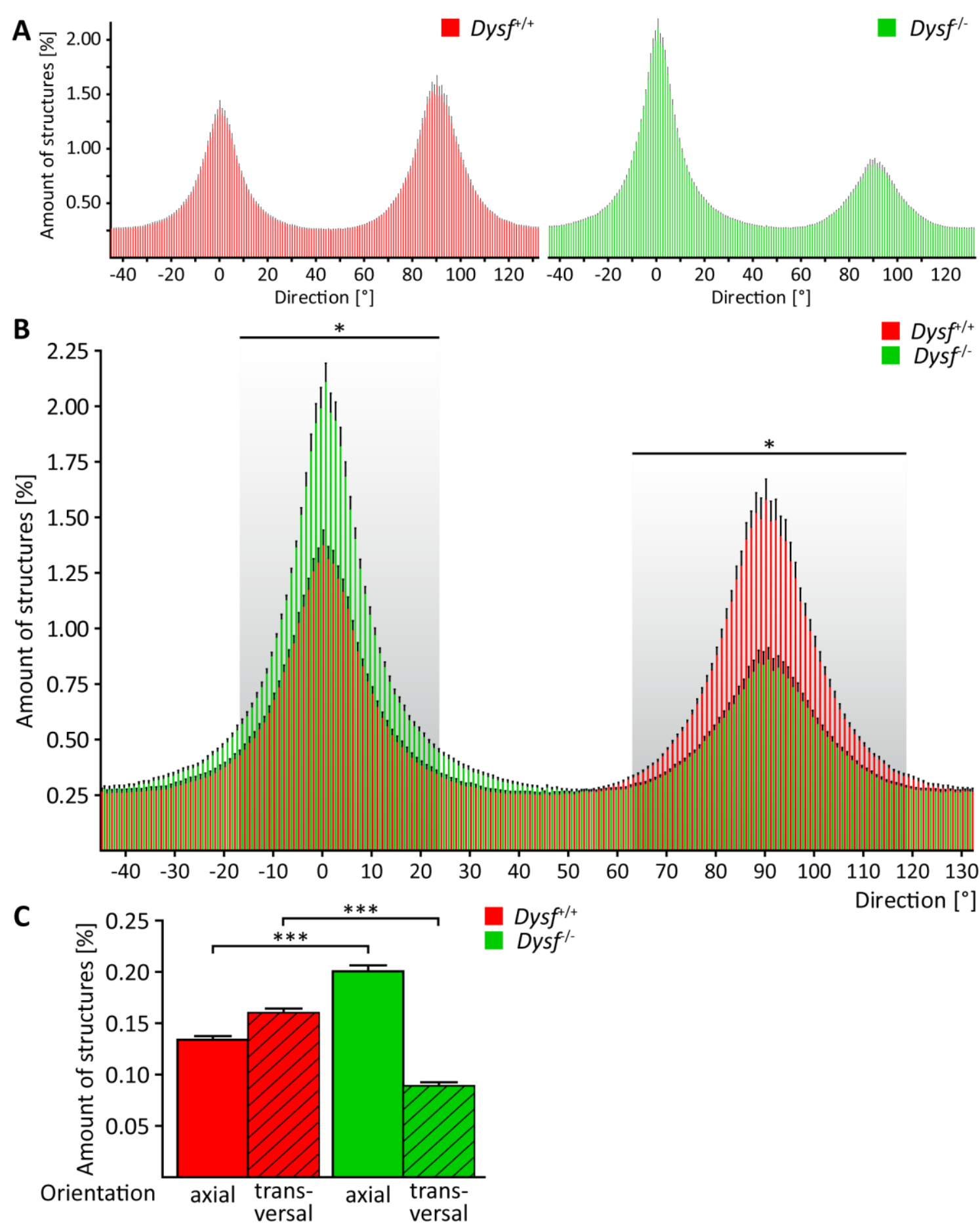

Figure 10 | Altered directionality of transverse-axial tubule system in ventricular cardiomyocytes of dysferlin-deficient mice. (A) Skeletonized images of di-8-ANEPPS-stained dysferlin-competent (Dysf ${ }^{+/+}$) and -deficient (Dysf ${ }^{-}$) cardiomyocytes (Figure 9) were used for quantification of structure directionality with ImageJ and depicted as histograms with one bar for each direction. $\mathrm{N}=8\left(\mathrm{Dysf}^{+/+}\right) / 5\left(\mathrm{Dysf}^{\prime-}\right)$ mice, (5-20 cells/mouse). Mean +/- SEM. (B) Histograms for Dysf $\mathrm{f}^{+/+}$and Dysf ${ }^{/-}$are depicted in one diagram with corresponding Dysf ${ }^{+/+}$and Dysf ${ }^{/-}$bars next to each other. Gray boxes mark area of direction with significant differences between Dysf ${ }^{/-}$and $\mathrm{Dysf}^{+/+}$for each bin $\left(16^{\circ}\right.$ to $24^{\circ}, 64^{\circ}$ to $118^{\circ}$. ${ }^{*}=\mathrm{P} \leq 0.05$ (Twoway ANOVA with repeated measures). (C) Summed amount of structures with axial $\left(0^{\circ}+/-5^{\circ}\right)$ and transverse $\left(90^{\circ}+/-5^{\circ}\right)$ orientation. Mean $+/-\mathrm{SEM}$. ${ }^{* * *}=\mathrm{P} \leq 0.001$. 


\subsubsection{Structural parameters of skeletonized tubular membranes are changed in dysferlin-deficient cardiomyocytes}

To characterize the membrane system of dysferlin-deficient compared to control cardiomyocytes more detailed, structural parameters such as skeleton length, number of structures, number of branches and number of end-point voxels were measured on the basis of the skeletonized di-8-ANEPPS images and normalized to the cell area (Wagner et al., 2014). Furthermore, the average branch length was assessed. The cell area was unchanged. The same is true for the average branch length. Though, the number of structures and the number of branches were decreased, thereby reducing the total skeleton length and the number of endpoint voxels. Thus, dysferlin-deficiency leads to a reorganization of the membrane system with redirection and reduction of tubular structures (Figure 11).
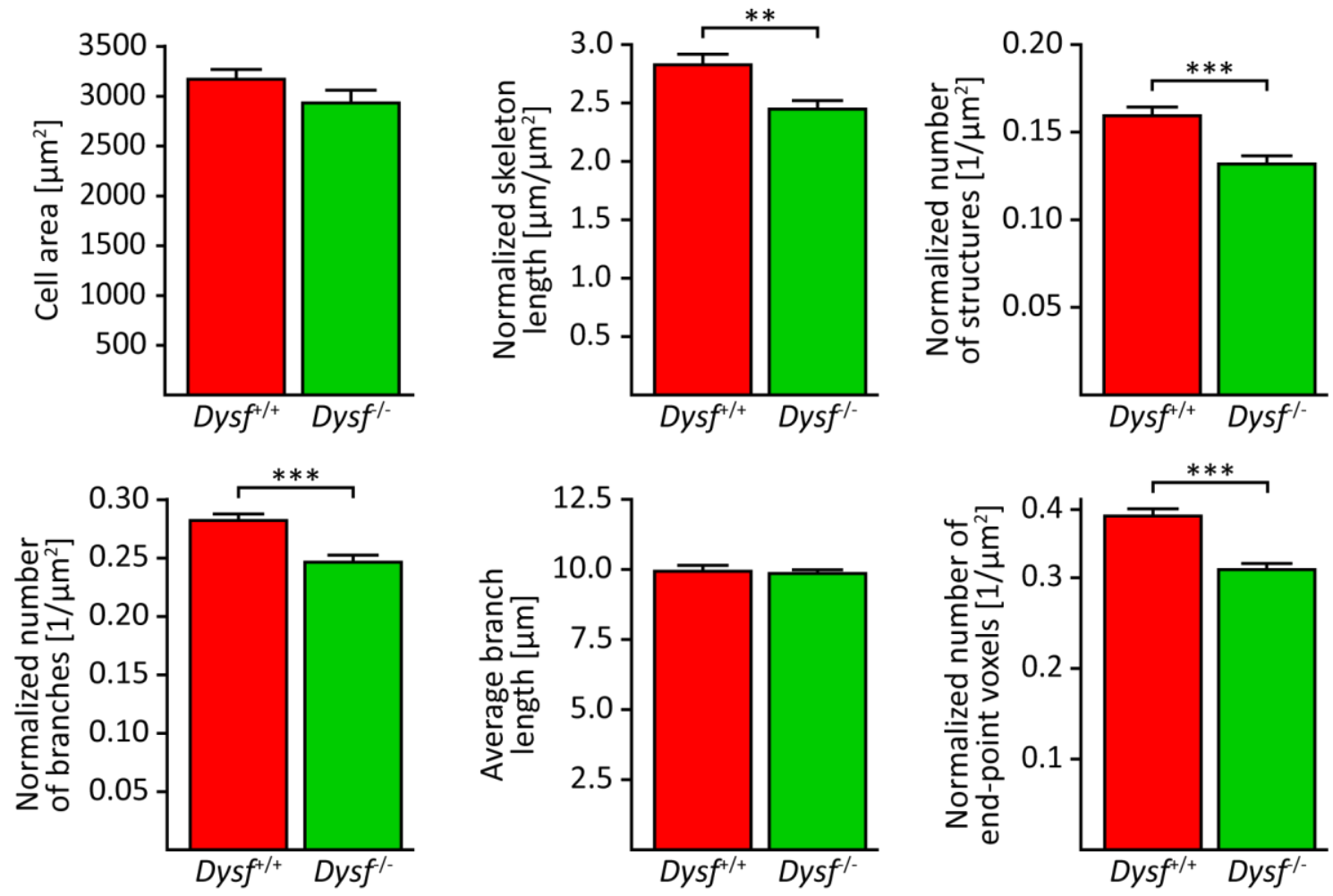

Figure 11 | Altered structural parameters of transverse-axial tubule system in ventricular cardiomyocytes of dysferlin-deficient mice. Skeletonized images of di-8-ANEPPS-stained dysferlincompetent $\left(\right.$ Dysf $^{+/+}$) and -deficient $\left(\right.$Dysf $^{/-}$) cardiomyocytes (Figure 9) were analyzed with the Analyze Skeleton (2D/3D) plugin of ImageJ. The following parameters were used to characterize the skeletonized transverse-axial tubule system: Cell area, normalized skeleton length, normalized number of structures, normalized number of branches, average branch length, normalized number of end-point voxels. Skeleton length, number of structures, number of branches and number of end-point voxels were normalized to the cell area. $\mathrm{N}=8\left(\right.$ Dysf $\left.^{+/+}\right) / 5\left(\right.$ Dysf $\left.^{-/}\right)$mice, $\left(5-20\right.$ cells/mouse) $+/-\mathrm{SEM}$. ${ }^{* *}=\mathrm{P} \leq 0.01$, $* * *=\mathrm{P} \leq 0.001$ (Student's t-test). 


\subsection{Dysferlin gets inserted into the ER}

To understand the pathomechanisms underlying dysferlin-deficient muscular dystrophy and to find therapeutic intervention targets it is important to know the route of dysferlin through the cell. Until now, little is known about the fate of the protein after its synthesis. Because of its single C-terminal transmembrane domain dysferlin is counted to the TA proteins, which are inserted into the ER membrane directly after their cytosolic translation. Integration of a protein into the ER can be analyzed by coupling the protein of interest to an opsin tag harboring an $\mathrm{N}$-glycosylation site and detection by western blot. The modification occurring in the lumen of the ER leads to a mobility shift of the protein during electrophoresis of up to 3 kDa (Helenius and Aebi, 2004). Thus, this method is well applicable to relatively small proteins (Figure 12).

A Opsin amino acid sequence:

G-P-N-F-Y-V-P-F-S-N-K-T-G

C Dysferlin-ops

A $][B][C]][D][E][F][G$

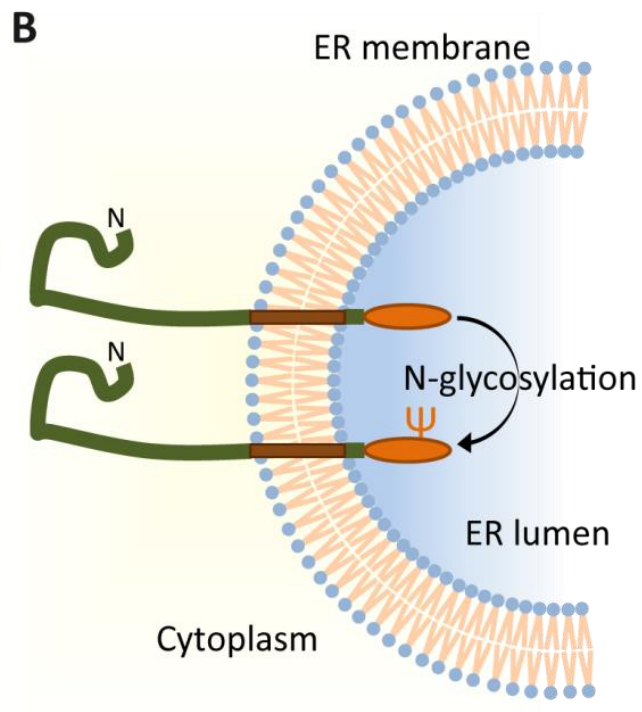

B

Figure 12 | Use of the glycosylation tag opsin as reporter for protein integration into the ER. (A) Amino acid sequence of the short variant of the glycosylation tag opsin, derived from the bovine rhodopsin, contains one glycosylation site (respective amino acids marked in bold letters, asparagine (N) which can be glycosylated indicated by a fork). (B) Schematic representation of the glycosylation of an opsin-tagged protein inside the ER lumen upon protein integration into the ER. (C) C-terminally opsintagged full-length dysferlin (Dysferlin-ops) used for expression in mammalian cells.

Though, dysferlin is a protein of $230 \mathrm{kDa}$ making it unfeasible to detect glycosylation when separating the full-length protein by SDS-PAGE. To overcome this obstacle, we aimed to cleave dysferlin and analyze a considerably smaller peptide with respect to glycosylation. The tool PeptideCutter (http://web.expasy.org/peptide_cutter/) of the bioinformatics resource portal ExPASy was used to search for proteases that specifically cleave the dysferlin protein. The 
enzyme thrombin was found to have two recognition sites within the dysferlin protein sequence at positions 187 aa and 1806 aa (Figure 13, A). To test, whether the cleavage of dysferlin by thrombin was specific and effective and whether dysferlin gets integrated into the ER membrane, HeLa cells were transfected with constructs encoding untagged or opsin-tagged full-length dysferlin (Dysferlin and dysferlin-ops, respectively). Cell lysates were either nontreated or digested with thrombin and analyzed by SDS-PAGE and western blot (Figure 13, B). Untagged dysferlin was detected by anti-dysferlin NCL-Hamlet antibody which recognizes an epitope at 1999 - 2016 aa of the dysferlin protein and dysferlin-ops was detected by antiopsin antibody (Scheme of antibody recognition sites in Figure 13, A). The anti-opsin antibody recognizes a protein at $35 \mathrm{kDa}$ independently of cell type, transfected construct (also untransfected control) or treatment of cells or cell lysates. Therefore, this prominent band is considered as unspecific for the antibody. Full-length dysferlin is detected in all samples at the top of the blot (above the $170 \mathrm{kDa}$ marking). Cleavage of uncoupled dysferlin by thrombin leads to a reduction of full-length dysferlin and to an additional protein band which is detected at approximately $33 \mathrm{kDa}$. This band represents the $\mathrm{C}$-terminal dysferlin fragment including the C2G and transmembrane domain. Digestion of dysferlin-ops by thrombin also results in the generation of smaller peptides. The two bands that are detected just above the $35 \mathrm{kDa}$ marking also represent the C-terminal fragment of dysferlin. In comparison to the untagged version, they have a reduced electrophoretic mobility due to the opsin tag and therefore are visible at a higher position on the blot. In contrast to uncoupled dysferlin, two well separated bands are detected for dysferlin-ops which might represent a nonglycosylated (lower band) and glycosylated (upper band) peptide. Thus, this result indicates that full-length dysferlin gets inserted into the ER in HeLa cells and thrombin cleavage is a feasible way to make glycosylation of opsin-tagged dysferlin detectable. 


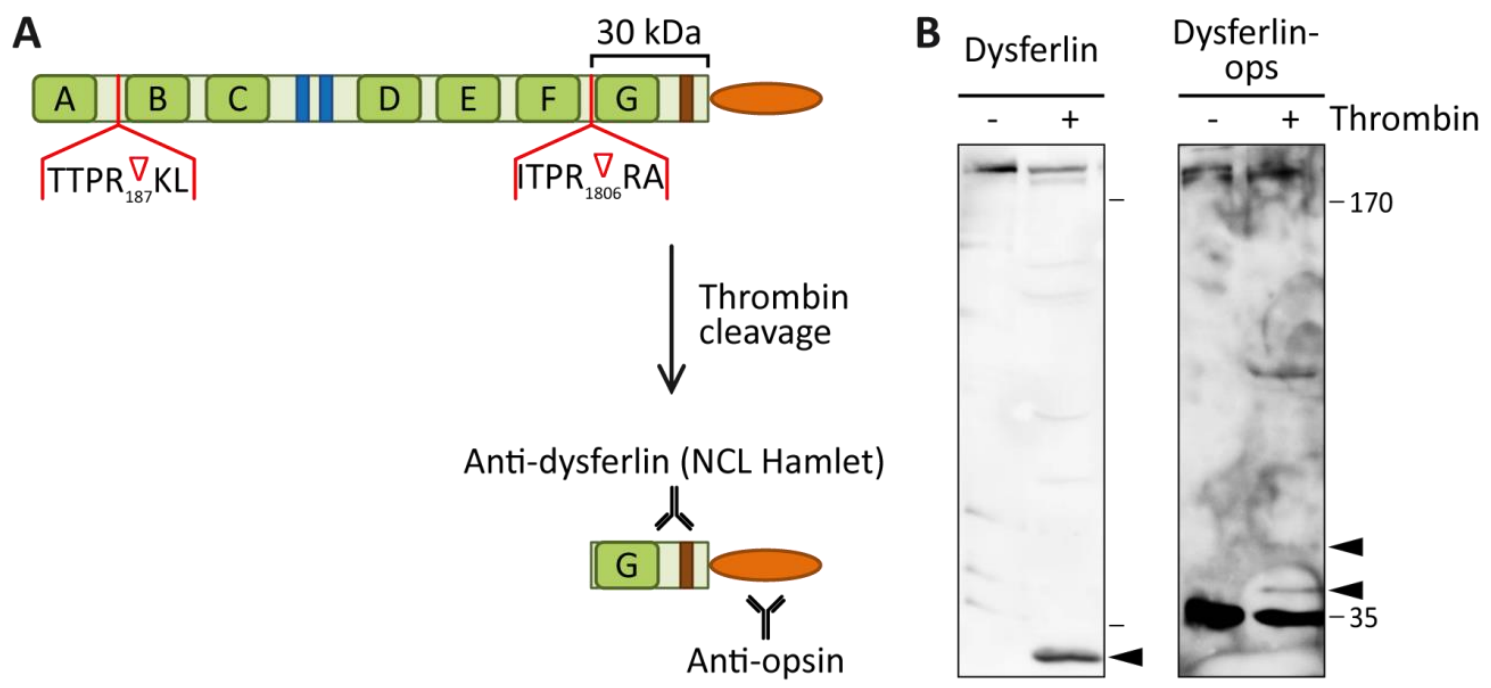

Figure 13 | Site-specific Thrombin cleavage of dysferlin as prerequesite for glycosylation analysis. (A) Thrombin cleavage of full-length opsin-tagged dysferlin at the positions aa 187 and aa 1806 results in a C-terminal peptide of approximately $30 \mathrm{kDa}$ which can be detected either by anti-dysferlin (NCL-Hamlet) or anti-opsin antibody. (B) HeLa cells were transfected with dysferlin or dysferlin-ops and harvested 48 $\mathrm{h}$ post transfection for western blot analysis. Protein samples of $20 \mu \mathrm{g}$ were either nontreated or digested with thrombin for $1 \mathrm{~h}$ at $37^{\circ} \mathrm{C}$ and loaded on SDS-PAGE. Dysferlin was detected by antidysferlin (NCL-Hamlet) antibody and dysferlin-ops by anti-opsin antibody. Arrowheads indicate cleaved C-terminal part of dysferlin (left blot) or dysferlin-ops (right blot).

\subsubsection{Efficiency of dysferlin insertion into the ER varies between mammalian cell lines}

Analysis of opsin-tagged dysferlin expressed in HeLa cells and cleaved with thrombin shows that two bands can be detected by western blot (Figure 13, B). To verify that the upper band represents an $\mathrm{N}$-glycosylated form of the lower one, the thrombin digested lysate was additionally treated with the endoglycosidase Endo $\mathrm{H}$ which removes $\mathrm{N}$-linked oligosaccharide modifications (Roth et al., 2012). Western blot of Endo H-treated samples shows the disappearance of the upper band and increased level of the lower band compared to the untreated sample (Figure 14, A) confirming that the electrophoretic mobility shift is due to glycosylation and that dysferlin is C-terminally inserted into the membrane of the ER in HeLa cells. To answer the question whether dysferlin insertion into the ER is specific for HeLa cells, dysferlin-ops glycosylation was analyzed in the mammalian cell lines HEK293, COS-7 and CHOK1. A glycosylated form of dysferlin can be detected in all tested cell lines (Figure 14, A). However, the level of glycosylated protein compared to the nonglycosylated is not equal. Thus, the proportion of glycosylated dysferlin was calculated by the ratio of glycosylated to total dysferlin-ops protein level (Figure 14, B). This analysis reveals that the efficiency of 
glycosylation and therewith the integration of dysferlin into the ER differs between cell lines. HeLa cells have the lowest insertion efficiency with $56 \%$ of dysferlin being glycosylated. Glycosylation is significantly higher in COS-7 and CHO-K1 cells with a proportion of $77 \%$ and 89\%, respectively. Glycosylation in HEK293 cells also tends to be higher compared to HeLa cells, but the difference is not significant. The trafficking of dysferlin is of particular interest in muscle cells as mutations in the DYSF gene lead to alterations in protein transport and stability causing muscular dystrophy. Therefore, glycosylation of dysferlin-ops was analyzed in the myoblast cell line $\mathrm{C} 2 \mathrm{C} 12$. Also in these immature skeletal muscle fibers dysferlin is inserted into the membrane of the ER as shown by western blot (Figure 14, C). Quantification reveals that approximately $80 \%$ of dysferlin are glycosylated (Figure 14, D). Thus, using the opsin tag as glycosylation sensor it could be shown that dysferlin is being integrated into the ER with its Cterminus facing the lumen in different cell lines including a muscle cell line and that the efficiency of ER insertion varies in these cell systems.

A

Dysferlin-ops

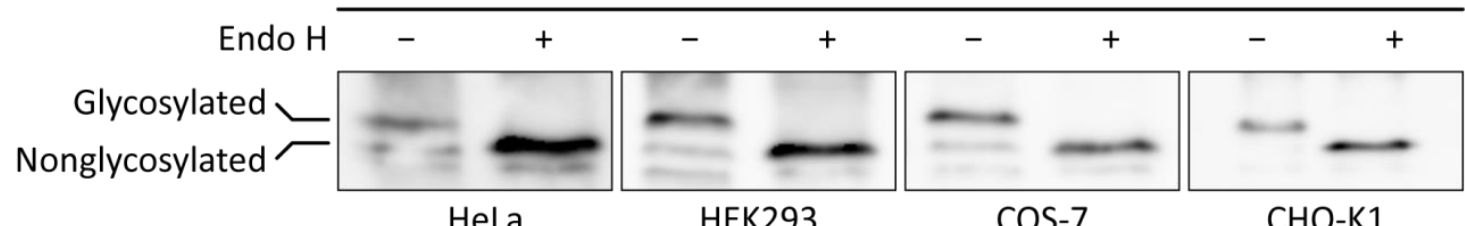

HeLa

HEK293

COS-7

CHO-K1

B

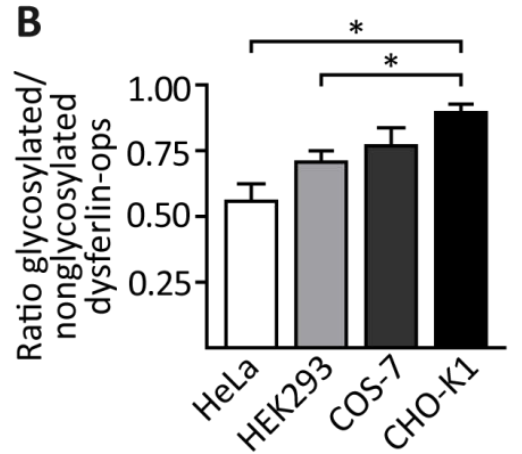

C

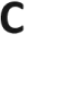

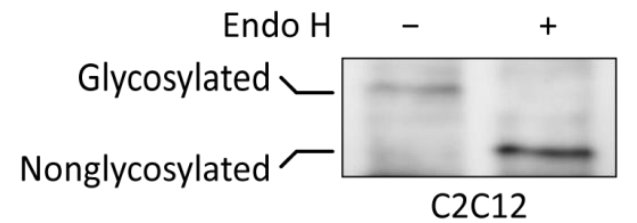

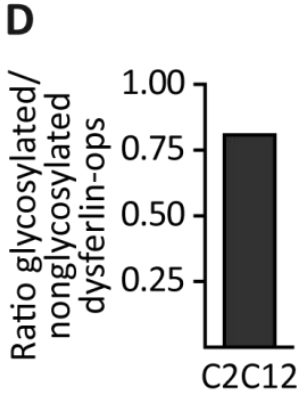

Figure 14 | Differential glycosylation of dysferlin-ops in mammalian cell lines. Glycosylation of dysferlin-opsin in mammalian cells was analyzed via western blot using an anti-opsin antibody. Bands representing glycosylated and nonglycosylated dysferlin-ops are indicated. (A) Non-muscle cell lines HeLa, HEK293, COS-7 and CHO-K1 were transfected dysferlin tagged to the glycosylation sensor opsin (dysferlin-ops) and harvested $48 \mathrm{~h}$ post transfection. Cell lysates of $30 \mu \mathrm{g}$ protein were thrombindigested for $1 \mathrm{~h}$ at $37{ }^{\circ} \mathrm{C}$ and either nontreated or treated with Endo $\mathrm{H}$ for $1 \mathrm{~h}$ at $37^{\circ} \mathrm{C}$. (B) Western blots were analyzed using the software Fiji to calculate the ratio of glycosylated dysferlin-ops relative to total level. $\mathrm{N} \geq 4+/-\mathrm{SEM},{ }^{*}=\mathrm{P} \leq 0.05,{ }^{* *}=\mathrm{P} \leq 0.01$ (Student's t-test). (C) C2C12 myoblasts were transfected with dysferlin-ops and harvested $72 \mathrm{~h}$ post transfection. Cell lysates of $65 \mu \mathrm{g}$ protein were thrombin-digested for $1 \mathrm{~h}$ at $37^{\circ} \mathrm{C}$ and either nontreated further or treated with Endo $\mathrm{H}$ for $1 \mathrm{~h}$ at $37^{\circ} \mathrm{C}$. (D) The ratio of glycosylated dysferlin-ops level in $\mathrm{C} 2 \mathrm{C} 12$ myoblasts was analyzed using Fiji software. $\mathrm{N}=1$ (preliminary data). 


\subsubsection{Increased glycosylation of dysferlin mutant L1341P compared to wild- type in HeLa cells}

LGMD2B and MM are often caused by missense mutations in the DYSF gene. The substitution of a single amino acid in the 2080 aa protein can be sufficient to cause structural changes, mislocalization, instability and degradation, ultimately resulting in loss of functional dysferlin. In this study two missense mutations were characterized which are often found in dysferlinopathy patients: mutation c.2875C $>\mathrm{T}$ causes the substitution of arginine to tryptophan at protein position 959 in the C2D domain of the protein (R959W) and c.4022T>C causing the substitution of leucine to proline at protein position 1341 which is in the $\mathrm{C} 2 \mathrm{E}$ domain (L1341P) ((Klinge et al., 2010b; Wenzel et al., 2006)). It has been reported that L1341P is prone to aggregation in the ER and autophagic degradation (Fujita et al., 2007).
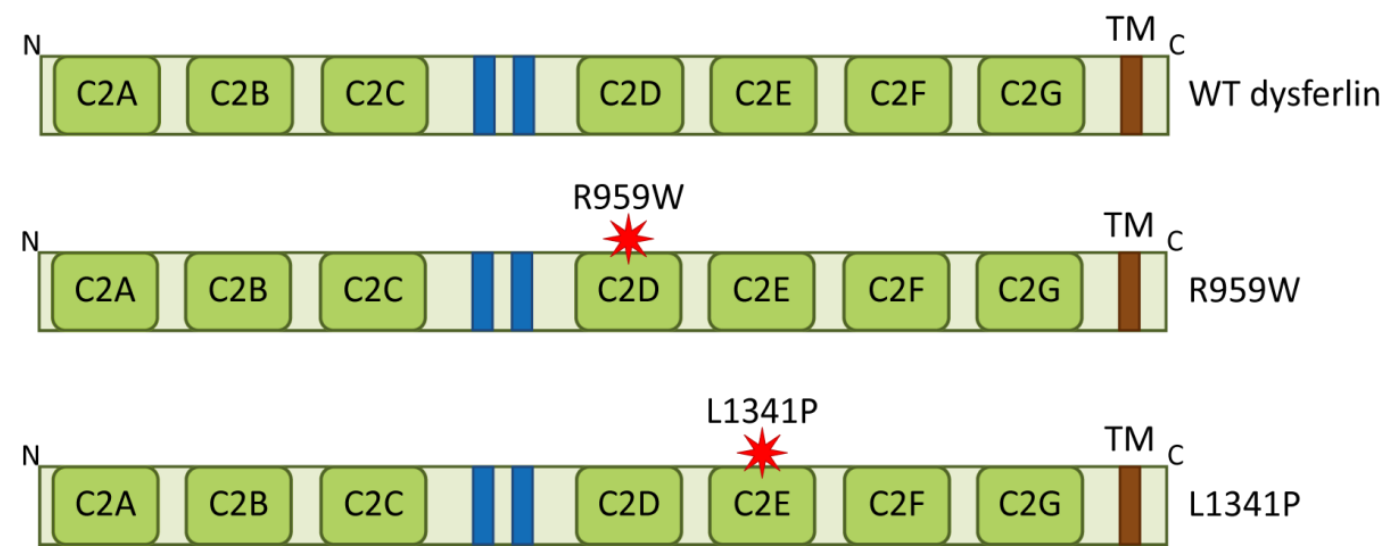

Figure 15 | Protein domain diagram of dysferlin variants. C2 domains are depicted in green (C2), the transmembrane domain is depicted in brown (TM), ferlin domains are depicted in blue. The wild-type dysferlin (WT dysferlin) at the top row. Missense mutations R959W and L1341P are indicated by red stars at the respective protein position.

To analyze whether the insertion of mutant L1341P into the ER membrane is altered in comparison to wild-type dysferlin, HeLa cells were transfected with constructs encoding one or the other dysferlin variant tagged to the glycosylation sensor opsin. Cell lysates were treated with thrombin to obtain a shorter peptide and subsequently either nondigested or digested with the endoglycosidase Endo H. Glycosylation was visualized by western blot (Figure 16, A) and proportion of glycosylated protein was calculated by the ratio of glycosylated to total protein level (Figure 16, B). This experiment reveals that the proportion of glycosylated protein is about 1.5 -fold higher for the dysferlin mutant L1341P compared to wild-type dysferlin indicating that insertion into the ER is more efficient. Additionally, the total protein level of L1341P is higher than the wild-type protein level. 
A

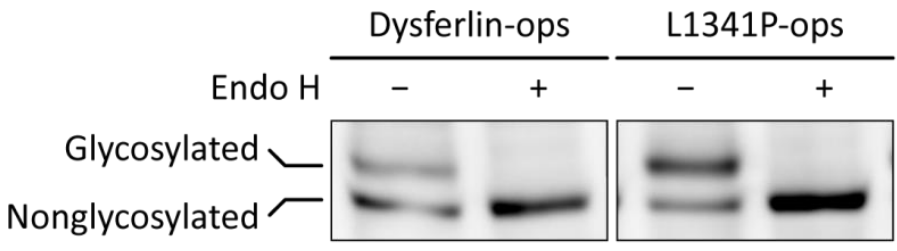

B

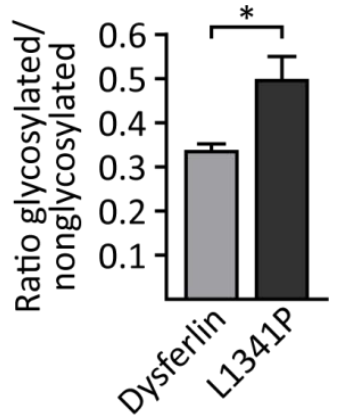

Figure 16 | Increased glycosylation of mutant L1341P compared to wild-type in HeLa cells. Glycosylation of opsin-tagged dysferlin wild-type and mutant dysferlin was analyzed via western blot. (A) HeLa cells were transfected with constructs encoding either dysferlin wild-type (Dysferlin-ops) or mutant L1341 (L1341-ops) coupled to the glycosylation sensor opsin and harvested $48 \mathrm{~h}$ post transfection. Cell lysates of $30 \mu \mathrm{g}$ protein were thrombin-digested for $1 \mathrm{~h}$ at $37^{\circ} \mathrm{C}$ and either nontreated further or treated with EndoH for $1 \mathrm{~h}$ at $37{ }^{\circ} \mathrm{C}$ to remove glycosylation modifications. A representative western blot is depicted. (B) Western blots were analyzed using the software Fiji to calculate the ratio of glycosylated relative to total dysferlin-ops and L1341P levels. N3 +/- SEM, ${ }^{*}=\mathrm{P} \leq 0.05$ (Student's t-test).

\subsection{Depletion of the TRC40 pathway component WRB has no effect on the localization or steady-state level of dysferlin}

TA proteins have a single transmembrane domain at the very C-terminus causing the requirement of a special post-translational membrane insertion mechanism. One targeting pathway depending on the cytosolic ATPase TRC40 and its ER membrane-located receptor complex consisting of WRB and CAML was found to post-translationally insert a number of tail-anchored proteins into the ER (Favaloro et al., 2008; Pfaff et al., 2016; Stefanovic and Hegde, 2007). The mechanism of ER insertion highly depends on the hydrophobicity of the transmembrane domain. TA proteins with transmembrane domains of high hydrophobicity are preferentially inserted by the TRC40-dependent pathway (Rabu et al., 2008; Stefanovic and Hegde, 2007). On the route to its target membrane the TA protein dysferlin is also inserted into the membrane of the ER (Figure 13-Figure 15) and the transmembrane domain has a comparably high hydrophobicity of 70.6 (According to hydropathy scale of (Kyte and Doolittle, 1982). Furthermore, dysferlin is highly expressed at the T-tubule system of developing cardiomyocytes (Figure 8). Thus, the effect of TRC40 pathway loss on the expression and localization of dysferlin in ventricular cardiomyocytes was investigated in cooperation with $\mathrm{Dr}$. Jhon Rivera-Monroy and Prof. Blanche Schwappach from the department of Molecular Biology, University Medical Center Göttingen. Cardiomyocytes were isolated by Langendorffperfusion (Bell et al., 2011), performed by Dr. Jhon Rivera-Monroy) from cardiomyocytespecific inducible WRB knockout mice two weeks after tamoxifen administration and indirect 
immunofluorescence was performed (Rivera-Monroy et al., 2016). Dysferlin was expressed in both, WRB-knockout and control cells and showed striated expression pattern indicating Ttubule localization as well as localization to intercalated discs (Figure 17, A). Dysferlin expression level was analyzed on the basis of confocal immunofluorescence images and calculated as corrected total cell fluorescence (CTCF) by subtracting the background multiplied with the cell area from the integrated cell intensity. No change in dysferlin CTCF was observed for WRB-knockout compared to control cardiomyocytes (Figure 17, B). Additionally, dysferlin steady-state level was assessed by western blot of heart homogenates from cardiomyocytespecific WRB-deleted mice and densitometric evaluation (Figure 17, C, performed by Dr. Jhon Rivera-Monroy). There was no altered dysferlin steady-state level upon WRB-knockout (Figure 17, D). Dysferlin is a TA protein with a strongly hydrophobic domain. However, knockout of the TRC40 insertion pathway does not lead to an effect on dysferlin expression or localization in ventricular cardiomyocytes.

A $W r b^{f / f}$
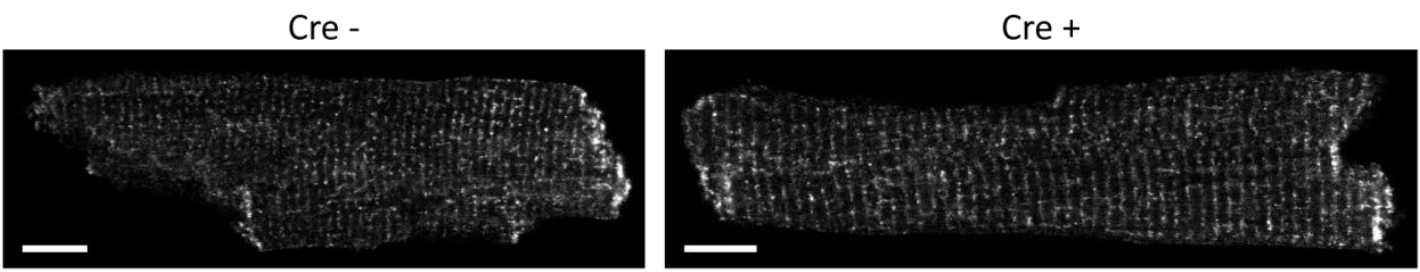

B

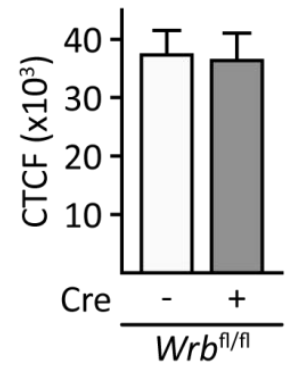

C

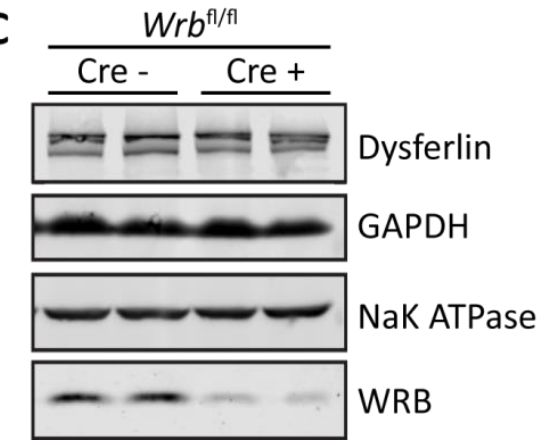

D

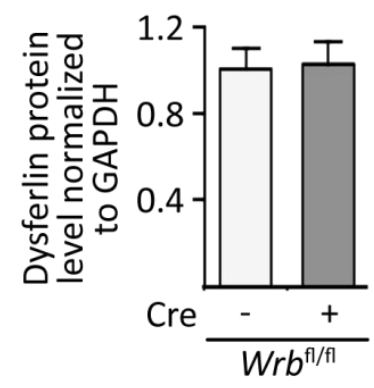

Figure 17 | No effect of cardiac Wrb knockout on dysferlin localization and expression. Mouse ventricular cardiomyocytes were isolated from 8 week-old MerCreMer - (Cre-) and MerCreMer + (Cre-, knockout) $\mathrm{Wrb}^{\mathrm{fl} / \mathrm{fl}}$ littermates after tamoxifen induction (Performed by Dr. Jhon Rivera-Monroy). (A) Localization and expression of dysferlin was analyzed by indirect immunofluorescence and confocal microscopy (LSM 710). Representative confocal immunofluorescence images are depicted. Scale bars 10 $\mu \mathrm{m}$. (B) Quantification of dysferlin expression on the basis of confocal immunofluorescence images. Calculated as corrected total cell fluorescence (CTCF) by subtracting the background multiplied with the cell area from the integrated cell intensity. $\mathrm{N}=3$ mice per genotype ( 5 cells/mouse). Mean +/- SEM. (C) Dysferlin steady-state level was assessed by western blot using anti-dysferlin antibody. Anti- GAPDH and Anti-sodium potassium ATPase (NaK ATPase) served as loading control. Anti-WRB antibody was used to confirm downregulation of WRB. (D) Densitometric quantification of dysferlin steady-state protein level normalized to GAPDH. $\mathrm{N}=6$ mice per genotype. Mean +/- SEM. 


\subsection{PBA increases steady-state level of dysferlin variants}

In this study two mutations were characterized with regard to protein level and a possibility to stabilize the proteins. This would provide information about the pathomechanism of dysferlinopathy and possible targets for the treatment of this disease. Dysferlin variants harboring the two missense mutations R959W and L1341P, located in the C2D and C2E domain, respectively, were analyzed (Figure 15). Initially, the expression levels were investigated. HeLa cells were transfected with constructs encoding either wild-type dysferlin or one of the mutant variants and cell lysates were analyzed by western blot. Both mutants show reduced steady-state levels compared to wild-type dysferlin (Figure 18). It has been reported that R959W leads to structural changes in the dysferlin protein (Espinoza-Fonseca, 2016) and L1341P is prone to aggregation in the ER and autophagic degradation (Fujita et al., 2007). This might explain the reduced steady-state levels of mutated dysferlin. Small molecules, which have the ability to shield hydrophobic regions of misfolded proteins and thereby reduce protein aggregation, may be called hydrophobic chaperones (Cortez and Sim, 2014). The short chain aromatic fatty acid 4-phenylbutyrate (PBA) is converted in vivo into phenylacetate by $\beta$-oxidation and this metabolic intermediate is degraded by conjugation to the amino acid glutamine and eliminated via the urinary system (Brusilow, 1991). Due to is metabolic pathway, PBA functions as an "ammonia scavenger" (Iannitti and Palmieri, 2011) and is therefore approved by the FDA for the clinical treatment of children with urea cycle disorders (https://www.fda.gov/default.htm). Additionally, PBA acts as histone deacetylase inhibitor and protein chaperone. It modulates cellular gene expression and reduces ER stress as well as the unfolded protein response leading to reduced ER-stress induced apoptosis (Iannitti and Palmieri, 2011). Due to is versatile functions, PBA is currently under investigation for the treatment of several disorders, such as cystic fibrosis (Lim et al., 2004; Rubenstein et al., 1997), neurogenerative diseases like Alzheimer's disease (Bondulich et al., 2016; Cuadrado-Tejedor et al., 2011), myocardial ischemia (Takatori et al., 2017), cancer (Carducci et al., 2001) and many others (Braun and Schweizer, 2017; Cao et al., 2016; Collins et al., 1995; Khan et al., 2017; Liu et al., 2016).

PBA is a regulator of cellular proteostasis and was therefore used in this study to test whether it is a suitable therapeutic for the treatment of dysferlinopathy by ameliorating the reduced protein level of dysferlin mutants. Transfected HeLa cells were treated with PBA for $24 \mathrm{~h}$ and cell lysates were analyzed by western blot. PBA treatment leads to a significant increase of steady-state level for wild-type and R959W. Also, the protein level of mutant L1341P tends to be higher upon chaperone addition (Figure 18). The protein level of mutant R959W upon PBA 
treatment is 1.5-fold of the wild-type level without PBA. Thus, PBA has the potency to increase reduced steady-state levels of dysferlin mutants and also the level of wild-type dysferlin.

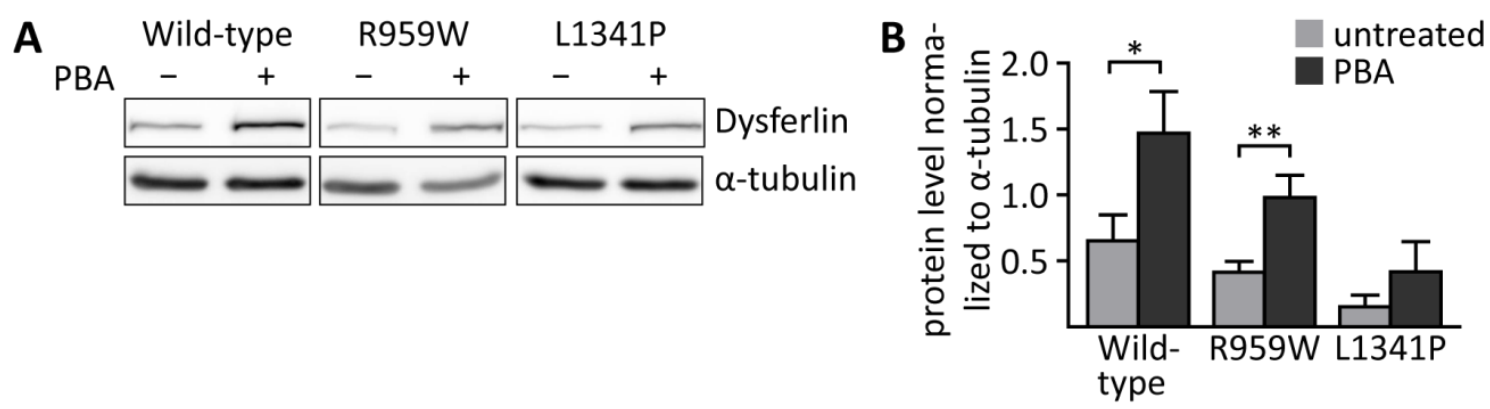

Figure 18 | Increased steady-state level of dysferlin WT and mutants R959W and L1341P upon PBA treatment. (A) Representative immunoblots of lysates from HeLa cells transfected with dysferlin wildtype or missense mutants R959W and L1341P and either nontreated or treated with the chemical chaperone PBA at $5 \mathrm{mM}$ for $24 \mathrm{~h}$. Dysferlin was deteted by anti-dyferlin (NCL-Hamlet), anti- $\alpha$-tubulin served as loading control. (B) Densitometric quantification of western blot. Dysferlin level was normalized to $\alpha$-tubulin. N=3-8. Mean $+/-\mathrm{SEM} .{ }^{*}=\mathrm{P} \leq 0.05,{ }^{* *}=\mathrm{P} \leq 0.01$ (Student's t-test).

\subsection{No effect of PBA on tubulation properties of wild-type dysferlin in HeLa cells}

Heterologous expression of wild-type dysferlin in non-muscle cells leads to the generation of membrane tubules which were shown to have similarities to T-tubules of muscle cell with regard to structure and lipid composition (Hofhuis et al., 2017). Previous work of our group suggests that the ability of dysferlin to form membrane tubules is a central function of the protein during development and maintenance of the T-tubule system. As previously reported by our group, wild-type dysferlin expressed in non-muscle cells does neither colocalize with the Golgi apparatus, nor with the ER (Hofhuis et al., 2017) as shown by immunostaining of EGFP-dysferlin transfected cells for giantin and PDI as Golgi and ER marker, respectively (Figure 19, $A$ and $B$, top). To analyze whether the increased steady-state level upon PBA treatment leads to a distinct localization of dysferlin, transfected cells were incubated with PBA for $24 \mathrm{~h}$ and subsequently used for indirect immunofluorescence. No change in expression or localization of wild-type dysferlin is detectable by epifluorescence microscopy of dysferlintransfected and immunostained cells (Figure 19, A and B, bottom). 
A
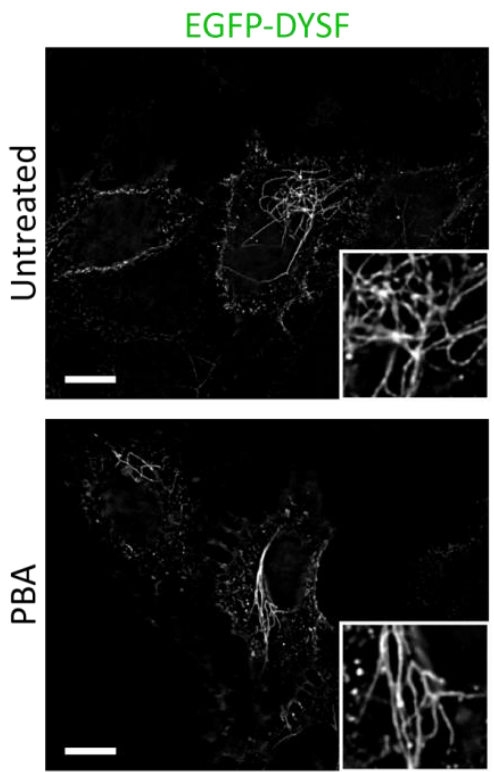

B
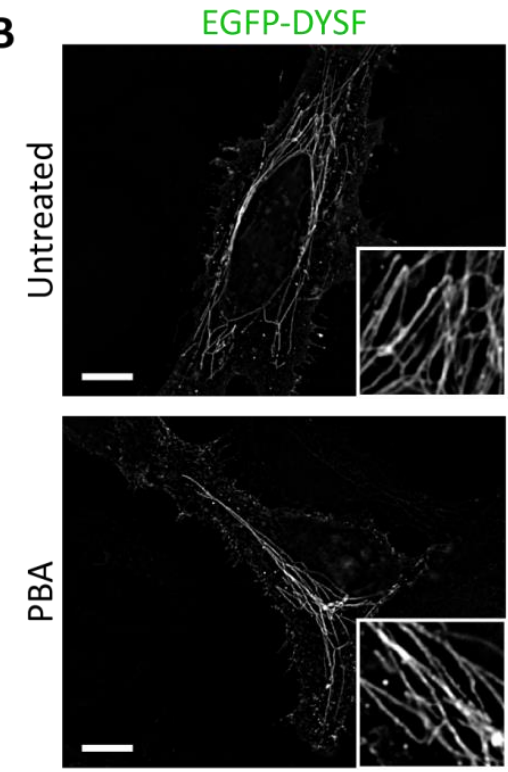

Anti-giantin
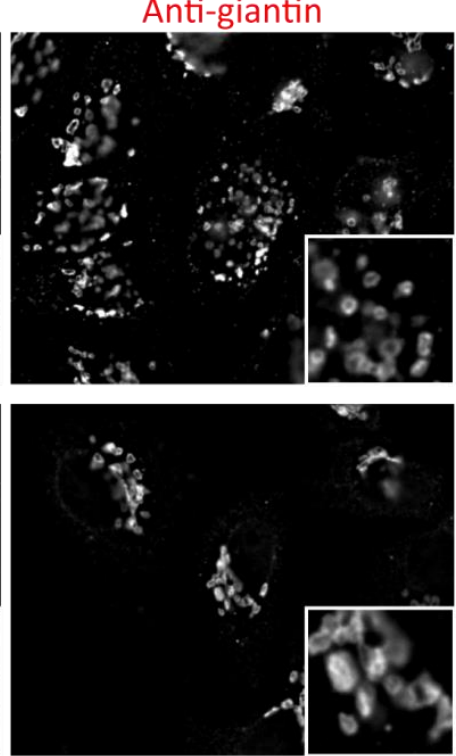

Anti-PDI
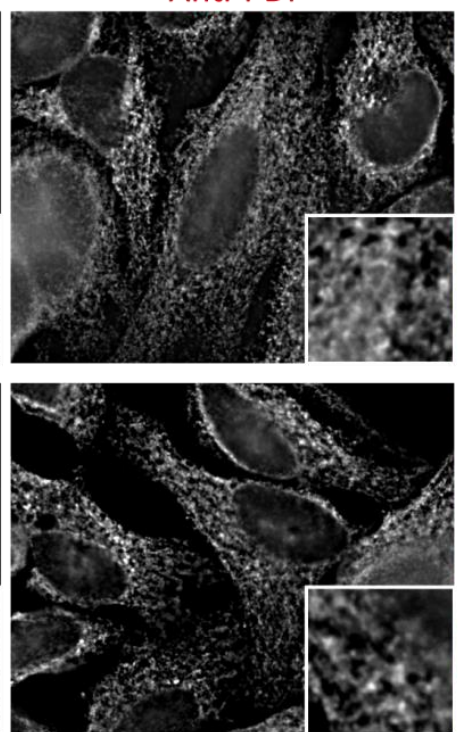

Merge
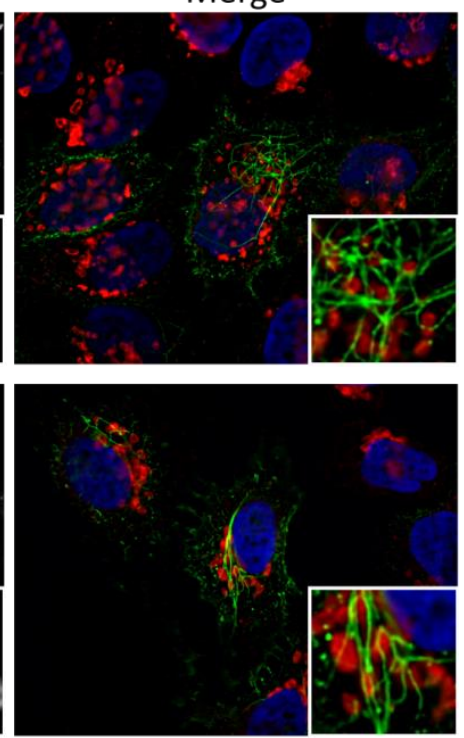

Merge
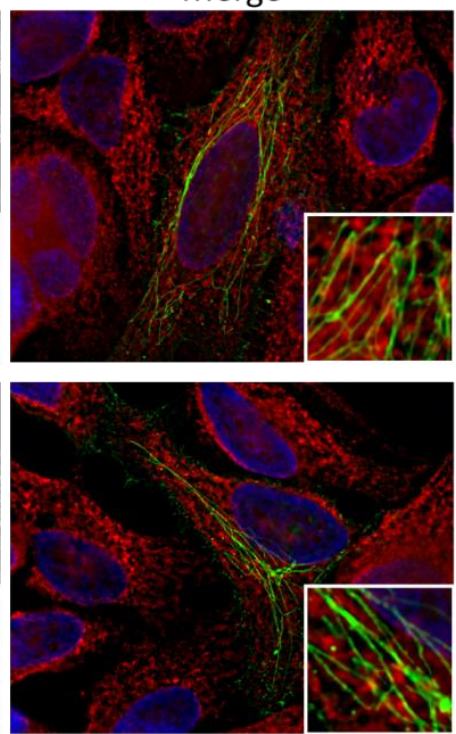

Figure 19 | Wild-type dysferlin does neither colocalize with Golgi marker giantin, nor with ER marker PDI. Representative immunofluorescence images of HeLa cells transfected with EGFP-tagged wild-type dysferlin (EGFP-DYSF) and either nontreated or treated with the chemical chaperone PBA at $5 \mathrm{mM}$ for $24 \mathrm{~h}$. (A) The Golgi network was immunolabed with an antibody against giantin (red). (B) The ER was immunolabed with an antibody against PDI (red). Nuclei are stained with DAPI (blue). Cells were analyzed by epifluorescence microscopy and z-stacks were deconvoluted. Scale bars $10 \mu \mathrm{m}$.

PBA ameliorates the tubulation deficiency of dysferlin mutant R959W, but has no effect on

\section{L1341P in HeLa cells}

When assuming that deformation of membranes into tubular structures is the main function of dysferlin in muscle cells, the tubulation property of dysferlin variants in non-muscle cells can be used as read-out for proper dysferlin function. Localization to cellular organelles and tubulation property of dysferlin mutants R959W and L1341P were analyzed in HeLa cells. In 
contrast to wild-type dysferlin, heterologous expression of R959W does not lead to the de novo synthesis of tubular membranes (Figure 20, A and B, top). R959W does not localize with ER marker PDI (Figure 20, B, top) but shows strong overlap with Golgi marker giantin (Figure 20, A, top). More detailed comparison of R959W- and giantin-labeled structures reveals that they do not completely overlap, but are rather strongly associated with each other. Assuming that a certain minimal protein level of full-length dysferlin is necessary for its tubulation function, the absence of R959W-induced membrane tubules might be explained by its reduced steady-state level due to protein instability caused by the amino acid substitution (Figure 18). Thus, the effect of PBA on localization of mutant R959W was investigated to analyze whether the increased protein level correlates with tubulation. PBA treatment leads to the generation R959W-labeled membrane tubules as reported for wild-type dysferlin in a proportion of transfected HeLa cells. The tubular structures do neither colocalizes with the Golgi apparatus, nor with the ER (Figure 20).

The dysferlin mutant L1341P also has no tubulation ability in untreated HeLa cells (Figure 21, A and $B$, top). The mutated protein localizes to the ER as shown by strong overlap with the PDI signal (Figure 21, B, top) and reported previously (Fujita et al., 2007). Colocalization with the Golgi apparatus is not detectable by epifluorescence microscopy (Figure 21, A, top). Treatment of L1341P-transfected HeLa cells had no effect on the expression or localization of the mutant in immunofluorescence and did not lead to induced membrane tubulation (Figure 21, A and B, bottom).

Heterologous expression of dysferlin mutants R959W and L1341P shows that none of the mutants have tubulation properties, but rather associate with the cellular organelles Golgi and ER, respectively. PBA ameliorates the tubulation deficiency of Golgi-associated R959W, but not of ER-localized L1341P in HeLa cells. 
A
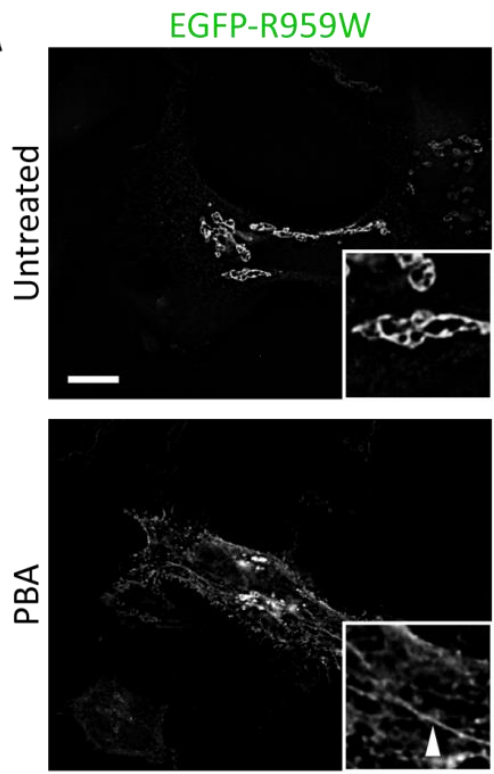

B
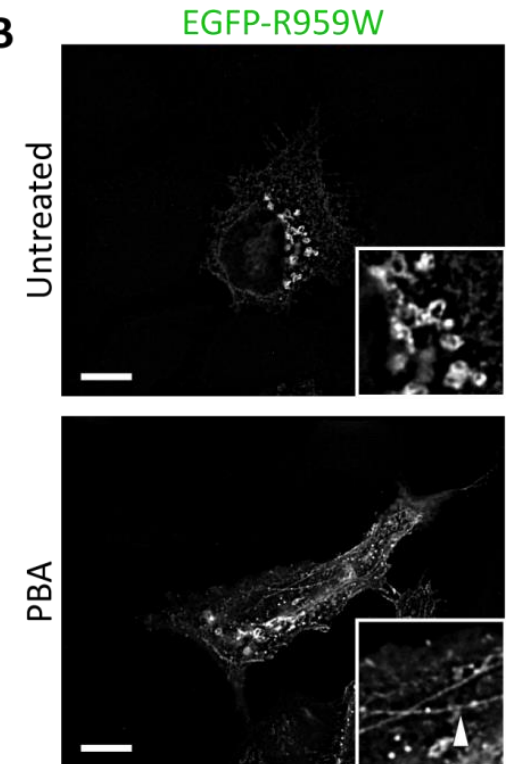

Anti-giantin
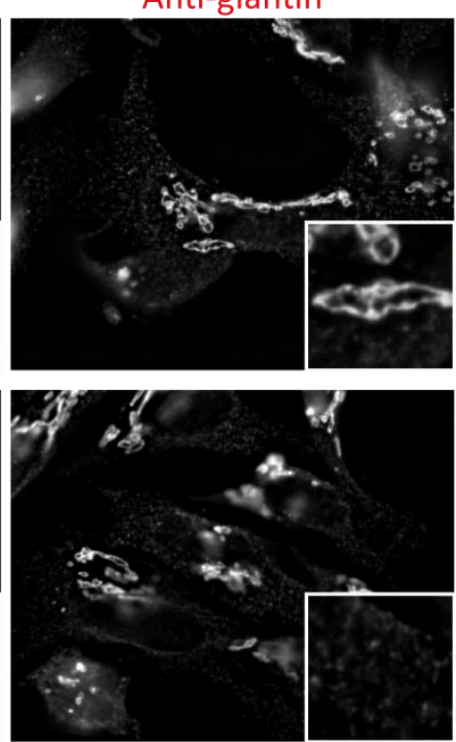

Anti-PDI
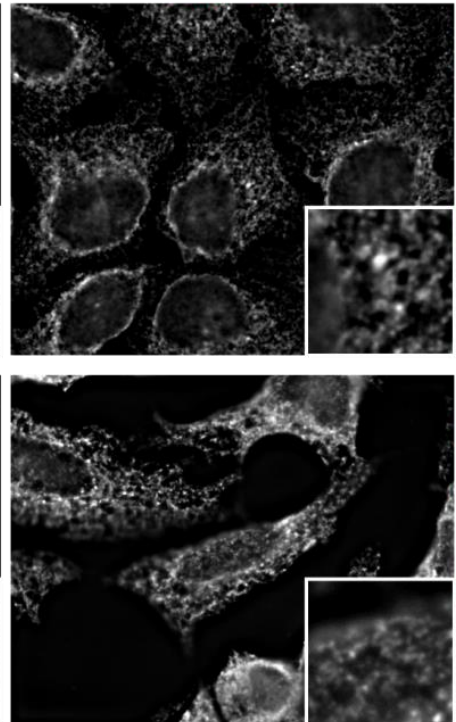

Merge
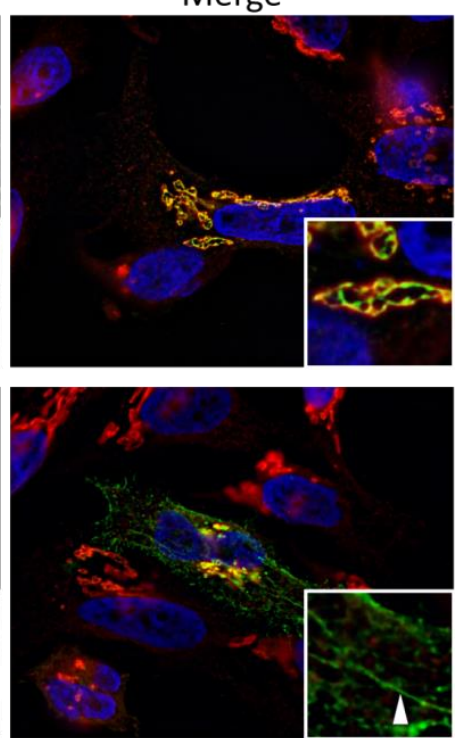

Merge
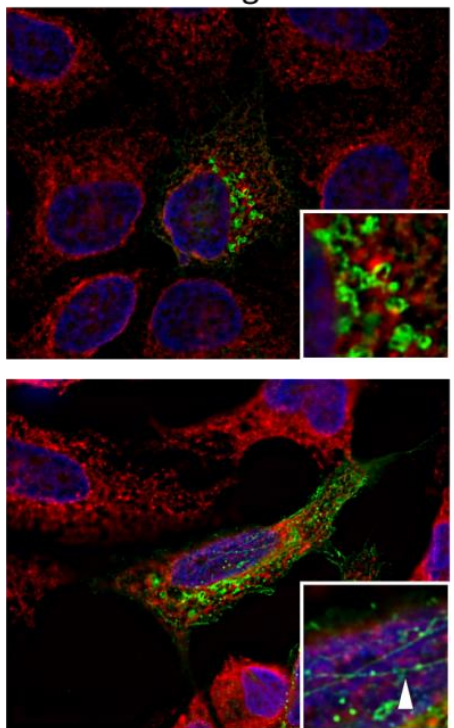

Figure 20 | Dysferlin mutant R959W colocalizes with giantin and PBA rescues tubulation deficiency of R959W mutant. Representative immunofluorescence images of HeLa cells transfected with the EGFPtagged dysferlin missense mutant R959W (EGFP-R959W) and either nontreated or treated with the chemical chaperone PBA at $5 \mathrm{mM}$ for $24 \mathrm{~h}$. (A) The Golgi network was immunolabed with an antibody against giantin (red). (B) The ER was immunolabed with an antibody against PDI (red). Nuclei are stained with DAPI (blue). Cells were analyzed by epifluorescence microscopy and z-stacks were deconvoluted. Scale bars $10 \mu \mathrm{m}$. 
A
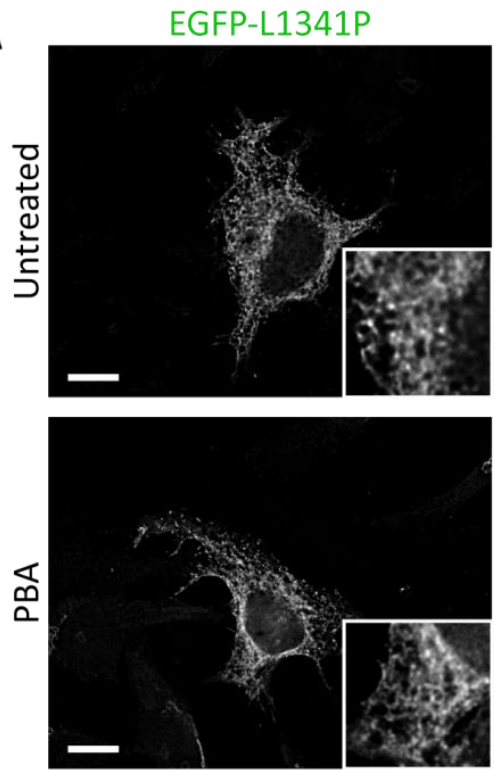

B
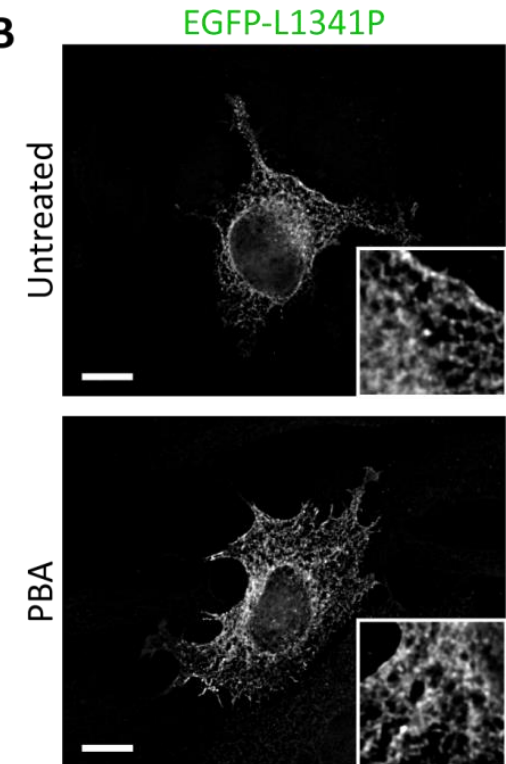

Anti-giantin
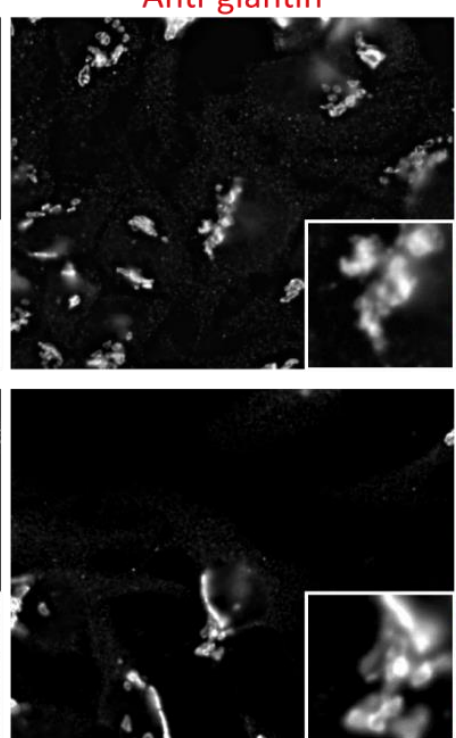

Anti-PDI
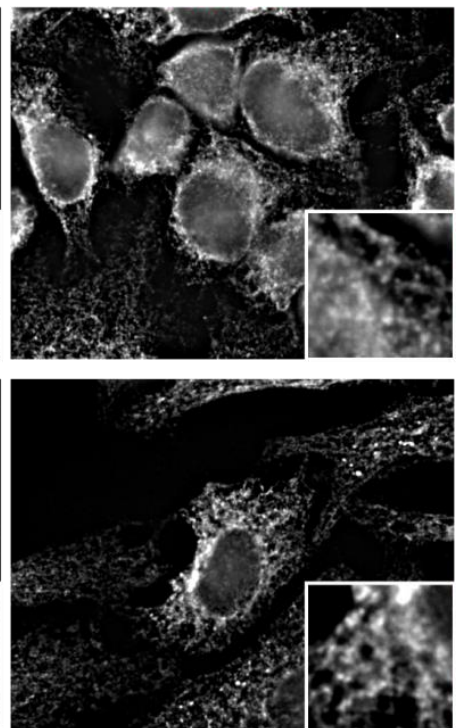

Merge
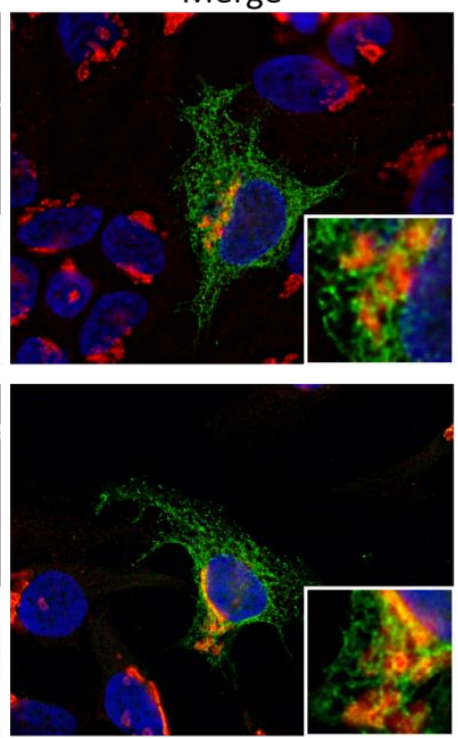

Merge
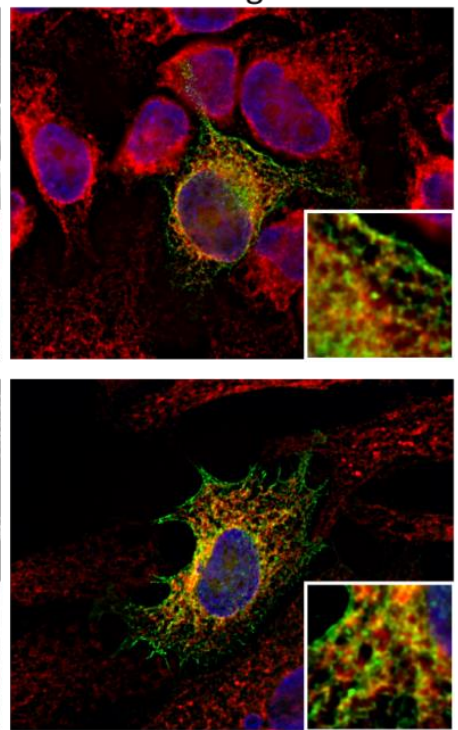

Figure 21 | Dysferlin mutant L1341P partially colocalizes with the ER marker PDI. Representative immunofluorescence images of HeLa cells transfected with the EGFP-tagged dysferlin missense mutant L1341P (EGFP-L1341P) and either nontreated or treated with the chemical chaperone PBA at $5 \mathrm{mM}$ for 24 h. (A) The Golgi network was immunolabed with an antibody against giantin (red). (B) The ER was immunolabed with an antibody against PDI (red). Nuclei are stained with DAPI (blue). Cells were analyzed by epifluorescence microscopy and z-stacks were deconvoluted. Scale bars $10 \mu \mathrm{m}$. 


\subsection{Dysferlin mutant R959W closely associates with the Golgi marker giantin in C2C12 myoblasts}

To get further insight into the pathomechanism of dysferlinopathy caused by missense mutations, the localization of dysferlin mutant R959W was investigated in differentiated C2C12 myoblasts, a model system for T-tubule development in skeletal muscle cells. Therefore, $\mathrm{C} 2 \mathrm{C} 12$ myoblasts were transfected with either EGFP-tagged wild-type or mutant dysferlin and differentiated for 5 days in culture. Differentiated myotubes were used for indirect immunofluorescence to label the Golgi by staining the marker giantin. As previously reported, wild-type dysferlin labels predominantly tubular structures with longitudinal orientation, representing the maturating T-tubule system (Hofhuis et al., 2017). EGFP-dysferlin does not show overlap with the giantin signal but in several regions of the cells dysferlinlabeled tubules are in close contact and seem to entangle giantin-labeled Golgi sheets (Figure 22, A). Heterologously expressed dysferlin mutant R959W does not localize to the longitudinal membrane structures of the developing T-tubule system. Like in HeLa cells, R959W shows partial overlap with giantin-labeled portions of the Golgi apparatus (Figure 21, B). As the overlap is not complete, this speaks rather for a close association of R959W- and giantintagged cellular components than for the immediate molecular proximity. 
A
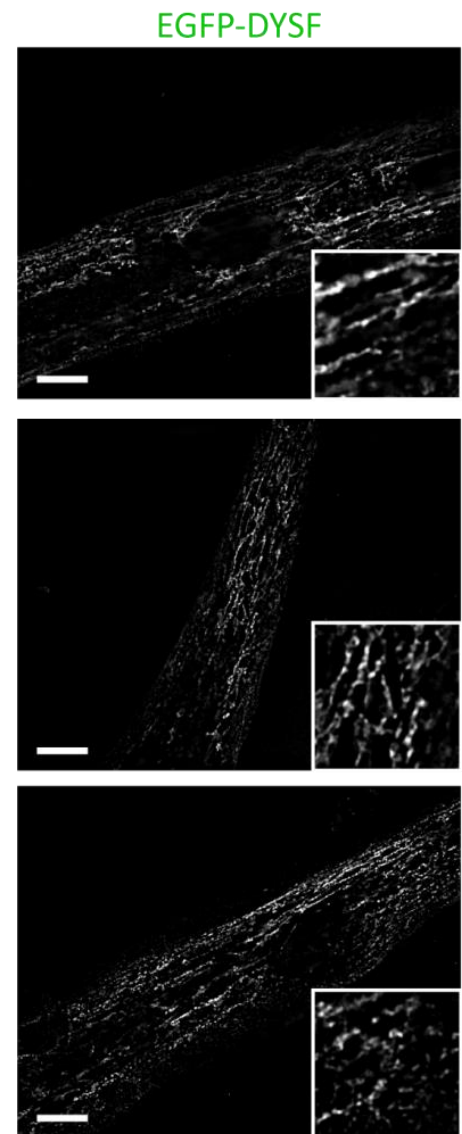

B
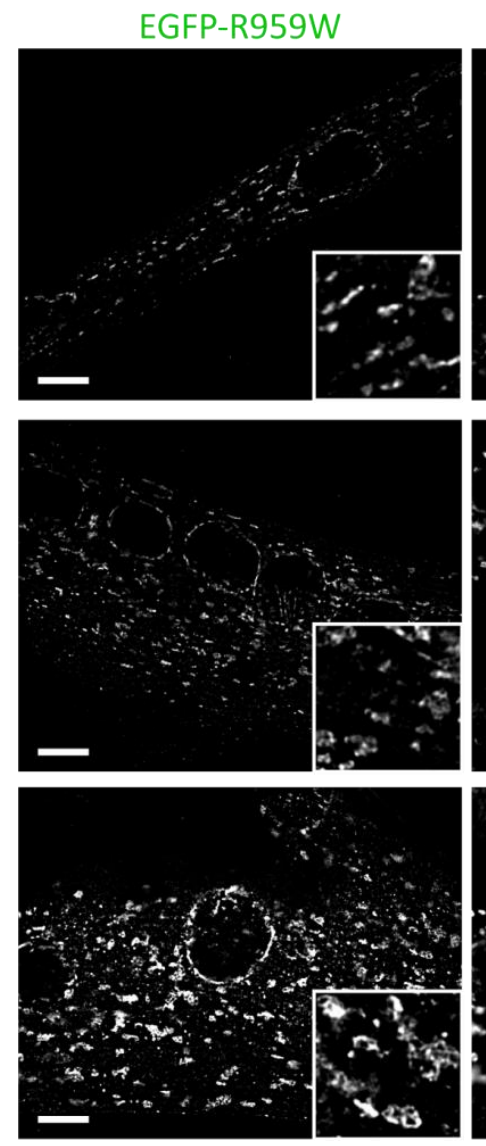

Anti-giantin
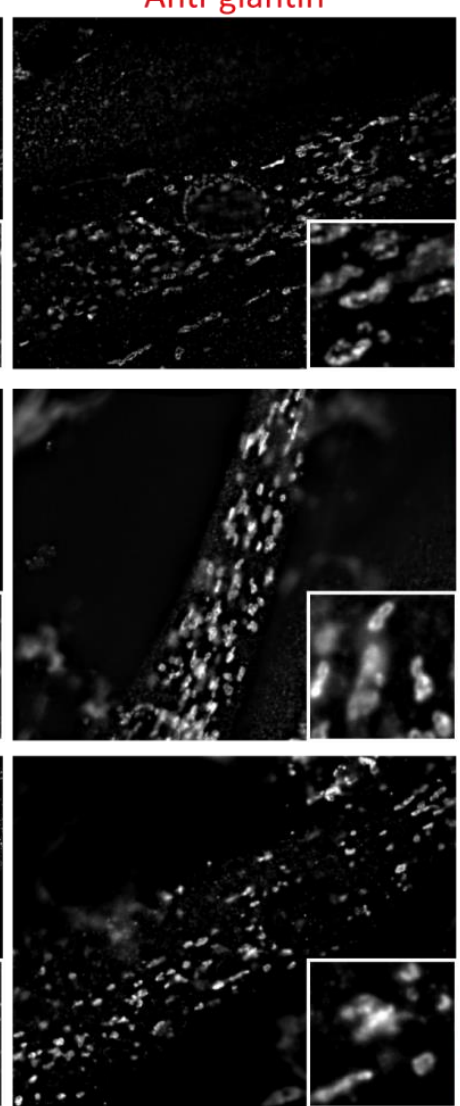

Anti-giantin
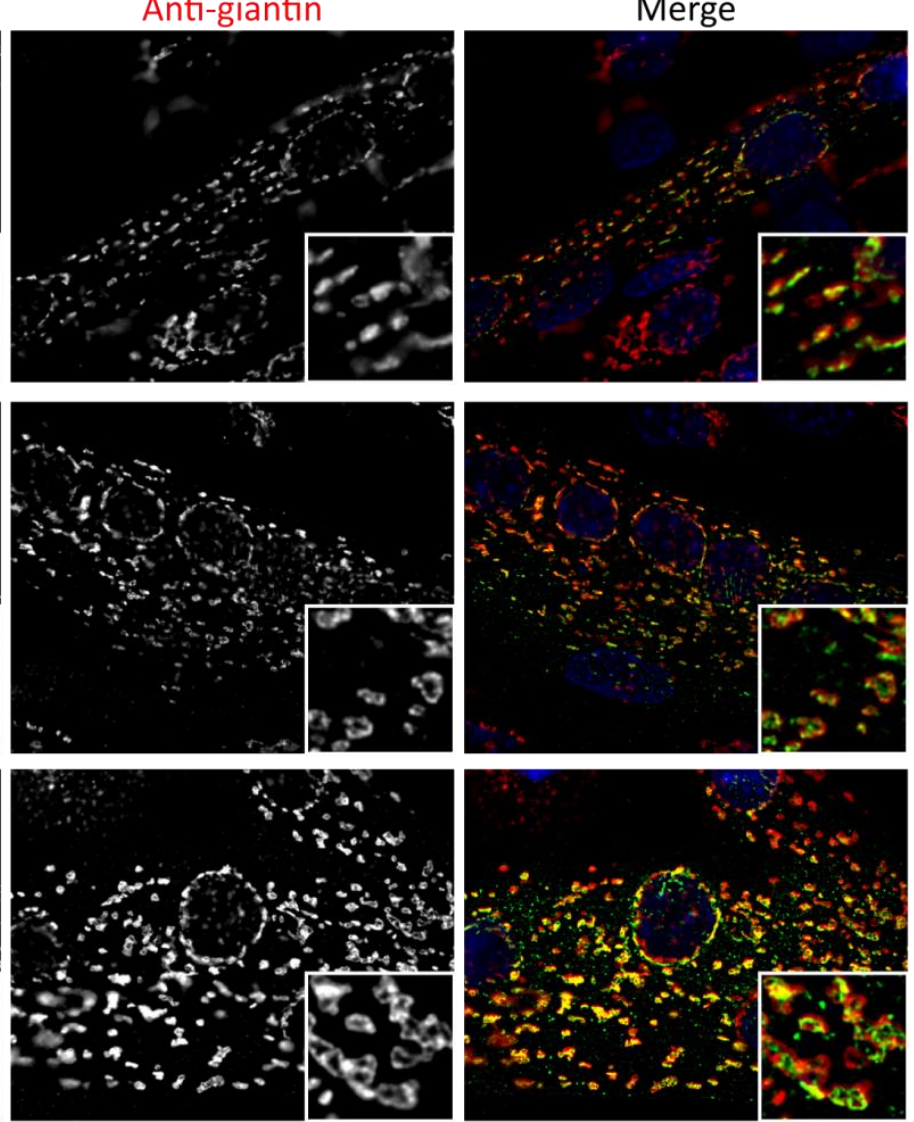

Figure 22 | While wild-type dysferlin localizes to the T-tubule system, mutant R959W closely associates with giantin in C2C12 cells. Representative immunofluorescence images of $\mathrm{C} 2 \mathrm{C} 12$ myotubes 
transfected with either EGFP-tagged wild-type dysferlin (EGFP-DYSF, (A)) or the missense mutant R959W (EGFP-R959W, (B)). The Golgi network was immunolabed with an antibody against giantin (red). Nuclei are stained with DAPI (blue). Cells were analyzed by epifluorescence microscopy and z-stacks were deconvoluted. Scale bars $10 \mu \mathrm{m}$.

\subsection{Readthrough of DYSF patient nonsense codons can be differentially induced by $\mathrm{G} 418$}

Dysferlinopathy is caused by mutations in the DYSF gene. 80 different mutations are known in at least three unrelated patients (UMD-DYSF mutations database, http://www.umd.be/DYSF/W_DYSF/mutation.html). In 25\% of the patients disease is caused by mutations leading to the generation of a stop codon and consequently to premature termination of translation (Figure 23 ).

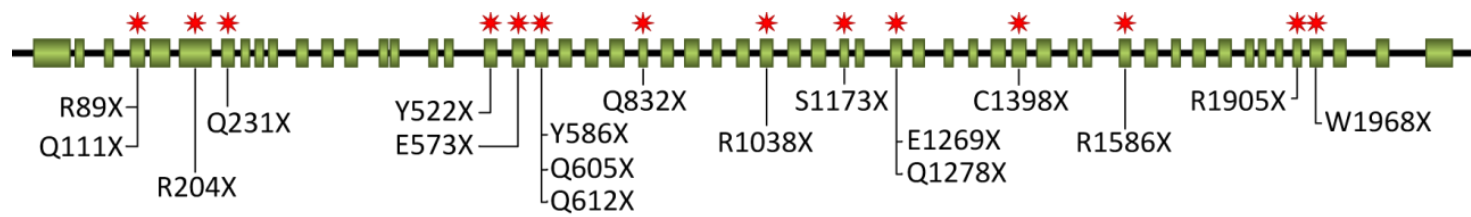

Figure 23 | Spectrum of nonsense mutations in the DYSF gene. Figure shows the positions of all known mutations leading to the generation of a premature stop codon (nonsense mutation) in the human DYSF gene in at least three unrelated index patients (information extracted from UMD-DYSF mutations database, http://www.umd.be/DYSF/W_DYSF/mutation.html) and the affected amino acids of the dysferlin protein.

One therapeutic approach for the treatment of genetic diseases caused by premature stop codons is the application of aminoglycosides, their derivatives or other small molecules which are able to induce translational readthrough of premature stop codons leading to production of the full-length protein. Gentamicin and G418 are aminoglycosides investigated as readthrough inducers, e.g. for the treatment of Duchenne muscular dystrophy (Barton-Davis et al., 1999; Loufrani et al., 2004). However, these substances have a narrow therapeutic window and they are nephro- and ototoxic. Therefore, the application of these aminoglycosides should be carefully evaluated. The therapeutic efficacy varies strongly from patient to patient and currently no prediction about whether and to which extent readthrough will be induced can be made prior to treatment. Our group has established a very sensitive dual reporter assay for analyzing readthrough of a given SCC (stop codon +10 bp upstream 
and downstream) by flow cytometric analysis of cells transfected with a SCC-encoding construct (Hofhuis et al., 2017b).

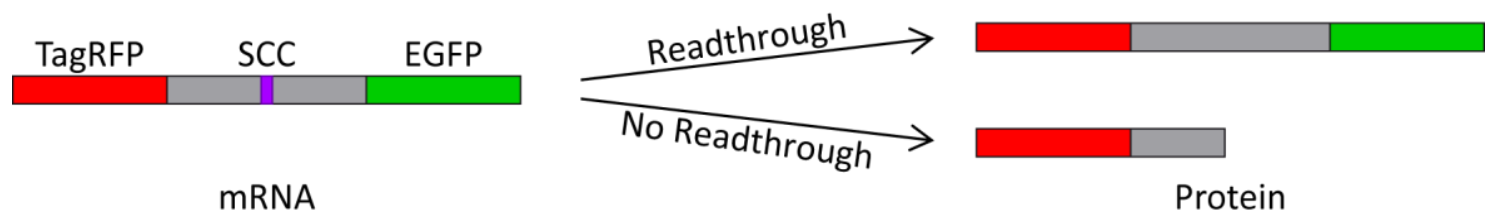

Figure 24 | Schematic representation of dual reporter for readthrough analysis in mammalian cells. A construct consisting of the stop codon (violet) of interest and its adjacent nucleotides (Stop codon context, SCC) surrounded by genes encoding TagRFP and EGFP up- and downstream of the SCC, respectively is transfected into mammalian cells. Following flow cytometric acquisition of the fluorescent signal, the extent of readthrough at the respective stop codon is calculated as EGFP over TagRFP fluorescence ratio.

Readthrough extent is influenced only by the stop codon itself (UGA having the highest readthrough propensity) and the nucleotides surrounding the stop codon (Schueren et al., 2014; Tate et al., 1996). The dual reporter assay was used to investigate the basal (without induction) and G418-induced readthrough of the 18 known nonsense codons in the DYSF gene. Therefore, the SCCS (Table 14) were cloned into a mammalian expression construct with an N-terminal TagRFP sequence as internal expression control and a C-terminal EGFP sequence as readthrough sensor (Performed by Corinna Dickel and Marco Schmidt). HeLa cells were transfected and subsequently either nontreated or incubated with G418 for $18 \mathrm{~h}$. Cells were analyzed $24 \mathrm{~h}$ after transfection by two channel fluorescence flow cytometry for the expression of TagRFP and EGFP. Readthrough was calculated as green over red fluorescence ratio and normalized to a $100 \%$ readthrough control (no stop codon between TagRFP and EGFP coding sequences).

Table 14 | DYSF nonsense mutations

\begin{tabular}{l|l|l} 
Amino acid position & cDNA position & SCC \\
\hline \hline R89X & $265 C>T$ & G GTC CCA CTC TGA GAG GTC CTC G \\
\hline Q111X & $331 \mathrm{C}>\mathrm{T}$ & C ACC AAG AAG TAG CCC ACA GGG G \\
\hline R204X & $610 \mathrm{C}>\mathrm{T}$ & CAA AGA AAG TGA AGT GCG CCT A \\
\hline Q231X & $691 \mathrm{C}>\mathrm{T}$ & T GGG CCC TGC TAG ATC AAC CTC T \\
\hline Y522X & $1566 C>G$ & A CAG AAG GTG TAG GAC CTT CCT G \\
\hline E586X & $1717 G>T$ &
\end{tabular}




\begin{tabular}{l|l|l|}
\hline Y586X & $1758 C>T$ & G GTG GAG AAG TAG CTT AGG AGG C \\
\hline E605X & $1813 C>T$ & C ACC ATG CTG TAG GAT GTG GAT G \\
\hline E612X & $1834 C>T$ & T GAT GCC ATC TAG TTT GAG GTC A \\
\hline E832X & $2494 C>T$ & T GGG AAG CTA TAG ACA ATC TTT C \\
\hline R1038X & $3112 C>T$ & C TAC ACA CAC TGA CGG CGG CGC T \\
\hline S1173X & $3516 \_3517$ delTT & A CTC TTT TTC TGA TCC CTA TGC C \\
\hline Q1269X & $3805 G>T$ & G CCG TCG GGG TAG CTG CTG GCC T \\
\hline E1278X & $3832 C>T$ & T GAG CTC ATC TAG AGA GAG AAG C \\
\hline C1398X & $4194 C>A$ & G GAG CTC TAC TGA CCC CCC ATC A \\
\hline R1586X & $4756 C>T$ & C TAC ATT GTC TGA GCA TTT GGC C \\
\hline R1905X & $5713 C>T$ & A ATC CCA GCA TGA GTG GTG TTC C \\
\hline W1968X & $5903 G>A$ & A GTG AAG GGC TGA TGG CCC TGT G \\
\hline
\end{tabular}

The basal translational readthrough of DYSF nonsense SCCs is less than $1 \%$, ranging from $0.29 \%$ (R204X) to $0.87 \%$ (E1278X) (Figure 25). Treatment with G418 leads to significant readthrough induction for all tested SCCs. Readthrough of induced SCCs ranges from $1.46 \%$ (E832X) to $10.40 \%$ (W1968X), thus, readthrough level differs by up to 7 -fold. The readthrough level upon induction does not correlate with the basal level. If the readthrough level is equivalent to the proportion of translated full-length protein, the results suggest that without induction less than $1 \%$ of protein is produced but induction with G418 increases amount of full-length protein to up to $10.4 \%$ (W1968X). 


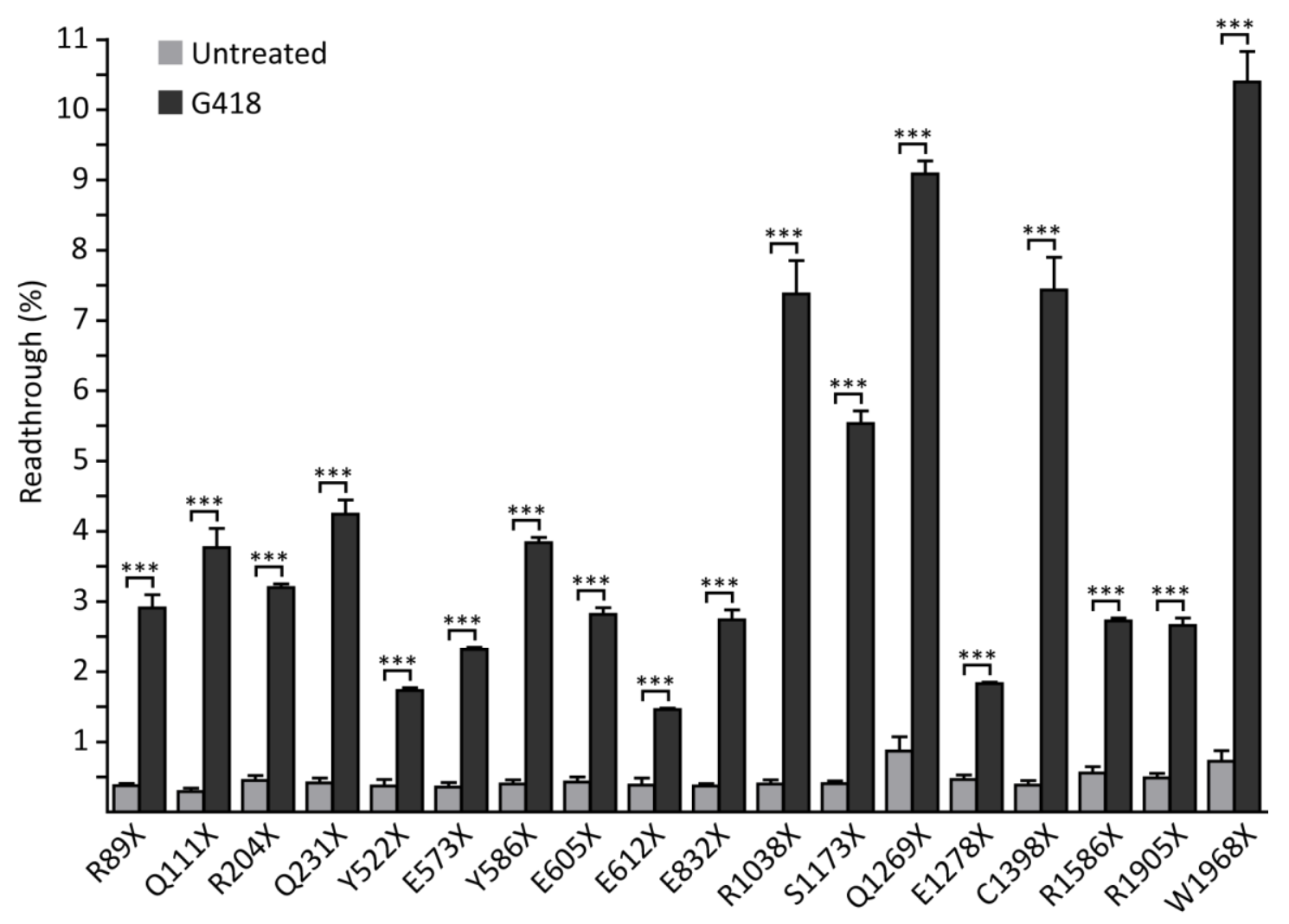

Figure 25 | Differential readthrough induction efficiancy of DYSF SCCs by G418. HeLa cells were transfection with the dual fluorescence reporter construct encoding SCCs of the known nonsense mutations in the human DYSF gene or a construct with no stop codon between the fluorescence tags (100\% readthrough control) (cloned by Corinna Dickel and Marco Schmidt). $6 \mathrm{~h}$ after transfection, cells were either nontreated or treated with $\mathrm{G} 418(100 \mu \mathrm{g} / \mathrm{mL})$ for another $18 \mathrm{~h}$. Reporter fluorescence was analyzed $24 \mathrm{~h}$ post transfection by flow cytometry. Following gating according to FSC/SSC and green/red fluorescence, readthrough was calculated as EGFP over TagRFP fluorescence ratio normalized to the $100 \%$ readthrough control. $\mathrm{N}=3$. Mean $+/-\mathrm{SEM} .{ }^{* * *}=\mathrm{P} \leq 0.001$ (Student's t-test). 


\section{Discussion}

Dysferlin is a protein which is mainly expressed in skeletal and heart muscle. For a long time, it has mainly been implicated in membrane repair (Bansal and Campbell, 2004; Cai et al., 2009; Lek et al., 2013). In recent years, accumulating evidence uncovered an additional and fundamental role for dysferlin. Dysferlin leads to the generation of elongated membranes upon heterologous expression in non-muscle cells or incubation with liposomes. These tubules are characterized by biochemical and morphological similarities with the muscular tubule system leading to the hypothesis that the tubulation capacity of dysferlin mirrors the primary cellular function of the protein, namely the formation of the T-tubule system in skeletal muscle (Hofhuis et al., 2017).

\subsection{Dysferlin and BIN1 function at different subcompartments of the tubule system during development}

The BAR domain protein BIN1 is an established key player during biogenesis of the tubule system (Hong et al., 2014, 2010; Lee et al., 2002). It is found early at the membrane of the developing tubule system and regulates recruitment and clustering of EC coupling proteins Ltype $\mathrm{Ca}^{2+}$ channel and RyR at the functional units of the muscle cells (Fu et al., 2016; Hong et al., 2014, 2010; Lee et al., 2002). One of BIN1's molecular functions was determined by heterologous expression in non-muscle cells and incubation of recombinant BIN1 with liposomes (Lee et al., 2002). In these systems, the generation of membrane tubules was observed. The tubules are analogous to those observed in dysferlin-induced tubulation with partial colocalization when expressed in one system. Still, also differences comparing BIN1and dysferlin-induced tubules were observed. BIN1-induced tubules are longer and more branched then those induced by dysferlin. In contrast to BIN1, dysferlin induces membrane tubulation in a dynamin 2-independent manner. These differences indicate that the mechanism underlying membrane tubulation differs between BIN1 and dysferlin (Hofhuis et al., 2017). To follow up on the difference between those two T-tubule proteins, their endogenous localization was studied in $\mathrm{C} 2 \mathrm{C} 12$ myotubes in the frame of this study. In culture differentiated $\mathrm{C} 2 \mathrm{C} 12$ cells resemble differentiation of skeletal myofibers and biogenesis of the T-tubule system. Dysferlin and BIN1 show partial colocalization in this system. Though, BIN1 and dysferlin also label different structures with dysferlin localizing to central tubules and BIN1 labeling tubules in proximity to the plasma membrane. Thus, dysferlin and BIN1 localize to different subcompartments of the developing T-tubule system indicating that they might have 
distinct specialized roles for the formation of the tubule system. During embryonic development and initial phases of tubule biogenesis, $\mathrm{Ca}_{v} 1.1$, the L-type $\mathrm{Ca}^{2+}$ channel in skeletal muscles, is localized at the sarcolemma before translocating to the tubule membrane in later stages (Romey et al., 1989). BIN1 is strongly associated with the L-type $\mathrm{Ca}^{2+}$ channel during development. In cardiomyocytes, BIN1 recruits Cav1.2 molecules, which are transported on polymerizing microtubules, arising from the Golgi, to the membrane of the tubule system and clusters them compactly in membrane microdomains (Hong et al., 2010). The BIN1-mediated recruitment and anchoring of $\mathrm{Ca}^{2+}$ channels to the tubule membrane might also take place in skeletal muscle. This idea is supported by the observation that BIN1 is at the sarcolemma and proximate tubule structures, which is the site of Cav1.1 accumulation during early tubule biogenesis. Dysferlin, on the other hand, localizes to tubule membranes in $\mathrm{C} 2 \mathrm{C} 12$ myotubes which are more in the center of the cell. In adult myofibers, dysferlin also localizes to the Ttubule system (Kerr et al., 2013). Upon plasma membrane rupture, dysferlin-containing vesicles quickly accumulate at lesion sites and fuse with each other and with the plasma membrane to repair the membrane lesion (Lek et al., 2013; Redpath et al., 2014). Due to the incorporation of dysferlin in both, T-tubule membrane and repair vesicle membrane, it is suggestive that the T-tubule system represents the membrane reservoir that is provided to seal membrane ruptures. In this scenario, dysferlin-containing vesicles might be very quickly pinched off from the preexisting membrane tubule by an endocytosis-like mechanism and translocate to the site of membrane lesion. The possibility that the membrane reservoir, needed for lesion repair, origins from the plasma membrane is less conceivable as this process would require more steps of membrane modulation. Initially, membrane buds would have to be formed prior to pinching of and translocating to the lesion site, making this mechanism unfeasible for fast sarcolemma repair. Thus, the membranes needed for membrane lesion repair might arise from the T-tubules with dysferlin orchestrating the process of membrane modulation. The differentiation of myofibers is a very dynamic process with numerous membrane rearrangement events. The localization of dysferlin at central tubules inside the myofiber indicates that the protein has a role in dynamic membrane remodeling during membrane repair, but also development and maturation of the T-tubule system. The differential localization of endogenous dysferlin and BIN1 during T-tubule biogenesis and possible specific functions that are associated with their cellular localization might explain the distinct pathologies arising from deficiency of either BIN1 or dysferlin. 


\subsection{Early developmental abnormalities of the T-tubule system in patient myoblasts due to dysferlin loss}

Dysferlinopathy is characterized by progressive weakening and wasting of the skeletal muscle. Histologically, muscles show typical signs of dystrophy including loss of muscle fibers, increased fiber size variation, and accumulation of connective and fat tissue. These phenotypes are secondary to defects in cellular functions and need to be investigated to understand the pathophysiology of dysferlin-deficient muscular dystrophy. The identification of primary molecular and cellular alterations is not simple, because many patients remain undiagnosed or maldiagnosed for several years after onset of symptoms (Harris et al., 2016). At the time point of correct diagnosis, muscular dystrophy is fairly advanced. Thus, primary alterations of the skeletal muscle cannot easily be determined. Animal models of muscular dystrophy are therefore required in order to investigate the pathophysiology of dysferlindeficiency. The adult skeletal muscle T-tubule system of dysferlin-deficient mice shows dramatic rearrangements with dilated, irregularly shaped and longitudinally orientated tubules (Klinge et al., 2010a). Also during regeneration after notexin-induced muscle damage in a mouse model of dysferlin-deficiency, the T-tubule system is abnormally formed tubules are vacuolated (Hofhuis et al., 2017). As dysferlin plays a role during the biogenesis of the Ttubule system (Hofhuis et al., 2017), the present study aimed to analyze the effect of dysferlindeficiency in a human model of early T-tubule development. The membrane system in a considerable proportion of patient myotubes is massively altered as assessed by membrane staining with the dye $\operatorname{DilC}_{16}(3)$. Instead of single tubules and vesicles as in control cells, dense bundles of longitudinal tubules in perinuclear regions were observed in dysferlin-deficient myotubes. This result shows that dysferlin is not only necessary for membrane repair and maintenance of T-tubules in adult myofibers, but the protein is essential during a very early stage of myofiber differentiation for proper biogenesis of the tubular network.

Previous work of our group has identified a strong association between the phospholipid $\mathrm{PI}(4,5) \mathrm{P}_{2}$ and dysferlin. Heterologous expression of dysferlin in non-muscle cells leads to formation of membrane tubules. $\mathrm{PI}(4,5) \mathrm{P}_{2}$ is recruited to these dysferlin-containing tubules indicating that they share similarities with the T-tubule system of muscle cells, which are enriched in $\mathrm{PI}(4,5) \mathrm{P}_{2}$ (Hofhuis et al., 2017; Milting et al., 1994). Additionally, the existence of $\mathrm{PI}(4,5) \mathrm{P}_{2}$ and binding of dysferlin to $\mathrm{PI}(4,5) \mathrm{P}_{2}$ is a prerequisite for dysferlin's tubulation capacity. Thus, the function of dysferlin is highly dependent on $\mathrm{PI}(4,5) \mathrm{P}_{2}$. As dysferlin is located at the plasma and T-tubule membrane system in myofibers and strongly associates with 
$\mathrm{PI}(4,5) \mathrm{P}_{2}$, dysferlin-deficiency might also lead to a reduced level of $\mathrm{PI}(4,5) \mathrm{P}_{2}$ in membranes that usually contain dysferlin. $\mathrm{PI}(4,5) \mathrm{P}_{2}$ is an important mediator of cellular signaling and trafficking (Hofgaard et al., 2008; Itoh and Takenawa, 2004; Suh and Hille, 2005; Sun et al., 2013; Takenawa et al., 1999). Among others, it anchors the growing plus-ends of microtubules at the plasma membrane (Golub and Caroni, 2005). It has been shown that dysferlin interacts with $\alpha$ tubulin and dysferlin-induced tubules depend on the microtubule system (Azakir et al., 2010; Hofhuis et al., 2017). Thus, the accumulation of membrane tubules in perinuclear bundles upon loss of dysferlin might be explained by the disability of the plasma membrane to anchor the microtubule-associated developing T-tubule system, which is deficient in dysferlin and probably therefore contains lower amount of $\mathrm{PI}(4,5) \mathrm{P}_{2}$.

\subsection{Dysferlin is also a key player of cardiac tubule system biogenesis}

The implication of dysferlin in the development of the T-tubule system in skeletal muscle is based on the following findings: Dysferlin localizes to the developing and regenerating Ttubule system in skeletal muscle (Hofhuis et al., 2017; Klinge et al., 2010a). Furthermore, the T-tubule system has an abnormal morphology upon dysferlin-deficiency (Klinge et al., 2010a). The results of this study show that the formation of the membrane system is disturbed in in patient myotubes. These observations correspond to the dystrophic symptoms affecting almost exclusively the skeletal muscles of dysferlinopathy patients. In only a few patients a cardiac dysfunction is reported (Kuru et al., 2004; Wenzel et al., 2006, 2007). By contrast, cardiac involvement is more pronounced in some mouse models of dysferlin-deficiency. Without excessive strain, no or only a mild cardiac phenotype is detected, whereas physical stress results in several signs of cardiac dysfunction (Chase et al., 2009; Han et al., 2007; Rubi et al., 2015; Tzeng et al., 2014; Wei et al., 2015; Wenzel et al., 2007). Consequently, a putative role of dysferlin in the development of the cardiac tubule system was hypothesized and addressed in this study. In this study, expression and localization of dysferlin was analyzed in rat cardiomyocytes in the first three weeks of live, the time window when maturation of the cardiac tubule system occurs (Chen et al., 2013). Localization of dysferlin at the developing Ttubule system was assessed by co-staining with the T-tubule marker $\mathrm{Ca}_{\vee} 1.2$ and appeared to increase over the course of 20 days after birth. Thus, before maturation of the transverse and axial membrane tubules dysferlin and $\mathrm{Ca}_{v} 1.2$ localize to different areas of the cardiomyocyte and co-assemble at membrane tubules during maturation. Cardiac dysferlin protein expression is similar in neonatal rats of P11 and adult rats. In the first three weeks of live, dysferlin protein level increases with a peak at P20 before decreasing again. At this time point the 
tubular system is largely mature and transverse and axial tubules are achieving their final structure. Consequently, the expression pattern of dysferlin indicates that the protein is not only involved in the development of skeletal muscle T-tubule system, but also in the maturation of the cardiac TATS.

The highly rearranged TATS in the cardiomyocytes of dysferlin-deficient mice strongly supports the hypothesis that dysferlin also exerts an important function in the heart: The distribution between transverse and axial orientated tubules is shifted to a higher amount of membrane components with axial orientation in dysferlin-deficient cardiomyocytes indicative of a reorientation of the TATS system. Not only transverse tubules get lost upon dysferlindeficiency, but also the total amount of membrane structures per cell is decreased, reducing the overall tubule length in mice lacking dysferlin. Thus, a disorganized T-tubule system upon deficiency of dysferlin is detected in both, skeletal and heart muscle substantiating the role of dysferlin in the biogenesis of the tubule system in both muscle types.

Reorganization of the cardiac T-tubule system is a characteristic of patients suffering from heart failure and is verified in several animal models of heart failure (Gómez et al., 1997; Heinzel et al., 2008; Louch et al., 2004; Pieske et al., 1999). The rearrangements start very early in cardiac pathology even before the transition to heart failure, a condition when the metabolic demands of the body are insufficiently covered (Chen et al., 2015; Levy et al., 1996; Wei et al., 2010). The TATS of failing cardiomyocytes shows similar features as detected upon dysferlin-deficiency: loss of tubule system components, axialization and dilatation of membrane tubules (Cannell et al., 2006; Pinali et al., 2017; Wei et al., 2010). Thus, dysferlindeficiency might lead to a phenotype which is comparable to the early subclinical stages of heart failure without affection of heart function under normal conditions. Thereby, the abnormalities of the T-tubule system and resulting molecular changes can be compensated by the cells to prevent effects on a global level. Though, dysferlin-deficient mice have a disturbed cardiac function under physical stress. This indicates that the effects of a destructed cardiac TATS cannot be compensated if the requirements for the heart dramatically increase leading to detectable cardiac dysfunction.

The distinct affection of skeletal and heart muscle upon dysferlin-deficiency might be explained by the structural and molecular differences between these two muscle types. Concretely, the diameter of skeletal muscle T-tubules is 5 - to 10 -fold smaller than the diameter of cardiac T-tubules (Franzini-Armstrong et al., 1975; Soeller and Cannell, 1999; 
Wagner et al., 2012b). The membrane of cardiac tubules is extensively folded into microdomains with low ion diffusion (Hong et al., 2014). Such membrane folding has not been reported for the T-tubule system of skeletal myofibers. Transverse tubules occur in doublets with one tubule between each sarcomeric A- and I-band in skeletal myofibers, whereas only one tubule per sarcomere, which is anchored at the Z-line, is found in cardiomyocytes. Furthermore, cardiomyocytes have an intracellular membrane system composed of transverse and axial tubules forming a complex network (Forbes et al., 1984; Soeller and Cannell, 1999; Sperelakis and Rubio, 1971). Axial membrane tubules are largely missing in skeletal myofibers. In skeletal muscle cells, EC coupling occurs in triads with Cav1.1 and RyR1 physically interacting with each other presupposing that the T-tubule and SR membrane are separated by an extremely narrow gap (Ashcroft, 1991; Bezanilla et al., 1972; Boncompagni et al., 2006). In cardiomyocytes, Cav1.2 and RyR2 are only functionally coupled as $\mathrm{Ca}^{2+}$ release from the SR is induced by $\mathrm{Ca}^{2+}$ influx through $\mathrm{Ca}_{\mathrm{v}} 1.2$ and not by a conformational change of the channel (DiFranco et al., 2005; Fabiato, 1983; Hong and Shaw, 2017; Ibrahim et al., 2011). Consequently, cardiomyocytes might be more resistant to morphological changes of the tubule system than skeletal muscle cells as they do not depend on a direct association of the $\mathrm{Ca}_{v} 1.2$ with RyR2. This might explain that dysferlin-deficiency causing an abnormal tubule system in both, cardiomyocytes and skeletal myofibers, is mainly leading to clinical pathology of the skeletal and to a much lesser extent of the heart muscle.

\subsection{First stop on the route of dysferlin: the Endoplasmic reticulum}

To understand the pathomechanism underlying dysferlin-deficient muscular dystrophy and to develop therapeutic targets for this disease, the trafficking route of dysferlin through the myofiber or cardiomyocyte should be elucidated. Until now, very little is known about the transport of dysferlin from its synthesis in the cytoplasm to its target organelle, the plasma and T-tubule membrane. The nature of dysferlin as a TA protein with a highly hydrophobic transmembrane domain suggests that the protein is posttranslationally and chaperoneassisted inserted into the membrane of the ER. This hypothesis was tested using a short peptide, the opsin tag, which is derived from the bovine rhodopsin (Adamus et al., 1991), as a sensor for ER integration. $\mathrm{N}$-glycosylation of a specific arginine inside the recognition site of the opsin tag, which occurs through the activity of glycosyltransferases inside the ER lumen, can be detected by western blot as a mobility shift. As dysferlin has a molecular weight of 230 $\mathrm{kDa}$, a shift due to glycosylation of a single residue inside the opsin tag would not be visible. Specific cleavage of full-length dysferlin by the protease thrombin allows identification of a C- 
terminal fragment that is small enough to assess glycosylation on western blot either by antidysferlin or anti-opsin antibodies. The coupling of dysferlin to the opsin tag and cleavage by thrombin was subsequently used to analyze insertion of dysferlin into the ER of different mammalian cell lines (HeLa, HEK293, COS-7, CHO-K1, C2C12). Indeed, dysferlin gets Cterminally integrated into the ER in all tested systems suggesting that the ER membrane is the first endomembrane into which dysferlin is inserted after its synthesis in the cytoplasm. Surprisingly, the glycosylation is highly variable between the cell lines with CHO-K1 having the highest and HeLa the lowest amount of modified dysferlin. As glycosylation of dysferlin was also observed in $\mathrm{C} 2 \mathrm{C} 12$ cells - a model system for myogenic development - it is possible that the posttranslational integration of dysferlin into the ER in muscle tissue is physiologically important. The variable glycosylation efficiency of dysferlin in different cell lines might be explained by several cellular factors. These include different chaperone proteins or complexes that might be involved in the cotranslational shielding or folding, protein quality control and targeting to the ER membrane (Casson et al., 2016; Hegde and Keenan, 2011; Johnson et al., 2013). The components of the cytoplasmic and ER-membrane resident insertion machinery as well the glycosyltransferases inside the ER might be cell-type adapted (Aebi, 2013; Ellgaard et al., 2016; Johnson et al., 2013). Furthermore, glycosylation extent might be influenced by the duration of ER lumen exposure as some cell types might be more sensitive to ER stress then others resulting in the retention of proteins inside the ER (Oslowski and Urano, 2011; Sano and Reed, 2013). As dysferlin-ops was heterologously overexpressed in the tested cell lines, a certain degree of induced ER stress is plausible. Also, the morphology and the size of the ER is cell type-dependent and might influence the insertion of proteins into the ER.

Patients with the DYSF mutation c.4022T>C show clinical symptoms of LGMD2B and partially of cardiomyopathy (Klinge et al., 2010b; Wenzel et al., 2006, 2007). Mutation c.4022T>C in exon 38 is leading to the amino acid change L1341P. The position L1341 is located in the C2E domain and is highly conserved, thus, an amino acid substitution might have dramatic effects on protein structure. Dysferlin L1341P accumulates in the ER of human myofibers and is prone to degradation by the autophagy-lysosome pathway (Fujita et al., 2007). In this study, the ER integration of wild-type and mutant dysferlin was analyzed to uncover possible trafficking defects of the mutant dysferlin. As expected, the proportion of glycosylated L1341P is 1.5-fold higher than glycosylated wild-type dysferlin. The increased amount of glycosylated protein might have different causes. Either, the integration into the ER is more efficient for the mutant then for the wild-type dysferlin. Or, exposure of the L1341P mutant protein to the ER lumen is 
prolonged leading to more opportunities for glycosyltransferases to glycosylate the opsin tag. Taking into consideration that the mutant L1341P does not localize to the plasma membrane in myofibers but rather accumulates in the ER (Fujita et al., 2007), the second explanation of increased glycosylation is more plausible. Substitution of leucine to proline at position 1341 probably leads to a conformational change of the dysferlin protein which does not perturb insertion into the ER membrane. Instead, the altered protein structure interferes with dysferlin trafficking possible by inhibiting protein exit from the ER. This leads to loss of dysferlin at the plasma membrane and aggregation of L1341P inside the ER as detected in patient myofibers harboring the respective mutation (Fujita et al., 2007). Consequently, mutations inside conserved regions of dysferlin perturb cellular protein trafficking leading to deficiency of the full-length protein at its target organelle and causing muscular dystrophy.

Dysferlin gets integrated into the membrane of the ER, but mechanistic details of this insertion are currently unknown. In recent years, a pathway has been identified, that mediates insertion of TA proteins into the ER and which is also involved in protein quality control (Favaloro et al., 2010; Payapilly and High, 2014; Rodrigo-Brenni et al., 2014; Stefanovic and Hegde, 2007; Vilardi et al., 2011; Yamamoto and Sakisaka, 2012). The dependence of the TA protein dysferlin on the TRC40/WRB insertion pathway in cardiomyocytes was analyzed in cooperation with Dr. Jhon Rivera-Monroy and Prof. Blanche Schwappach from the department of Molecular Biology, University Medical Center Göttingen. The ER membrane-located receptor component WRB was cardiac-specifically deleted in an inducible mouse model. This leads not only to a significant reduction of WRB protein level, but also the steady-state levels of other main pathway components, TRC40 and CAML, decrease upon WRB gene deletion resulting to complete disruption of the pathway (Rivera-Monroy et al., 2016). Cardiomyocytes were isolated from 8-week old mice and 2 weeks after gene knockout induction by administration of tamoxifen (Performed by Dr. Jhon Rivera-Monroy). Cells were analyzed with regard to dysferlin expression and localization by western blot and indirect immunofluorescence, respectively. Neither the steady-state protein level, nor the localization of dysferlin is affected by disruption of the TRC40/WRB pathway in ventricular cardiomyocytes. These results indicate a probable TRC40/WRB-independent trafficking of dysferlin in cardiomyocytes, although the missing effect on dysferlin upon TRC40/WRB disruption does not exclude that dysferlin might be targeted via this pathway to the ER. Alternative chaperone and insertion pathways have been identified previously, which operate in parallel and to some extent might compensate for the loss of each other (Abell et al., 2007; Ast et al., 2013; Aviram et al., 2016; Rabu et al., 
2008). TA proteins containing a transmembrane domain with comparably high hydrophobicity, like in the case of dysferlin, are suitable candidates for ER insertion via the TRC40/WRB pathway (Rabu et al., 2008). As TRC40/WRB disruption does not lead to a mislocalized or destabilized dysferlin pool, the hydrophobicity is not the only criterion which dictates whether a certain TA is an obligatory client for the TRC40/WRB pathway (Rivera-Monroy et al., 2016). Dysferlin has a very large $\mathrm{N}$-terminal domain upstream of the transmembrane domain incorporating seven $\mathrm{C} 2$ domains and several other domains which require proper folding and quality control already during the process of translation. This might be ensured by specialized cytosolic chaperones. BAG6, which is also a component of the cytosolic TRC40 chaperone complex, is additionally involved in quality control. Mislocalized proteins are BAG6dependently polyubiquitinated by the ubiquitin ligase RNF126 and subsequently degraded by the proteasome (Rodrigo-Brenni et al., 2014). It has been reported that the proteasome is involved in the degradation of wild-type dysferlin (Fujita et al., 2007). Thus, it is conceivable that the BAG6-mediated initiation of proteasomal degradation is one component of the quality control system necessary for proper dysferlin synthesis. In conclusion, dysferlin is Cterminally inserted into the membrane of the ER probably directly after its synthesis and this process does not depend on the TRC40/WRB integration pathway.

\subsection{4-Phenylbutyrate as potential therapeutic for the treatment of dysferlinopathy}

Dysferlin-deficiency is often associated with dysferlin mislocalization, instability and/or degradation due to mutations in the DYSF gene. In this study two missense mutants were analyzed with regard to possible therapeutic intervention. Mutation R959W is located in the C2D domain and is reported to cause structural changes in the dysferlin protein (EspinozaFonseca, 2016). Dysferlin harboring the mutation L1341P, which is located in the C2E domain, is prone to aggregation in the ER (Fujita et al., 2007). In this study, the steady-state protein level is decreased for both dysferlin variants compared to wild-type dysferlin. Treatment with PBA leads to an increased levels of wild-type, R959W and L1341P proteins with mutant R959W exceeding the basal wild-type level. Thus, PBA is a potent substance for the amelioration of reduced mutant dysferlin protein level in dysferlinopathy. There are several possible mechanisms by which PBA elevates the protein level of dysferlin variants. One is the general function of PBA as a chaperone (Cortez and Sim, 2014). The hydrophobic chain of PBA might bind to and shield hydrophobic regions of dysferlin variants, thereby facilitating accurate 
folding and probably reducing the unfolded protein response which would lead to protein degradation (Lindholm et al., 2017). This could explain the effect that not only mutant dysferlin variants, but also the wild-type dysferlin becomes stabilized. Dysferlin is a large protein making it plausible that folding errors occur also under normal conditions. Thus, PBA may assist in protein folding and thereby increase steady-state levels of dysferlin wild-type and mutants. Recently, the mode of action of PBA as a regulator of proteostasis was addressed by Ma and colleagues (Ma et al., 2017). They hypothesize that PBA affects trafficking from the ER to the Golgi via COPII-coated vesicles. Accordingly, PBA displaces the protein p24 from binding to COPII proteins and thereby reduces stringency of misfolded protein retention inside the ER (Ma et al., 2017). By this mechanism, dysferlin variants, which are partially ER-trapped under basal conditions, would be extruded from the ER by PBA. A distinct line of research has uncovered a role of PBA in inducing the expression of the 70-kDa heat shock protein (Hsp70), which is activated upon ER stress and binds to unfolded or misfolded proteins (Choo-Kang and Zeitlin, 2001). It was suggested that PBA induces Hsp70 expression via activation of elongator protein 2 (ELP2) and signal transducer and activator of transcription-3 (STAT-3). Hsp70 in turn mediates maturation and trafficking of mutated forms of cystic fibrosis transmembrane conductance regulator (CFTR), the cause for cystic fibrosis (Choo-Kang and Zeitlin, 2001; Suaud et al., 2011). Thus, stabilization of dysferlin R959W and L1341P steady-state protein level might also be mediated by induction of Hsp70 alleviating the degradation of these mutants. Additionally to a chaperone-mediated elevation of dysferlin protein, the function of PBA as histone deacetylase inhibitor might ameliorate reduced protein level by modulating cellular gene expression.

Several lines of evidence suggest that the deformation of membranes into elongated tubules during biogenesis of the T-tubule system is the primary function of dysferlin in the muscle fiber (Hofhuis et al., 2017). The induction of membrane tubules upon heterologous expression of dysferlin in non-muscle cells is considered as analogous to its physiological function. Thus, the ability to tubulate membranes in non-muscle cells can be used as a read-out for proper dysferlin function (Hofhuis et al., 2017). The dysferlin mutants R959W and L1341P were analyzed with regard to their functionality using this assay. Both mutants are incapable in the generation of membrane tubules when expressed in HeLa cells. R959W is partially colocalizing with the cis-Golgi marker giantin (Linstedt and Hauri, 1993; Puthenveedu and Linstedt, 2001). As the overlap was not complete, it is conceivable that this mutant rather is trapped in the medial or trans Golgi compartment. This localization was confirmed in $\mathrm{C} 2 \mathrm{C} 12$ myotubes. As 
reported, L1341P is found to be retained in the ER (Fujita et al., 2007). Taking into consideration that both mutants harbor only a single amino acid substitution, which obviously affects protein trafficking, it is plausible that they might be functional when localized at the appropriate cellular position. As steady-state protein level is stabilized by PBA, also the effect on mutant localization was analyzed. Wild-type and L1341P localization is unaffected by PBA treatment. Mutant R595W is mainly localizing to the Golgi compartment, but also the induction of membrane tubules is detectable in a considerable proportion of cells. Consequently, the elevation of R959W steady-state level by PBA-mediated improvement of trafficking leads to some extent to correct localization of mutant dysferlin and partial restoration of its function as membrane modulator. In contrast to R959W, the mutant L1341P does not lead to detectable generation of membrane tubules even upon PBA treatment. This might be explained by the different steady-state levels that are reached by PBA. The level of R959W exceeds the basal level of wild-type dysferlin. These results indicate that even higher amounts of mutant R959W upon PBA compared to nontreated wild-type dysferlin, only partially restore the function of R959W because of structural changes due to the amino acid change. Steady-state levels of L1341P upon PBA treatment are still lower than levels of untreated wild-type dysferlin. Thus, either the improved trafficking for the mutant is not sufficient to restore tubulation in the cell system, or the mutation leads not only to retention inside the ER but also to loss of function. Assuming that dysferlin follows the secretory pathway to traffic from the ER through the Golgi to its target membrane (Azakir et al., 2010), the mutant L1341 gets trapped at an earlier stage of this route than the mutant R959W making it putatively easier for the latter to be extruded by pharmacological intervention. Further investigation is necessary to assess whether PBA might have an ameliorating effect on the functionality of L1341P mutated dysferlin under different conditions or other systems. In conclusion, PBA is a potent pharmacological substance for the restoration of dysferlin function, as shown for the mutant R959W. To determine, whether the functional rescue observed in a cell culture system can be confirmed in vivo, the efficiency of PBA treatment in dysferlin-deficient animal models harboring point mutations needs to be investigated regard to progression of muscular dystrophy. PBA is considered as a safe and well-tolerable compound with only mild and reversible adverse effects (Mokhtarani et al., 2013; Perrine et al., 2011). Though, effects on the amino acid homeostasis, caused by the metabolism of PBA, with decreased blood plasma levels of glutamine and branch-chained amino acids valine, leucine, isoleucine, have been reported (Brunetti-Pierri et al., 2011; Burrage et al., 2014; Darmaun et al., 1998; Scaglia et al., 2004). Therefore, a supplementation with glutamine and 
branch-chained amino acids was recently recommended for the clinical use of PBA (Holecek et al., 2017). PBA is under investigation for the treatment of several diseases and might also be a potent pharmacological therapeutic for dysferlinopathy. As PBA is already FDA-approved for the treatment of children with urea cycle disorders, it might be feasible to perform clinical trials investigating PBA as treatment for dysferlinopathy in the near future.

\subsection{Therapeutic modulation of dysferlin expression by translational readthrough}

$25 \%$ of recurrent mutations in the DYSF gene that cause dysferlin-deficiency and the development of muscular dystrophy are mutations leading to the generation of termination codons (UMD-DYSF mutations database, http://www.umd.be/DYSF/W_DYSF/mutation.html). These stop signals cause mRNA instability and nonsense-mediated mRNA decay, or the premature termination of translation resulting in the production of truncated unfunctional proteins that are prone to degradation (Yang et al., 2016). Aminoglycosides can provoke the binding of a near-cognate aminoacyl-tRNA instead of a release factor at premature termination codons (PTCs) by interacting with conserved ribosomal RNA in the ribosomal decoding center (Wimberly et al., 2000). This leads to the incorporation of an amino acid, continuation of translation and synthesis of the full-length protein (Lee and Dougherty, 2012). This approach is approved for the treatment of cystic fibrosis patients and is under investigation for other genetic diseases with premature stop codons, such as Duchenne muscular dystrophy (Barton-Davis et al., 1999; Lee and Dougherty, 2012; Loufrani et al., 2004). The in vivo use of aminoglycosides gentamicin and G418 as readthrough inducers is accompanied by severe adverse effects of those drugs. Oto- and nephrotoxicity are the most critical side effects reported (Smyth, 2010). Therefore, a prediction for the treatability of certain PTCs by aminoglycosides would be beneficial for the patients to avoid ineffective readthrough induction and severe side effects. This concept was addressed by the treatment of cystic fibrosis and Duchenne muscular dystrophy (Bidou et al., 2004; Howard et al., 2000; Sermet-Gaudelus et al., 2007). In a systematic analysis, the basal and G418-induced readthrough of the 18 recurrent nonsense codons known in dysferlinopathy patients was assessed in this study. For this purpose, a very sensitive dual reporter expressing TagRFP and EGFP fluorescent protein genes upstream and downstream of an SCC, respectively, was used. Interestingly, a variable level of basal and G418-induced readthrough was detected indicating that at certain SCCs translational readthrough is more likely to occur than at others. Previous 
work of our group showed that only the stop codon itself and the adjacent nucleotides have a dominant impact on the basal readthrough propensity (Schueren et al., 2014). The estimation of readthrough propensity for all SCCS of the human genome by an in silico regression model lead to the identification of a 6-nucleotide consensus motif for high readthrough tendency: UGA CUA (stop codon in bold, positions 1-6, (Schueren et al., 2014). The stop codon UGA is reported to be most leaky with regard to readthrough (Howard et al., 2000; Schueren et al., 2014; Tate et al., 1996). All of the five patient mutations with SCCs yielding the highest induced readthrough levels in our assay (R1038X, S1173X, Q1269X, C1398X, W1968X) harbor the UGA stop codon (table). The high-readthrough consensus motif (Schueren et al., 2014) indicates that a cytosine $(C)$ at position +4 correlates with high basal readthrough, but also the readthrough level achieved by induction with aminoglycosides is positively influenced by this nucleotide at the respective position (Howard et al., 2000; Keeling and Bedwell, 2002; Manuvakhova et al., 2000). Based on their results using a dual reporter assay for the assessment of readthrough induction, Howard and colleagues have graded the four nucleotides at position +4 according to their positive influence on readthrough and showed that $\mathrm{C}$ is the most powerful nucleotide following by uracil (U). The five SCCs with the highest induced readthrough in our assay harbor either a C (R1038X, Q1269X, C1398X) or a U (S1173X, W1968X). Therefore, the results obtained for the SCCS of DYSF nonsense mutations are in concordance with previously reported data. Schueren et al. suggested that a guanine (G) at position +7 might also contribute to high basal readthrough (Schueren et al., 2014). Interestingly, all of the five SCCs with highest G418-induced readthrough have a C at position +7. Thus, a $G$ at this position may correlate with high readthrough under basal conditions, but when aminoglycosides are bound to the ribosome a $C$ at position +7 of the mRNA may be more beneficial for readthrough induction. Howard and colleagues proposed an inverse correlation between the induced readthrough level and the stringency of translational termination in the absence of aminoglycosides (Howard et al., 2000). This observation was not reflected by this study as no correlation was observed between basal and induced readthrough levels. The results of this study indicate that basal readthrough of a given SCC is positively influenced by a distinct nucleotide composition then readthrough upon induction with aminoglycosides. This hypothesis is supported by the observation that a $\mathrm{G}$ at position +7 correlates with high basal readthrough (Schueren et al., 2014), but a C at the same position is located in all of the five SCCS with highest induced readthrough in this study. The results obtained by analysis of DYSF nonsense SCCS indicate that the benefit of aminoglycoside treatment would be highly variable depending on the mutation. Thus, the question arises, 
whether knowledge of readthrough levels derived from a cell culture system can be translated to the therapeutic success in clinics. The comparison of readthrough induction in a dual reporter assay and the animal model of Duchenne muscular dystrophy by Bidou and colleagues led to the conclusion that results obtained in a cell culture system cannot be transferred into in vivo systems (Bidou et al., 2004). The work of Sermet-Gaudelus and colleagues contradicted this conclusion (Sermet-Gaudelus et al., 2007). They analyzed readthrough induction of SCCS from all nonsense mutations found in cystic fibrosis patients by a dual reporter assay and compared these results to the beneficial effects of aminoglycoside treatment of cystic fibrosis patients. The readthrough levels obtained in the reporter assay correlate with the production of the full-length protein in nasal epithelial cells of the treated patients suggesting that a dual reporter assay used in a cell culture system has the potency to predict therapeutic success (Sermet-Gaudelus et al., 2007). Another study analyzed the production of full-length protein in patients treated with aminoglycosides and their initial level of the targeted transcript. Accordingly, patients with high levels of transcript prior to treatment showed better response to readthrough therapy. This indicates that the process of nonsense-mediated mRNA decay and therewith the level of transcript should be considered for each patient (Linde et al., 2007). In conclusion, the sensitive dual reporter assay used in this study to assess basal and G418-induced readthrough of patient SCCs may be suitable as a prediction for the treatability of dysferlinopathy patients with nonsense mutations. According to the obtained results upon G418 treatment, patients harboring the mutations R1038X, S1173X, Q1269X, C1398X, W1968X may be suitable candidates for the treatment with aminoglycosides. 


\section{References}

Aartsma-Rus, A., Singh, K.H.K., Fokkema, I.F.A.C., Ginjaar, I.B., van Ommen, G.-J., den Dunnen, J.T., and van der Maarel, S.M. (2010). Therapeutic exon skipping for dysferlinopathies? Eur. J. Hum. Genet. EJHG 18, 889-894.

Abell, B.M., Rabu, C., Leznicki, P., Young, J.C., and High, S. (2007). Post-translational integration of tail-anchored proteins is facilitated by defined molecular chaperones. J. Cell Sci. 120, 17431751.

Achanzar, W.E., and Ward, S. (1997). A nematode gene required for sperm vesicle fusion. J. Cell Sci. 110 ( Pt 9, 1073-1081.

Adamus, G., Zam, Z.S., Arendt, A., Palczewski, K., McDowell, J.H., and Hargrave, P.A. (1991). Anti-rhodopsin monoclonal antibodies of defined specificity: characterization and application. Vision Res. 31, 17-31.

Aebi, M. (2013). N-linked protein glycosylation in the ER. Biochim. Biophys. Acta BBA - Mol. Cell Res. 1833, 2430-2437.

Allen, D.G., Gervasio, O.L., Yeung, E.W., and Whitehead, N.P. (2010). Calcium and the damage pathways in muscular dystrophy. Can. J. Physiol. Pharmacol. 88, 83-91.

Ampong, B.N., Imamura, M., Matsumiya, T., Yoshida, M., and Takeda, S. (2005). Intracellular localization of dysferlin and its association with the dihydropyridine receptor. Acta Myol. Myopathies Cardiomyopathies Off. J. Mediterr. Soc. Myol. Ed. Gaetano Conte Acad. Study Striated Muscle Dis. 24, 134-144.

Anderson, L. V, Davison, K., Moss, J. a, Young, C., Cullen, M.J., Walsh, J., Johnson, M. a, Bashir, R., Britton, S., Keers, S., et al. (1999). Dysferlin is a plasma membrane protein and is expressed early in human development. Hum. Mol. Genet. 8, 855-861.

Arganda-Carreras, I., Fernández-González, R., Muñoz-Barrutia, A., and Ortiz-De-Solorzano, C. (2010). 3D reconstruction of histological sections: Application to mammary gland tissue. Microsc. Res. Tech. 73, 1019-1029.

Ashcroft, F.M. (1991). Ca2+ channels and excitation-contraction coupling. Curr. Opin. Cell Biol. 3, 671-675.

Ast, T., Cohen, G., and Schuldiner, M. (2013). A Network of Cytosolic Factors Targets SRPIndependent Proteins to the Endoplasmic Reticulum. Cell 152, 1134-1145.

Aviram, N., Ast, T., Costa, E.A., Arakel, E.C., Chuartzman, S.G., Jan, C.H., Haßdenteufel, S., Dudek, J., Jung, M., Schorr, S., et al. (2016). The SND proteins constitute an alternative targeting route to the endoplasmic reticulum. Nature 540, 134-138.

Azakir, B.A., Fulvio, S.D., Therrien, C., and Sinnreich, M. (2010). Dysferlin Interacts with Tubulin and Microtubules in Mouse Skeletal Muscle. PLOS ONE 5, e10122.

Azakir, B.A., Di Fulvio, S., Salomon, S., Brockhoff, M., Therrien, C., and Sinnreich, M. (2012). Modular dispensability of dysferlin C2 domains reveals rational design for mini-dysferlin molecules. J. Biol. Chem. 287, 27629-27636. 
Bansal, D., and Campbell, K.P. (2004). Dysferlin and the plasma membrane repair in muscular dystrophy. Trends Cell Biol. 14, 206-213.

Bansal, D., Miyake, K., Vogel, S.S., Groh, S., Chen, C.-C., Williamson, R., McNeil, P.L., and Campbell, K.P. (2003). Defective membrane repair in dysferlin-deficient muscular dystrophy. $423,168-172$.

Barthélémy, F., Wein, N., Krahn, M., Lévy, N., and Bartoli, M. (2011). Translational research and therapeutic perspectives in dysferlinopathies. Mol. Med. Camb. Mass 17, 875-882.

Barthélémy, F., Blouin, C., Wein, N., Mouly, V., Courrier, S., Dionnet, E., Kergourlay, V., Mathieu, Y., Garcia, L., Butler-Browne, G., et al. (2015). Exon 32 Skipping of Dysferlin Rescues Membrane Repair in Patients' Cells. J. Neuromuscul. Dis. 2, 281-290.

Barton-Davis, E.R., Cordier, L., Shoturma, D.I., Leland, S.E., and Sweeney, H.L. (1999). Aminoglycoside antibiotics restore dystrophin function to skeletal muscles of mdx mice. J. Clin. Invest. 104, 375-381.

Bashir, R., Britton, S., Strachan, T., Keers, S., Vafiadaki, E., Lako, M., Richard, I., Marchand, S., Bourg, N., Argov, Z., et al. (1998). A gene related to Caenorhabditis elegans spermatogenesis factor fer-1 is mutated in limb-girdle muscular dystrophy type 2B. Nat. Genet. 20, 37-42.

Bauerfeind, R., Takei, K., and De Camilli, P. (1997). Amphiphysin I Is Associated with Coated Endocytic Intermediates and Undergoes Stimulation-dependent Dephosphorylation in Nerve Terminals. J Biol Chem 272, 30984-30992.

Bedwell, D.M., Kaenjak, a, Benos, D.J., Bebok, Z., Bubien, J.K., Hong, J., Tousson, a, Clancy, J.P., and Sorscher, E.J. (1997). Suppression of a CFTR premature stop mutation in a bronchial epithelial cell line. Nat. Med. 3, 1280-1284.

Bell, R.M., Mocanu, M.M., and Yellon, D.M. (2011). Retrograde heart perfusion: The Langendorff technique of isolated heart perfusion. J. Mol. Cell. Cardiol. 50, 940-950.

Bensley, J.G., Matteo, R.D., Harding, R., and Black, M.J. (2016). Three-dimensional direct measurement of cardiomyocyte volume, nuclearity, and ploidy in thick histological sections. Sci. Rep. 6, srep23756.

Betz, R.C., Schoser, B.G., Kasper, D., Ricker, K., Ramírez, A., Stein, V., Torbergsen, T., Lee, Y.A., Nöthen, M.M., Wienker, T.F., et al. (2001). Mutations in CAV3 cause mechanical hyperirritability of skeletal muscle in rippling muscle disease. Nat. Genet. 28, 218-219.

Bezanilla, F., Caputo, C., Gonzalez-Serratos, H., and Venosa, R.A. (1972). Sodium dependence of the inward spread of activation in isolated twitch muscle fibres of the frog. J. Physiol. 223, 507-523.

Bidou, L., Hatin, I., Perez, N., Allamand, V., Panthier, J.-J., and Rousset, J.-P. (2004). Premature stop codons involved in muscular dystrophies show a broad spectrum of readthrough efficiencies in response to gentamicin treatment. Gene Ther. 11, 619-627.

Böhm, J., Yiş, U., Ortaç, R., Cakmakçı, H., Kurul, S.H., Dirik, E., and Laporte, J. (2010). Case report of intrafamilial variability in autosomal recessive centronuclear myopathy associated to a novel BIN1 stop mutation. Orphanet J. Rare Dis. 5, 35. 
Böhm, J., Vasli, N., Maurer, M., Cowling, B.S., Cowling, B., Shelton, G.D., Kress, W., Toussaint, A., Prokic, I., Schara, U., et al. (2013). Altered splicing of the BIN1 muscle-specific exon in humans and dogs with highly progressive centronuclear myopathy. PLoS Genet. 9, e1003430.

Böhm, J., Biancalana, V., Malfatti, E., Dondaine, N., Koch, C., Vasli, N., Kress, W., Strittmatter, M., Taratuto, A.L., Gonorazky, H., et al. (2014). Adult-onset autosomal dominant centronuclear myopathy due to BIN1 mutations. Brain J. Neurol. 137, 3160-3170.

Bolte, S., and Cordelières, F.P. (2006). A guided tour into subcellular colocalization analysis in light microscopy. J. Microsc. 224, 213-232.

Boncompagni, S., d'Amelio, L., Fulle, S., Fanò, G., and Protasi, F. (2006). Progressive disorganization of the excitation-contraction coupling apparatus in aging human skeletal muscle as revealed by electron microscopy: a possible role in the decline of muscle performance. J. Gerontol. A. Biol. Sci. Med. Sci. 61, 995-1008.

Bondulich, M.K., Guo, T., Meehan, C., Manion, J., Rodriguez Martin, T., Mitchell, J.C., Hortobagyi, T., Yankova, N., Stygelbout, V., Brion, J.-P., et al. (2016). Tauopathy induced by low level expression of a human brain-derived tau fragment in mice is rescued by phenylbutyrate. Brain J. Neurol. 139, 2290-2306.

Borgese, N., Colombo, S., and Pedrazzini, E. (2003a). The tale of tail-anchored proteins: coming from the cytosol and looking for a membrane. J. Cell Biol. 161, 1013-1019.

Borgese, N., Brambillasca, S., Soffientini, P., Yabal, M., and Makarow, M. (2003b). Biogenesis of tail-anchored proteins. Biochem. Soc. Trans. 31, 1238-1242.

Braun, D., and Schweizer, U. (2017). The Chemical Chaperone Phenylbutyrate Rescues MCT8 Mutations Associated With Milder Phenotypes in Patients With Allan-Herndon-Dudley Syndrome. Endocrinology 158, 678-691.

Brunetti-Pierri, N., Lanpher, B., Erez, A., Ananieva, E.A., Islam, M., Marini, J.C., Sun, Q., Yu, C., Hegde, M., Li, J., et al. (2011). Phenylbutyrate therapy for maple syrup urine disease. Hum. Mol. Genet. 20, 631-640.

Brusilow, S.W. (1991). Phenylacetylglutamine may replace urea as a vehicle for waste nitrogen excretion. Pediatr. Res. 29, 147-150.

Burrage, L.C., Jain, M., Gandolfo, L., Lee, B.H., Members of the Urea Cycle Disorders Consortium, and Nagamani, S.C.S. (2014). Sodium phenylbutyrate decreases plasma branchedchain amino acids in patients with urea cycle disorders. Mol. Genet. Metab. 113, 131-135.

Cai, C., Masumiya, H., Weisleder, N., Matsuda, N., Nishi, M., Hwang, M., Ko, J.-K., Lin, P., Thornton, A., Zhao, X., et al. (2009). MG53 nucleates assembly of cell membrane repair machinery. Nat. Cell Biol. 11, 56-64.

Cannell, M.B., Crossman, D.J., and Soeller, C. (2006). Effect of changes in action potential spike configuration, junctional sarcoplasmic reticulum micro-architecture and altered t-tubule structure in human heart failure. J. Muscle Res. Cell Motil. 27, 297-306.

Cao, A.-L., Wang, L., Chen, X., Wang, Y.-M., Guo, H.-J., Chu, S., Liu, C., Zhang, X.-M., and Peng, W. (2016). Ursodeoxycholic acid and 4-phenylbutyrate prevent endoplasmic reticulum stress- 
induced podocyte apoptosis in diabetic nephropathy. Lab. Investig. J. Tech. Methods Pathol. $96,610-622$.

Carducci, M.A., Gilbert, J., Bowling, M.K., Noe, D., Eisenberger, M.A., Sinibaldi, V., Zabelina, Y., Chen, T.L., Grochow, L.B., and Donehower, R.C. (2001). A Phase I clinical and pharmacological evaluation of sodium phenylbutyrate on an 120-h infusion schedule. Clin. Cancer Res. Off. J. Am. Assoc. Cancer Res. 7, 3047-3055.

Casson, J., McKenna, M., and High, S. (2016). On the road to nowhere: cross-talk between post-translational protein targeting and cytosolic quality control. Biochem. Soc. Trans. 44, 796-801.

Cenacchi, G., Fanin, M., De Giorgi, L.B., and Angelini, C. (2005). Ultrastructural changes in dysferlinopathy support defective membrane repair mechanism. J. Clin. Pathol. 58, 190-195.

Chase, T.H., Cox, G.A., Burzenski, L., Foreman, O., and Shultz, L.D. (2009). Dysferlin Deficiency and the Development of Cardiomyopathy in a Mouse Model of Limb-Girdle Muscular Dystrophy 2B. Am. J. Pathol. 175, 2299-2308.

Chen, B., Guo, A., Zhang, C., Chen, R., Zhu, Y., Hong, J., Kutschke, W., Zimmerman, K., Weiss, R.M., Zingman, L., et al. (2013). Critical roles of junctophilin-2 in T-tubule and excitationcontraction coupling maturation during postnatal development. Cardiovasc. Res. 100, 54-62.

Chen, B., Zhang, C., Guo, A., and Song, L.-S. (2015). In situ single photon confocal imaging of cardiomyocyte T-tubule system from Langendorff-perfused hearts. Front. Physiol. 6.

Chiu, Y.-H., Hornsey, M. a, Klinge, L., Jørgensen, L.H., Laval, S.H., Charlton, R., Barresi, R., Straub, V., Lochmüller, H., and Bushby, K. (2009). Attenuated muscle regeneration is a key factor in dysferlin-deficient muscular dystrophy. Hum. Mol. Genet. 18, 1976-1989.

Choo-Kang, L.R., and Zeitlin, P.L. (2001). Induction of HSP70 promotes $\triangle$ F508 CFTR trafficking. Am. J. Physiol. - Lung Cell. Mol. Physiol. 281, L58-L68.

Claeys, K.G., Maisonobe, T., Böhm, J., Laporte, J., Hezode, M., Romero, N.B., Brochier, G., Bitoun, M., Carlier, R.Y., and Stojkovic, T. (2010). Phenotype of a patient with recessive centronuclear myopathy and a novel BIN1 mutation. Neurology 74, 519-521.

Collins, A.F., Pearson, H.A., Giardina, P., McDonagh, K.T., Brusilow, S.W., and Dover, G.J. (1995). Oral sodium phenylbutyrate therapy in homozygous beta thalassemia: a clinical trial. Blood 85, 43-49.

Cortez, L., and Sim, V. (2014). The therapeutic potential of chemical chaperones in protein folding diseases. Prion 8, 197-202.

Coussens, L., Parker, P., Rhee, L., Yang-Feng, T., Chen, E., Waterfield, M., Francke, U., and Ullrich, A. (1986). Multiple, distinct forms of bovine and human protein kinase $C$ suggest diversity in cellular signaling pathways. Science $233,859-866$.

Cuadrado-Tejedor, M., García-Osta, A., Ricobaraza, A., Oyarzabal, J., and Franco, R. (2011). Defining the mechanism of action of 4-phenylbutyrate to develop a small-molecule-based therapy for Alzheimer's disease. Curr. Med. Chem. 18, 5545-5553. 
Darmaun, D., Welch, S., Rini, A., Sager, B.K., Altomare, A., and Haymond, M.W. (1998). Phenylbutyrate-induced glutamine depletion in humans: effect on leucine metabolism. Am. J. Physiol. 274, E801-807.

David, C., McPherson, P.S., Mundigl, O., and de Camilli, P. (1996). A role of amphiphysin in synaptic vesicle endocytosis suggested by its binding to dynamin in nerve terminals. Proc. Natl. Acad. Sci. U. S. A. 93, 331-335.

Davis, D.B., Doherty, K.R., Delmonte, A.J., and McNally, E.M. (2002). Calcium-sensitive phospholipid binding properties of normal and mutant ferlin C2 domains. J. Biol. Chem. 277, 22883-22888.

Demonbreun, A.R., Fahrenbach, J.P., Deveaux, K., Earley, J.U., Pytel, P., and McNally, E.M. (2011). Impaired muscle growth and response to insulin-like growth factor 1 in dysferlinmediated muscular dystrophy. Hum. Mol. Genet. 20, 779-789.

Demonbreun, A.R., Rossi, A.E., Alvarez, M.G., Swanson, K.E., Deveaux, H.K., Earley, J.U., Hadhazy, M., Vohra, R., Walter, G. a, Pytel, P., et al. (2014). Dysferlin and myoferlin regulate transverse tubule formation and glycerol sensitivity. Am. J. Pathol. 184, 248-259.

DiFranco, M., Capote, J., and Vergara, J.L. (2005). Optical imaging and functional characterization of the transverse tubular system of mammalian muscle fibers using the potentiometric indicator di-8-ANEPPS. J. Membr. Biol. 208, 141-153.

Dillingham, B.C., Benny Klimek, M.E., Gernapudi, R., Rayavarapu, S., Gallardo, E., Van der Meulen, J.H., Jordan, S., Ampong, B., Gordish-Dressman, H., Spurney, C.F., et al. (2015). Inhibition of inflammation with celastrol fails to improve muscle function in dysferlin-deficient A/J mice. J. Neurol. Sci. 356, 157-162.

Doherty, K.R., Cave, A., Davis, D.B., Delmonte, A.J., Posey, A., Earley, J.U., Hadhazy, M., and McNally, E.M. (2005). Normal myoblast fusion requires myoferlin. Dev. Camb. Engl. 132, 55655575 .

Ellgaard, L., McCaul, N., Chatsisvili, A., and Braakman, I. (2016). Co- and Post-Translational Protein Folding in the ER. Traffic 17, 615-638.

Espinoza-Fonseca, L.M. (2016). Pathogenic mutation R959W alters recognition dynamics of dysferlin inner DysF domain.pdf. Mol Biosyst 12, 973-981.

Fabiato, A. (1983). Calcium-induced release of calcium from the cardiac sarcoplasmic reticulum. Am. J. Physiol. 245, C1-14.

Favaloro, V., Spasic, M., Schwappach, B., and Dobberstein, B. (2008). Distinct targeting pathways for the membrane insertion of tail-anchored (TA) proteins. J. Cell Sci. 121, 18321840.

Favaloro, V., Vilardi, F., Schlecht, R., Mayer, M.P., and Dobberstein, B. (2010). Asna1/TRC40mediated membrane insertion of tail-anchored proteins. J. Cell Sci. 123, 1522-1530.

Fawcett, D.W., and McNutt, N.S. (1969). The ultrastructure of the cat myocardium. I. Ventricular papillary muscle. J. Cell Biol. 42, 1-45.

Flanigan, K.M. (2012). The muscular dystrophies. Semin. Neurol. 32, 255-263. 
Flucher, B.E., Takekura, H., and Franzini-Armstrong, C. (1993). Development of the excitationcontraction coupling apparatus in skeletal muscle: association of sarcoplasmic reticulum and transverse tubules with myofibrils. Dev. Biol. 160, 135-147.

Forbes, M.S., Hawkey, L.A., and Sperelakis, N. (1984). The transverse-axial tubular system (tats) of mouse myocardium: Its morphology in the developing and adult animal. Am. J. Anat. 170, 143-162.

Franzini-Armstrong, C. (1991). Simultaneous maturation of transverse tubules and sarcoplasmic reticulum during muscle differentiation in the mouse. Dev. Biol. 146, 353-363.

Franzini-armstrong, C., and Porter, K.R. (1964). SARCOLEMMAL INVAGINATIONS CONSTITUTING THE T SYSTEM IN FISH MUSCLE FIBERS. J. Cell Biol. 22, 675-696.

Franzini-Armstrong, C., Landmesser, L., and Pilar, G. (1975). Size and shape of transverse tubule openings in frog twitch muscle fibers. J. Cell Biol. 64, 493-497.

Fu, Y., Shaw, S.A., Naami, R., Vuong, C.L., Basheer, W.A., Guo, X., and Hong, T. (2016). Isoproterenol Promotes Rapid Ryanodine Receptor Movement to Bridging Integrator 1 (BIN1)Organized Dyads. Circulation 133, 388-397.

Fugier, C., Klein, A.F., Hammer, C., Vassilopoulos, S., Ivarsson, Y., Toussaint, A., Tosch, V., Vignaud, A., Ferry, A., Messaddeq, N., et al. (2011). Misregulated alternative splicing of BIN1 is associated with $\mathrm{T}$ tubule alterations and muscle weakness in myotonic dystrophy. Nat. Med. $17,720-725$.

Fujita, E., Kouroku, Y., Isoai, A., Kumagai, H., Misutani, A., Matsuda, C., Hayashi, Y.K., and Momoi, T. (2007). Two endoplasmic reticulum-associated degradation (ERAD) systems for the novel variant of the mutant dysferlin: ubiquitin/proteasome $\operatorname{ERAD}(\mathrm{I})$ and autophagy/lysosome ERAD(II). Hum. Mol. Genet. 16, 618-629.

Fuson, K., Rice, A., Mahling, R., Snow, A., Nayak, K., Shanbhogue, P., Meyer, A.G., Redpath, G.M.I., Hinderliter, A., Cooper, S.T., et al. (2014). Alternate splicing of dysferlin C2A confers $\mathrm{Ca}^{2+}$-dependent and $\mathrm{Ca}^{2+}$-independent binding for membrane repair. Struct. Lond. Engl. 1993 $22,104-115$.

Galbiati, F., Engelman, J.A., Volonte, D., Zhang, X.L., Minetti, C., Li, M., Hou, H., Kneitz, B., Edelmann, W., and Lisanti, M.P. (2001). Caveolin-3 null mice show a loss of caveolae, changes in the microdomain distribution of the dystrophin-glycoprotein complex, and t-tubule abnormalities. J. Biol. Chem. 276, 21425-21433.

Gallardo, E., Rojas-García, R., de Luna, N., Pou, A., Brown, R.H., and Illa, I. (2001). Inflammation in dysferlin myopathy: immunohistochemical characterization of 13 patients. Neurology 57, 2136-2138.

Golub, T., and Caroni, P. (2005). PI(4,5)P2-dependent microdomain assemblies capture microtubules to promote and control leading edge motility. J. Cell Biol. 169, 151-165.

Gómez, A.M., Valdivia, H.H., Cheng, H., Lederer, M.R., Santana, L.F., Cannell, M.B., McCune, S.A., Altschuld, R.A., and Lederer, W.J. (1997). Defective excitation-contraction coupling in experimental cardiac hypertrophy and heart failure. Science $276,800-806$. 
Han, J., Wu, H., Wang, Q., and Wang, S. (2013). Morphogenesis of T-tubules in heart cells: the role of junctophilin-2. Sci. China Life Sci. 56, 647-652.

Han, R., Bansal, D., Miyake, K., Muniz, V.P., Weiss, R.M., McNeil, P.L., and Campbell, K.P. (2007). Dysferlin-mediated membrane repair protects the heart from stress-induced left ventricular injury. J. Clin. Invest. 117, 1805-1813.

Harris, E., Bladen, C.L., Mayhew, A., James, M., Bettinson, K., Moore, U., Smith, F.E., Rufibach, L., Cnaan, A., Bharucha-Goebel, D.X., et al. (2016). The Clinical Outcome Study for dysferlinopathy. Neurol. Genet. 2.

Hattori, H., Nagata, E., Oya, Y., Takahashi, T., Aoki, M., Ito, D., and Suzuki, N. (2007). A novel compound heterozygous dysferlin mutation in Miyoshi myopathy siblings responding to dantrolene. Eur. J. Neurol. 14, 1288-1291.

Hayashi, T., Arimura, T., Ueda, K., Shibata, H., Hohda, S., Takahashi, M., Hori, H., Koga, Y., Oka, N., Imaizumi, T., et al. (2004). Identification and functional analysis of a caveolin-3 mutation associated with familial hypertrophic cardiomyopathy. Biochem. Biophys. Res. Commun. 313, 178-184.

Hegde, R.S., and Keenan, R.J. (2011). Tail-anchored membrane protein insertion into the endoplasmic reticulum. Nat. Rev. Mol. Cell Biol. 12, 787-798.

Heinzel, F.R., Bito, V., Biesmans, L., Wu, M., Detre, E., von Wegner, F., Claus, P., Dymarkowski, S., Maes, F., Bogaert, J., et al. (2008). Remodeling of T-tubules and reduced synchrony of Ca2+ release in myocytes from chronically ischemic myocardium. Circ. Res. 102, 338-346.

Helenius, A., and Aebi, M. (2004). Roles of N-Linked Glycans in the Endoplasmic Reticulum.

Hidalgo, C., Carrasco, M.A., Magendzo, K., and Jaimovich, E. (1986). Phosphorylation of phosphatidylinositol by transverse tubule vesicles and its possible role in excitationcontraction coupling. FEBS Lett. 202, 69-73.

High, S., and Abell, B.M. (2004). Tail-anchored protein biosynthesis at the endoplasmic reticulum: the same but different. Biochem. Soc. Trans. 32, 659-662.

Hofgaard, J.P., Banach, K., Mollerup, S., Jørgensen, H.K., Olesen, S.P., Holstein-Rathlou, N.-H., and Nielsen, M.S. (2008). Phosphatidylinositol-bisphosphate regulates intercellular coupling in cardiac myocytes. Pflugers Arch. 457, 303-313.

Hofhuis, J., Bersch, K., Büssenschütt, R., Drzymalski, M., Liebetanz, D., Nikolaev, V.O., Wagner, S., Maier, L.S., Gärtner, J., Klinge, L., et al. (2017a). Dysferlin mediates membrane tubulation and links T-tubule biogenesis to muscular dystrophy. J Cell Sci jcs.198861.

Hofhuis, J., Dieterle, S., George, R., Schueren, F., and Thoms, S. (2017b). Dual Reporter Systems for the Analysis of Translational Readthrough in Mammals. Methods Mol. Biol. Clifton NJ 1595, 81-92.

Holecek, M., Vodenicarovova, M., and Siman, P. (2017). Acute effects of phenylbutyrate on glutamine, branched-chain amino acid and protein metabolism in skeletal muscles of rats. Int. J. Exp. Pathol. 
Holtzer, H., and Abbott, J. (1958). Contraction of glycerinated embryonic myoblasts. Anat. Rec. $131,417-428$.

Hong, T., and Shaw, R.M. (2017). Cardiac T-Tubule Microanatomy and Function. Physiol. Rev. 97, 227-252.

Hong, T., Yang, H., Zhang, S.-S., Cho, H.C., Kalashnikova, M., Sun, B., Zhang, H., Bhargava, A., Grabe, M., Olgin, J., et al. (2014). Cardiac BIN1 folds T-tubule membrane, controlling ion flux and limiting arrhythmia. Nat. Med. 20, 624-632.

Hong, T.-T., Smyth, J.W., Gao, D., Chu, K.Y., Vogan, J.M., Fong, T.S., Jensen, B.C., Colecraft, H.M., and Shaw, R.M. (2010). BIN1 Localizes the L-Type Calcium Channel to Cardiac T-Tubules. PLoS Biol. 8.

Hong, T.-T., Smyth, J.W., Chu, K.Y., Vogan, J.M., Fong, T.S., Jensen, B.C., Fang, K., Halushka, M.K., Russell, S.D., Colecraft, H., et al. (2012). BIN1 is reduced and Cav1.2 trafficking is impaired in human failing cardiomyocytes. Heart Rhythm 9, 812-820.

Howard, M., Frizzell, R. a, and Bedwell, D.M. (1996). Aminoglycoside antibiotics restore CFTR function by overcoming premature stop mutations. Nat. Med. 2, 467-469.

Howard, M.T., Shirts, B.H., Petros, L.M., Flanigan, K.M., Gesteland, R.F., and Atkins, J.F. (2000). Sequence specificity of aminoglycoside-induced stop condon readthrough: potential implications for treatment of Duchenne muscular dystrophy. Ann. Neurol. 48, 164-169.

Iannitti, T., and Palmieri, B. (2011). Clinical and Experimental Applications of Sodium Phenylbutyrate. Drugs RD 11, 227-249.

Ibrahim, M., Gorelik, J., Yacoub, M.H., and Terracciano, C.M. (2011). The structure and function of cardiac t-tubules in health and disease. Proc. R. Soc. B Biol. Sci. 278, 2714-2723.

Illa, I., Serrano-Munuera, C., Gallardo, E., Lasa, A., Rojas-García, R., Palmer, J., Gallano, P., Baiget, M., Matsuda, C., and Brown, R.H. (2001). Distal anterior compartment myopathy: a dysferlin mutation causing a new muscular dystrophy phenotype. Ann. Neurol. 49, 130-134.

Ishikawa, H. (1968). Formation of elaborate networks of T-system tubules in cultured skeletal muscle with special reference to the T-system formation. J. Cell Biol. 38, 51-66.

Itoh, T., and Takenawa, T. (2004). Regulation of endocytosis by phosphatidylinositol 4,5bisphosphate and ENTH proteins. Curr. Top. Microbiol. Immunol. 282, 31-47.

Johnson, N., Powis, K., and High, S. (2013). Post-translational translocation into the endoplasmic reticulum. Biochim. Biophys. Acta BBA - Mol. Cell Res. 1833, 2403-2409.

Keeling, K.M., and Bedwell, D.M. (2002). Clinically relevant aminoglycosides can suppress disease-associated premature stop mutations in the IDUA and P53 cDNAs in a mammalian translation system. J. Mol. Med. Berl. Ger. 80, 367-376.

Kerr, J.P., Ziman, A.P., Mueller, A.L., Muriel, J.M., Kleinhans-Welte, E., Gumerson, J.D., Vogel, S.S., Ward, C.W., Roche, J. a, and Bloch, R.J. (2013). Dysferlin stabilizes stress-induced Ca2+ signaling in the transverse tubule membrane. Proc. Natl. Acad. Sci. U. S. A. 110, 20831-20836. 
Khan, S., Komarya, S.K., and Jena, G. (2017). Phenylbutyrate and $\beta$-cell function: contribution of histone deacetylases and ER stress inhibition. Epigenomics 9, 711-720.

Kirk, M.M., Izu, L.T., Chen-Izu, Y., McCulle, S.L., Wier, W.G., Balke, C.W., and Shorofsky, S.R. (2003). Role of the Transverse-Axial Tubule System in Generating Calcium Sparks and Calcium Transients in Rat Atrial Myocytes. J. Physiol. 547, 441-451.

Klinge, L., Laval, S., Keers, S., Haldane, F., Straub, V., Barresi, R., and Bushby, K. (2007). From Ttubule to sarcolemma: damage-induced dysferlin translocation in early myogenesis. FASEB J. Off. Publ. Fed. Am. Soc. Exp. Biol. 21, 1768-1776.

Klinge, L., Dean, A.F., Kress, W., Dixon, P., Charlton, R., Müller, J.S., Anderson, L. V, Straub, V., Barresi, R., Lochmüller, H., et al. (2008). Late onset in dysferlinopathy widens the clinical spectrum. Neuromuscul. Disord. NMD 18, 288-290.

Klinge, L., Harris, J., Sewry, C., Charlton, R., Anderson, L., Laval, S., Chiu, Y.-H., Hornsey, M., Straub, V., Barresi, R., et al. (2010a). Dysferlin associates with the developing T-tubule system in rodent and human skeletal muscle. Muscle Nerve 41, 166-173.

Klinge, L., Aboumousa, A., Eagle, M., Hudson, J., Sarkozy, A., Vita, G., Charlton, R., Roberts, M., Straub, V., Barresi, R., et al. (2010b). New aspects on patients affected by dysferlin deficient muscular dystrophy. J. Neurol. Neurosurg. Psychiatry 81, 946-953.

Koenig, M., Monaco, A.P., and Kunkel, L.M. (1988). The complete sequence of dystrophin predicts a rod-shaped cytoskeletal protein. Cell 53, 219-228.

Kojima, C., Hashimoto, A., Yabuta, I., Hirose, M., Hashimoto, S., Kanaho, Y., Sumimoto, H., Ikegami, T., and Sabe, H. (2004). Regulation of Bin1 SH3 domain binding by phosphoinositides. EMBO J. 23, 4413-4422.

Kostin, S., Scholz, D., Shimada, T., Maeno, Y., Mollnau, H., Hein, S., and Schaper, J. (1998). The internal and external protein scaffold of the T-tubular system in cardiomyocytes. Cell Tissue Res. 294, 449-460.

Krahn, M., Béroud, C., Labelle, V., Nguyen, K., Bernard, R., Bassez, G., Figarella-Branger, D., Fernandez, C., Bouvenot, J., Richard, I., et al. (2009). Analysis of the DYSF mutational spectrum in a large cohort of patients. Hum. Mutat. 30, E345-75.

Krahn, M., Wein, N., Bartoli, M., Lostal, W., Courrier, S., Bourg-Alibert, N., Nguyen, K., Vial, C., Streichenberger, N., Labelle, V., et al. (2010). A naturally occurring human minidysferlin protein repairs sarcolemmal lesions in a mouse model of dysferlinopathy. Sci. Transl. Med. 2, 50 ra69.

Krause, T., Gerbershagen, M.U., Fiege, M., Weisshorn, R., and Wappler, F. (2004). Dantrolene-a review of its pharmacology, therapeutic use and new developments. Anaesthesia 59, 364373.

Krolenko, S.A., and Adamian, S.I. (2000). [Stereologic analysis of vacuolization of the T-system of frog muscle fibers, detected using confocal fluorescence microscopy]. Tsitologiia 42, 11251133.

Krolenko, S.A., and Lucy, J.A. (2001). Reversible vacuolation of T-tubules in skeletal muscle: mechanisms and implications for cell biology. Int. Rev. Cytol. 202, 243-298. 
Krolenko, S.A., Amos, W.B., Brown, S.C., Tarunina, M.V., and Lucy, J.A. (1998). Accessibility of T-tubule vacuoles to extracellular dextran and DNA: mechanism and potential application of vacuolation. J. Muscle Res. Cell Motil. 19, 603-611.

Kuru, S., Yasuma, F., Wakayama, T., Kimura, S., Konagaya, M., Aoki, M., Tanabe, M., and Takahashi, T. (2004). [A patient with limb girdle muscular dystrophy type 2B (LGMD2B) manifesting cardiomyopathy]. Rinsho Shinkeigaku 44, 375-378.

Kutay, U., Hartmann, E., and Rapoport, T.A. (1993). A class of membrane proteins with a Cterminal anchor. Trends Cell Biol. 3, 72-75.

Kyte, J., and Doolittle, R.F. (1982). A simple method for displaying the hydropathic character of a protein. J. Mol. Biol. 157, 105-132.

Lännergren, J., Bruton, J.D., and Westerblad, H. (1999). Vacuole formation in fatigued single muscle fibres from frog and mouse. J. Muscle Res. Cell Motil. 20, 19-32.

Lee, H.-L.R., and Dougherty, J.P. (2012). Pharmaceutical therapies to recode nonsense mutations in inherited diseases. Pharmacol. Ther. 136, 227-266.

Lee, E., Marcucci, M., Daniell, L., Pypaert, M., Weisz, O. a, Ochoa, G.-C., Farsad, K., Wenk, M.R., and De Camilli, P. (2002). Amphiphysin 2 (Bin1) and T-tubule biogenesis in muscle. Science 297, 1193-1196.

Lek, A., Evesson, F.J., Lemckert, F.A., Redpath, G.M.I., Lueders, A.-K., Turnbull, L., Whitchurch, C.B., North, K.N., and Cooper, S.T. (2013). Calpains, cleaved mini-dysferlinC72, and L-type channels underpin calcium-dependent muscle membrane repair. J. Neurosci. Off. J. Soc. Neurosci. 33, 5085-5094.

Lennon, N.J., Kho, A., Bacskai, B.J., Perlmutter, S.L., Hyman, B.T., and Brown, R.H. (2003). Dysferlin Interacts with Annexins $A 1$ and $A 2$ and Mediates Sarcolemmal Wound-healing. J. Biol. Chem. 278, 50466-50473.

Lerario, A., Cogiamanian, F., Marchesi, C., Belicchi, M., Bresolin, N., Porretti, L., and Torrente, Y. (2010). Effects of rituximab in two patients with dysferlin-deficient muscular dystrophy. BMC Musculoskelet. Disord. 11, 157.

Levy, D., Larson, M.G., Vasan, R.S., Kannel, W.B., and Ho, K.K.L. (1996). The Progression From Hypertension to Congestive Heart Failure. JAMA 275, 1557-1562.

Lim, M., McKenzie, K., Floyd, A.D., Kwon, E., and Zeitlin, P.L. (2004). Modulation of deltaF508 cystic fibrosis transmembrane regulator trafficking and function with 4-phenylbutyrate and flavonoids. Am. J. Respir. Cell Mol. Biol. 31, 351-357.

Linde, L., Boelz, S., Nissim-Rafinia, M., Oren, Y.S., Wilschanski, M., Yaacov, Y., Virgilis, D., NeuYilik, G., Kulozik, A.E., Kerem, E., et al. (2007). Nonsense-mediated mRNA decay affects nonsense transcript levels and governs response of cystic fibrosis patients to gentamicin. J. Clin. Invest. 117, 683-692.

Lindholm, D., Korhonen, L., Eriksson, O., and Kõks, S. (2017). Recent Insights into the Role of Unfolded Protein Response in ER Stress in Health and Disease. Front. Cell Dev. Biol. 5, 48. 
Lindner, E. (1957). [Submicroscopic morphology of the cardiac muscle]. Z. Zellforsch. Mikrosk. Anat. Vienna Austria 1948 45, 702-746.

Linssen, W.H., Notermans, N.C., Van der Graaf, Y., Wokke, J.H., Van Doorn, P.A., Höweler, C.J., Busch, H.F., De Jager, A.E., and De Visser, M. (1997). Miyoshi-type distal muscular dystrophy. Clinical spectrum in 24 Dutch patients. Brain J. Neurol. 120 ( Pt 1, 1989-1996.

Linstedt, A.D., and Hauri, H.P. (1993). Giantin, a novel conserved Golgi membrane protein containing a cytoplasmic domain of at least $350 \mathrm{kDa}$. Mol. Biol. Cell 4, 679-693.

Liu, Z.Q. (1991). Scale space approach to directional analysis of images. Appl. Opt. 30, 13691373.

Liu, J., Aoki, M., Illa, I., Wu, C., Fardeau, M., Angelini, C., Serrano, C., Urtizberea, J. a, Hentati, F., Hamida, M.B., et al. (1998). Dysferlin, a novel skeletal muscle gene, is mutated in Miyoshi myopathy and limb girdle muscular dystrophy. Nat. Genet. 20, 31-36.

Liu, S.-H., Yang, C.-C., Chan, D.-C., Wu, C.-T., Chen, L.-P., Huang, J.-W., Hung, K.-Y., and Chiang, C.-K. (2016). Chemical chaperon 4-phenylbutyrate protects against the endoplasmic reticulum stress-mediated renal fibrosis in vivo and in vitro. Oncotarget 7, 22116-22127.

Lostal, W., Bartoli, M., Bourg, N., Roudaut, C., Bentaïb, A., Miyake, K., Guerchet, N., Fougerousse, F., McNeil, P., and Richard, I. (2010). Efficient recovery of dysferlin deficiency by dual adeno-associated vector-mediated gene transfer. Hum. Mol. Genet. 19, 1897-1907.

Lostal, W., Bartoli, M., Roudaut, C., Bourg, N., Krahn, M., Pryadkina, M., Borel, P., Suel, L., Roche, J.A., Stockholm, D., et al. (2012). Lack of Correlation between Outcomes of Membrane Repair Assay and Correction of Dystrophic Changes in Experimental Therapeutic Strategy in Dysferlinopathy. PLOS ONE 7, e38036.

Louch, W.E., Bito, V., Heinzel, F.R., Macianskiene, R., Vanhaecke, J., Flameng, W., Mubagwa, K., and Sipido, K.R. (2004). Reduced synchrony of Ca2+ release with loss of T-tubules-a comparison to $\mathrm{Ca} 2+$ release in human failing cardiomyocytes. Cardiovasc. Res. 62, 63-73.

Louch, W.E., Mørk, H.K., Sexton, J., Strømme, T.A., Laake, P., Sjaastad, I., and Sejersted, O.M. (2006). T-tubule disorganization and reduced synchrony of $\mathrm{Ca} 2+$ release in murine cardiomyocytes following myocardial infarction. J. Physiol. 574, 519-533.

Loufrani, L., Dubroca, C., You, D., Li, Z., Levy, B., Paulin, D., and Henrion, D. (2004). Absence of dystrophin in mice reduces NO-dependent vascular function and vascular density: total recovery after a treatment with the aminoglycoside gentamicin. Arterioscler. Thromb. Vasc. Biol. 24, 671-676.

De Luna, N., Freixas, A., Gallano, P., Caselles, L., Rojas-García, R., Paradas, C., Nogales, G., Dominguez-Perles, R., Gonzalez-Quereda, L., Vílchez, J.J., et al. (2007). Dysferlin expression in monocytes: a source of mRNA for mutation analysis. Neuromuscul. Disord. NMD 17, 69-76.

Lyon, A.R., MacLeod, K.T., Zhang, Y., Garcia, E., Kanda, G.K., Lab, M.J., Korchev, Y.E., Harding, S.E., and Gorelik, J. (2009). Loss of T-tubules and other changes to surface topography in ventricular myocytes from failing human and rat heart. Proc. Natl. Acad. Sci. U. S. A. 106, 6854-6859. 
Ma, W., Goldberg, E., and Goldberg, J. (2017). ER retention is imposed by COPII protein sorting and attenuated by 4-phenylbutyrate. ELife 6 .

Mahjneh, I., Passos-Bueno, M.R., Zatz, M., Vainzof, M., Marconi, G., Nashef, L., Bashir, R., and Bushby, K. (1996). The phenotype of chromosome 2 -linked limb-girdle muscular dystrophy. Neuromuscul. Disord. NMD 6, 483-490.

Manuvakhova, M., Keeling, K., and Bedwell, D.M. (2000). Aminoglycoside antibiotics mediate context-dependent suppression of termination codons in a mammalian translation system. RNA 6, 1044-1055.

Matsuda, C., Aoki, M., Hayashi, Y.K., Ho, M.F., Arahata, K., and Brown, R.H. (1999). Dysferlin is a surface membrane-associated protein that is absent in Miyoshi myopathy. Neurology 53, $1119-1122$.

Matsuda, C., Miyake, K., Kameyama, K., Keduka, E., Takeshima, H., Imamura, T., Araki, N., Nishino, I., and Hayashi, Y. (2012). The C2A domain in dysferlin is important for association with MG53 (TRIM72). PLOS Curr. Muscular Dystrophy.

McDade, J.R., and Michele, D.E. (2014). Membrane damage-induced vesicle-vesicle fusion of dysferlin-containing vesicles in muscle cells requires microtubules and kinesin. Hum. Mol. Genet. 23, 1677-1686.

McDade, J.R., Archambeau, A., and Michele, D.E. (2014). Rapid actin-cytoskeleton-dependent recruitment of plasma membrane-derived dysferlin at wounds is critical for muscle membrane repair. FASEB J. Off. Publ. Fed. Am. Soc. Exp. Biol. 28, 3660-3670.

Milting, H., Heilmeyer, L.M.G., and Thieleczek, R. (1994). Phosphoinositides in membranes that build up the triads of rabbit skeletal muscle. FEBS Lett. 345, 211-218.

Minetti, C., Sotgia, F., Bruno, C., Scartezzini, P., Broda, P., Bado, M., Masetti, E., Mazzocco, M., Egeo, A., Donati, M.A., et al. (1998). Mutations in the caveolin-3 gene cause autosomal dominant limb-girdle muscular dystrophy. Nat. Genet. 18, 365-368.

Mokhtarani, M., Diaz, G.A., Rhead, W., Berry, S.A., Lichter-Konecki, U., Feigenbaum, A., Schulze, A., Longo, N., Bartley, J., Berquist, W., et al. (2013). Elevated phenylacetic acid levels do not correlate with adverse events in patients with urea cycle disorders or hepatic encephalopathy and can be predicted based on the plasma PAA to PAGN ratio. Mol. Genet. Metab. 110, 446-453.

Montané, E., Vallano, A., and Laporte, J.R. (2004). Oral antispastic drugs in nonprogressive neurologic diseases: a systematic review. Neurology 63, 1357-1363.

Moore, S.A., Shilling, C.J., Westra, S., Wall, C., Wicklund, M.P., Stolle, C., Brown, C.A., Michele, D.E., Piccolo, F., Winder, T.L., et al. (2006). Limb-girdle muscular dystrophy in the United States. J. Neuropathol. Exp. Neurol. 65, 995-1003.

Nagaraju, K., Rawat, R., Veszelovszky, E., Thapliyal, R., Kesari, A., Sparks, S., Raben, N., Plotz, P., and Hoffman, E.P. (2008). Dysferlin deficiency enhances monocyte phagocytosis: a model for the inflammatory onset of limb-girdle muscular dystrophy 2B. Am. J. Pathol. 172, 774-785.

Nelson, D.A., and Benson, E.S. (1963). On the structural continuities of the transverse tubular system of rabbit and human myocardial cells. J. Cell Biol. 16, 297-313. 
Nguyen, K., Bassez, G., Krahn, M., Bernard, R., Laforêt, P., Labelle, V., Urtizberea, J.A., FigarellaBranger, D., Romero, N., Attarian, S., et al. (2007). Phenotypic study in 40 patients with dysferlin gene mutations: high frequency of atypical phenotypes. Arch. Neurol. 64, 1176-1182.

Nicot, A.-S., Toussaint, A., Tosch, V., Kretz, C., Wallgren-Pettersson, C., Iwarsson, E., Kingston, H., Garnier, J.-M., Biancalana, V., Oldfors, A., et al. (2007). Mutations in amphiphysin 2 (BIN1) disrupt interaction with dynamin 2 and cause autosomal recessive centronuclear myopathy. Nat. Genet. 39, 1134-1139.

Niks, E.H., and Aartsma-Rus, A. (2017). Exon skipping: a first in class strategy for Duchenne muscular dystrophy. Expert Opin. Biol. Ther. 17, 225-236.

Ohler, A., Weisser-Thomas, J., Piacentino, V., Houser, S.R., Tomaselli, G.F., and O'Rourke, B. (2010). Two-Photon Laser Scanning Microscopy of the Transverse-Axial Tubule System in Ventricular Cardiomyocytes from Failing and Non-Failing Human Hearts. Cardiol. Res. Pract. 2009, e802373.

van Ommen, G.-J., van Deutekom, J., and Aartsma-Rus, A. (2008). The therapeutic potential of antisense-mediated exon skipping. Curr. Opin. Mol. Ther. 10, 140-149.

van Oort, R.J., Garbino, A., Wang, W., Dixit, S.S., Landstrom, A.P., Gaur, N., De Almeida, A.C., Skapura, D.G., Rudy, Y., Burns, A.R., et al. (2011). Disrupted Junctional Membrane Complexes and Hyperactive Ryanodine Receptors Following Acute Junctophilin Knockdown in Mice. Circulation 123, 979-988.

Oslowski, C.M., and Urano, F. (2011). Measuring ER stress and the unfolded protein response using mammalian tissue culture system. Methods Enzymol. 490, 71-92.

Parton, R.G., and Simons, K. (2007). The multiple faces of caveolae. Nat. Rev. Mol. Cell Biol. 8 , 185-194.

Parton, R.G., Way, M., Zorzi, N., and Stang, E. (1997). Caveolin-3 associates with developing Ttubules during muscle differentiation. J. Cell Biol. 136, 137-154.

Payapilly, A., and High, S. (2014). BAG6 regulates the quality control of a polytopic ERAD substrate. J. Cell Sci. 127, 2898-2909.

Perrine, S.P., Wargin, W.A., Boosalis, M.S., Wallis, W.J., Case, S., Keefer, J.R., Faller, D.V., Welch, W.C., and Berenson, R.J. (2011). Evaluation of safety and pharmacokinetics of sodium 2,2 dimethylbutyrate, a novel short chain fatty acid derivative, in a phase 1 , double-blind, placebo-controlled, single-dose, and repeat-dose studies in healthy volunteers. J. Clin. Pharmacol. 51, 1186-1194.

Peter, B.J., Kent, H.M., Mills, I.G., Vallis, Y., Butler, P.J.G., Evans, P.R., and McMahon, H.T. (2004). BAR domains as sensors of membrane curvature: the amphiphysin BAR structure. Science 303, 495-499.

Pfaff, J., Monroy, J.R., Jamieson, C., Rajanala, K., Vilardi, F., Schwappach, B., and Kehlenbach, R.H. (2016). Emery-Dreifuss muscular dystrophy mutations impair TRC40-mediated targeting of emerin to the inner nuclear membrane. J Cell Sci 129, 502-516. 
Philippi, S., Bigot, A., Marg, A., Mouly, V., Spuler, S., and Zacharias, U. (2012). Dysferlindeficient immortalized human myoblasts and myotubes as a useful tool to study dysferlinopathy. PLoS Curr. 4.

Piccolo, F., Moore, S. a, Ford, G.C., and Campbell, K.P. (2000). Intracellular accumulation and reduced sarcolemmal expression of dysferlin in limb--girdle muscular dystrophies. Ann. Neurol. 48, 902-912.

Pieske, B., Maier, L.S., Bers, D.M., and Hasenfuss, G. (1999). Ca2+ handling and sarcoplasmic reticulum $\mathrm{Ca} 2+$ content in isolated failing and nonfailing human myocardium. Circ. Res. 85, 3846.

Pinali, C., Bennett, H., Davenport, J.B., Trafford, A.W., and Kitmitto, A. (2013). ThreeDimensional Reconstruction of Cardiac Sarcoplasmic Reticulum Reveals a Continuous Network Linking Transverse-Tubules. Circ. Res. 113, 1219-1230.

Pinali, C., Malik, N., Davenport, J.B., Allan, L.J., Murfitt, L., Iqbal, M.M., Boyett, M.R., Wright, E.J., Walker, R., Zhang, Y., et al. (2017). Post-Myocardial Infarction T-tubules Form Enlarged Branched Structures With Dysregulation of Junctophilin-2 and Bridging Integrator 1 (BIN-1). J. Am. Heart Assoc. 6, e004834.

Pryadkina, M., Lostal, W., Bourg, N., Charton, K., Roudaut, C., Hirsch, M.L., and Richard, I. (2015). A comparison of AAV strategies distinguishes overlapping vectors for efficient systemic delivery of the $6.2 \mathrm{~kb}$ Dysferlin coding sequence. Mol. Ther. Methods Clin. Dev. 2, 15009.

Puthenveedu, M.A., and Linstedt, A.D. (2001). Evidence that Golgi structure depends on a p115 activity that is independent of the vesicle tether components giantin and GM130. J. Cell Biol. 155, 227-238.

Rabu, C., Wipf, P., Brodsky, J.L., and High, S. (2008). A Precursor-specific Role for Hsp40/Hsc70 during Tail-anchored Protein Integration at the Endoplasmic Reticulum. J. Biol. Chem. 283, 27504-27513.

Ramakrishnan, N.A., Drescher, M.J., Morley, B.J., Kelley, P.M., and Drescher, D.G. (2014). Calcium Regulates Molecular Interactions of Otoferlin with SNARE Proteins Required for Hair Cell Exocytosis. J. Biol. Chem. 289, 8750-8766.

Ramjaun, a R., and McPherson, P.S. (1998). Multiple amphiphysin II splice variants display differential clathrin binding: identification of two distinct clathrin-binding sites. J. Neurochem. $70,2369-2376$.

Rayavarapu, S., Van der Meulen, J.H., Gordish-Dressman, H., Hoffman, E.P., Nagaraju, K., and Knoblach, S.M. (2010). Characterization of dysferlin deficient SJL/J mice to assess preclinical drug efficacy: fasudil exacerbates muscle disease phenotype. PloS One 5, e12981.

Razzaq, A., Robinson, I.M., McMahon, H.T., Skepper, J.N., Su, Y., Zelhof, A.C., Jackson, A.P., Gay, N.J., and O'Kane, C.J. (2001). Amphiphysin is necessary for organization of the excitationcontraction coupling machinery of muscles, but not for synaptic vesicle endocytosis in Drosophila. Genes Dev. 15, 2967-2979.

Redpath, G.M.I., Woolger, N., Piper, A.K., Lemckert, F.A., Lek, A., Greer, P.A., North, K.N., and Cooper, S.T. (2014). Calpain cleavage within dysferlin exon 40a releases a synaptotagmin-like module for membrane repair. Mol. Biol. Cell 25, 3037-3048. 
Reynolds, J.O., Chiang, D.Y., Wang, W., Beavers, D.L., Dixit, S.S., Skapura, D.G., Landstrom, A.P., Song, L.-S., Ackerman, M.J., and Wehrens, X.H.T. (2013). Junctophilin-2 is necessary for Ttubule maturation during mouse heart development. Cardiovasc. Res. 100, 44-53.

Rivera-Monroy, J., Musiol, L., Unthan-Fechner, K., Farkas, Á., Clancy, A., Coy-Vergara, J., Weill, U., Gockel, S., Lin, S.-Y., Corey, D.P., et al. (2016). Mice lacking WRB reveal differential biogenesis requirements of tail-anchored proteins in vivo. Sci. Rep. 6, 39464.

Rodrigo-Brenni, M.C., Gutierrez, E., and Hegde, R.S. (2014). Cytosolic Quality Control of Mislocalized Proteins Requires RNF126 Recruitment to Bag6. Mol. Cell 55, 227-237.

Romey, G., Garcia, L., Dimitriadou, V., Pincon-Raymond, M., Rieger, F., and Lazdunski, M. (1989). Ontogenesis and localization of Ca2+ channels in mammalian skeletal muscle in culture and role in excitation-contraction coupling. Proc. Natl. Acad. Sci. U. S. A. 86, 2933-2937.

Roostalu, U., and Strähle, U. (2012). In Vivo Imaging of Molecular Interactions at Damaged Sarcolemma. Dev. Cell 22, 515-529.

Rostgaard, J., and Behnke, O. (1965). Fine structural localization of adenine nucleoside phosphatase activity in the sarcoplasmic reticulum and the $T$ system of rat myocardium. J. Ultrastruct. Res. 12, 579-591.

Roth, Z., Yehezkel, G., and Khalaila, I. (2012). Identification and Quantification of Protein Glycosylation. Int. J. Carbohydr. Chem. 2012, e640923.

Rubenstein, R.C., Egan, M.E., and Zeitlin, P.L. (1997). In vitro pharmacologic restoration of CFTR-mediated chloride transport with sodium 4-phenylbutyrate in cystic fibrosis epithelial cells containing delta F508-CFTR. J. Clin. Invest. 100, 2457-2465.

Rubi, L., Gawali, V.S., Kubista, H., Todt, H., Hilber, K., and Koenig, X. (2015). Proper VoltageDependent Ion Channel Function in Dysferlin-Deficient Cardiomyocytes. Cell. Physiol. Biochem. 36, 1049-1058.

Sano, R., and Reed, J.C. (2013). ER stress-induced cell death mechanisms. Biochim. Biophys. Acta BBA - Mol. Cell Res. 1833, 3460-3470.

Savio-Galimberti, E., Frank, J., Inoue, M., Goldhaber, J.I., Cannell, M.B., Bridge, J.H.B., and Sachse, F.B. (2008). Novel features of the rabbit transverse tubular system revealed by quantitative analysis of three-dimensional reconstructions from confocal images. Biophys. J. 95, 2053-2062.

Scaglia, F., Carter, S., O'Brien, W.E., and Lee, B. (2004). Effect of alternative pathway therapy on branched chain amino acid metabolism in urea cycle disorder patients. Mol. Genet. Metab. 81 Suppl 1, S79-85.

Schiaffino, S., Cantini, M., and Sartore, S. (1977). T-system formation in cultured rat skeletal tissue. Tissue Cell 9, 437-446.

Schneider, C.A., Rasband, W.S., and Eliceiri, K.W. (2012). NIH Image to ImageJ: 25 years of image analysis. Nat. Methods 9, 671-675. 
Schueren, F., Lingner, T., George, R., Hofhuis, J., Dickel, C., Gärtner, J., and Thoms, S. (2014). Peroxisomal lactate dehydrogenase is generated by translational readthrough in mammals. ELife 3, 1-24.

Seidel, T., Navankasattusas, S., Ahmad, A., Diakos, N.A., Xu, W.D., Tristani-Firouzi, M., Bonios, M.J., Taleb, I., Li, D.Y., Selzman, C.H., et al. (2017). Sheet-Like Remodeling of the Transverse Tubular System in Human Heart Failure Impairs Excitation-Contraction Coupling and Functional Recovery by Mechanical Unloading. Circulation 135, 1632-1645.

Selcen, D., Stilling, G., and Engel, a G. (2001). The earliest pathologic alterations in dysferlinopathy. Neurology 56, 1472-1481.

Sermet-Gaudelus, I., Renouil, M., Fajac, A., Bidou, L., Parbaille, B., Pierrot, S., Davy, N., Bismuth, E., Reinert, P., Lenoir, G., et al. (2007). In vitro prediction of stop-codon suppression by intravenous gentamicin in patients with cystic fibrosis: a pilot study. BMC Med. 5, 5.

Shao, S., and Hegde, R.S. (2011). Membrane protein insertion at the endoplasmic reticulum. Annu. Rev. Cell Dev. Biol. 27, 25-56.

Shupliakov, O. (1997). Synaptic Vesicle Endocytosis Impaired by Disruption of Dynamin-SH3 Domain Interactions. Science 276, 259-263.

Sinnreich, M., Therrien, C., and Karpati, G. (2006). Lariat branch point mutation in the dysferlin gene with mild limb-girdle muscular dystrophy. Neurology 66, 1114-1116.

Smyth, A.R. (2010). Minimizing the toxicity of aminoglycosides in cystic fibrosis. J. R. Soc. Med. 103, S3-S5.

Soeller, C., and Cannell, M.B. (1999). Examination of the Transverse Tubular System in Living Cardiac Rat Myocytes by 2-Photon Microscopy and Digital Image-Processing Techniques. Circ. Res. 84, 266-275.

Sondergaard, P.C., Griffin, D.A., Pozsgai, E.R., Johnson, R.W., Grose, W.E., Heller, K.N., Shontz, K.M., Montgomery, C.L., Liu, J., Clark, K.R., et al. (2015). AAV.Dysferlin Overlap Vectors Restore Function in Dysferlinopathy Animal Models. Ann. Clin. Transl. Neurol. 2, 256-270.

Song, L.-S., Sobie, E.A., McCulle, S., Lederer, W.J., Balke, C.W., and Cheng, H. (2006). Orphaned ryanodine receptors in the failing heart. Proc. Natl. Acad. Sci. U. S. A. 103, 4305-4310.

Sperelakis, N., and Rubio, R. (1971). An orderly lattice of axial tubules which interconnect adjacent transverse tubules in guinea-pig ventricular myocardium. J. Mol. Cell. Cardiol. 2, 211220.

Stefanovic, S., and Hegde, R.S. (2007). Identification of a Targeting Factor for Posttranslational Membrane Protein Insertion into the ER. Cell 128, 1147-1159.

Stern, M.D. (1992). Theory of excitation-contraction coupling in cardiac muscle. Biophys. J. 63, 497-517.

Suaud, L., Miller, K., Panichelli, A.E., Randell, R.L., Marando, C.M., and Rubenstein, R.C. (2011). 4-Phenylbutyrate stimulates Hsp70 expression through the Elp2 component of elongator and STAT-3 in cystic fibrosis epithelial cells. J. Biol. Chem. 286, 45083-45092. 
Suh, B.-C., and Hille, B. (2005). Regulation of ion channels by phosphatidylinositol 4,5bisphosphate. Curr. Opin. Neurobiol. 15, 370-378.

Sun, Y., Thapa, N., Hedman, A.C., and Anderson, R.A. (2013). Phosphatidylinositol 4,5bisphosphate: targeted production and signaling. BioEssays News Rev. Mol. Cell. Dev. Biol. 35, 513-522.

Swift, F., Franzini-Armstrong, C., Øyehaug, L., Enger, U.H., Andersson, K.B., Christensen, G., Sejersted, O.M., and Louch, W.E. (2012). Extreme sarcoplasmic reticulum volume loss and compensatory T-tubule remodeling after Serca2 knockout. Proc. Natl. Acad. Sci. U. S. A. 109, 3997-4001.

Takatori, O., Usui, S., Okajima, M., Kaneko, S., Ootsuji, H., Takashima, S.-I., Kobayashi, D., Murai, H., Furusho, H., and Takamura, M. (2017). Sodium 4-Phenylbutyrate Attenuates Myocardial Reperfusion Injury by Reducing the Unfolded Protein Response. J. Cardiovasc. Pharmacol. Ther. 22, 283-292.

Takekura, H., Fujinami, N., Nishizawa, T., Ogasawara, H., and Kasuga, N. (2001). Eccentric exercise-induced morphological changes in the membrane systems involved in excitationcontraction coupling in rat skeletal muscle. J. Physiol. 533, 571-583.

Takenawa, T., Itoh, T., and Fukami, K. (1999). Regulation of phosphatidylinositol 4,5bisphosphate levels and its roles in cytoskeletal re-organization and malignant transformation. Chem. Phys. Lipids 98, 13-22.

Takeshima, H., Komazaki, S., Nishi, M., lino, M., and Kangawa, K. (2000). Junctophilins: a novel family of junctional membrane complex proteins. Mol. Cell 6, 11-22.

Tang, Z., Scherer, P.E., Okamoto, T., Song, K., Chu, C., Kohtz, D.S., Nishimoto, I., Lodish, H.F., and Lisanti, M.P. (1996). Molecular cloning of caveolin-3, a novel member of the caveolin gene family expressed predominantly in muscle. J. Biol. Chem. 271, 2255-2261.

Tate, W.P., Poole, E.S., and Mannering, S.A. (1996). Hidden infidelities of the translational stop signal. Prog. Nucleic Acid Res. Mol. Biol. 52, 293-335.

Taylor, M.J., Perrais, D., and Merrifield, C.J. (2011). A high precision survey of the molecular dynamics of mammalian clathrin-mediated endocytosis. PLoS Biol. 9, e1000604.

Therrien, C., Di Fulvio, S., Pickles, S., and Sinnreich, M. (2009). Characterization of lipid binding specificities of dysferlin C2 domains reveals novel interactions with phosphoinositides. Biochemistry (Mosc.) 48, 2377-2384.

Tidball, J.G. (2011). Mechanisms of muscle injury, repair, and regeneration. Compr. Physiol. 1, 2029-2062.

Tjondrokoesoemo, A., Park, K.H., Ferrante, C., Komazaki, S., Lesniak, S., Brotto, M., Ko, J.-K., Zhou, J., Weisleder, N., and Ma, J. (2011). Disrupted membrane structure and intracellular $\mathrm{Ca}^{2+}$ signaling in adult skeletal muscle with acute knockdown of Bin1. PloS One 6, e25740.

Toussaint, A., Cowling, B.S., Hnia, K., Mohr, M., Oldfors, A., Schwab, Y., Yis, U., Maisonobe, T., Stojkovic, T., Wallgren-Pettersson, C., et al. (2011). Defects in amphiphysin 2 (BIN1) and triads in several forms of centronuclear myopathies. Acta Neuropathol. (Berl.) 121, 253-266. 
Tzeng, H.-P., Evans, S., Gao, F., Chambers, K., Topkara, V.K., Sivasubramanian, N., Barger, P.M., and Mann, D.L. (2014). Dysferlin Mediates the Cytoprotective Effects of TRAF2 Following Myocardial Ischemia Reperfusion Injury. J. Am. Heart Assoc. 3, e000662.

Vafiadaki, E., Reis, A., Keers, S., Harrison, R., Anderson, L. V, Raffelsberger, T., Ivanova, S., Hoger, H., Bittner, R.E., Bushby, K., et al. (2001). Cloning of the mouse dysferlin gene and genomic characterization of the SJL-Dysf mutation. Neuroreport 12, 625-629.

Vatta, M., Ackerman, M.J., Ye, B., Makielski, J.C., Ughanze, E.E., Taylor, E.W., Tester, D.J., Balijepalli, R.C., Foell, J.D., Li, Z., et al. (2006). Mutant caveolin-3 induces persistent late sodium current and is associated with long-QT syndrome. Circulation 114, 2104-2112.

Vilardi, F., Lorenz, H., and Dobberstein, B. (2011). WRB is the receptor for TRC40/Asna1mediated insertion of tail-anchored proteins into the ER membrane. J. Cell Sci. 124, 13011307.

Wagner, E., Lauterbach, M.A., Kohl, T., Westphal, V., Williams, G.S.B., Steinbrecher, J.H., Streich, J.-H., Korff, B., Tuan, H.-T.M., Hagen, B., et al. (2012). Stimulated emission depletion live-cell super-resolution imaging shows proliferative remodeling of T-tubule membrane structures after myocardial infarction. Circ. Res. 111, 402-414.

Wagner, E., Brandenburg, S., Kohl, T., and Lehnart, S.E. (2014). Analysis of tubular membrane networks in cardiac myocytes from atria and ventricles. J. Vis. Exp. JoVE e51823.

Walter, M.C., Reilich, P., Thiele, S., Schessl, J., Schreiber, H., Reiners, K., Kress, W., MüllerReible, C., Vorgerd, M., Urban, P., et al. (2013). Treatment of dysferlinopathy with deflazacort: a double-blind, placebo-controlled clinical trial. Orphanet J. Rare Dis. 8, 26.

Washington, N.L., and Ward, S. (2006). FER-1 regulates Ca2+ -mediated membrane fusion during C. elegans spermatogenesis. J. Cell Sci. 119, 2552-2562.

Wechsler-Reya, R., Sakamuro, D., Zhang, J., Duhadaway, J., George, C., Wechsler-reya, R., and Prendergast, G.C. (1997). Structural Analysis of the Human BIN1 Gene : EVIDENCE FOR TISSUESPECIFIC TRANSCRIPTIONAL REGULATION AND ALTERNATE RNA SPLICING. J. Biol. Chem. 272, 31453-31458.

Wei, B., Wei, H., and Jin, J.-P. (2015). Dysferlin deficiency blunts $\beta$-adrenergic-dependent lusitropic function of mouse heart. J. Physiol. 593, 5127-5144.

Wei, S., Guo, A., Chen, B., Kutschke, W., Xie, Y.-P., Zimmerman, K., Weiss, R.M., Anderson, M.E., Cheng, H., and Song, L.-S. (2010). T-Tubule Remodeling During Transition From Hypertrophy to Heart Failure. Circ. Res. 107, 520-531.

Weiler, T., Bashir, R., Anderson, L. V, Davison, K., Moss, J.A., Britton, S., Nylen, E., Keers, S., Vafiadaki, E., Greenberg, C.R., et al. (1999). Identical mutation in patients with limb girdle muscular dystrophy type $2 \mathrm{~B}$ or Miyoshi myopathy suggests a role for modifier gene(s). Hum. Mol. Genet. 8, 871-877.

Wein, N., Avril, A., Bartoli, M., Beley, C., Chaouch, S., Laforêt, P., Behin, A., Butler-Browne, G., Mouly, V., Krahn, M., et al. (2010). Efficient bypass of mutations in dysferlin deficient patient cells by antisense-induced exon skipping. Hum. Mutat. 31, 136-142. 
Wenzel, K., Carl, M., Perrot, A., Zabojszcza, J., Assadi, M., Ebeling, M., Geier, C., Robinson, P.N., Kress, W., Osterziel, K.-J., et al. (2006). Novel sequence variants in dysferlin-deficient muscular dystrophy leading to mRNA decay and possible C2-domain misfolding. Hum. Mutat. 27, 599600.

Wenzel, K., Geier, C., Qadri, F., Hubner, N., Schulz, H., Erdmann, B., Gross, V., Bauer, D., Dechend, R., Dietz, R., et al. (2007). Dysfunction of dysferlin-deficient hearts. J. Mol. Med. Berl. Ger. 85, 1203-1214.

Wigge, P., Köhler, K., Vallis, Y., Doyle, C.A., Owen, D., Hunt, S.P., and McMahon, H.T. (1997a). Amphiphysin heterodimers: potential role in clathrin-mediated endocytosis. Mol. Biol. Cell 8 , 2003-2015.

Wigge, P., Vallis, Y., and McMahon, H.T. (1997b). Inhibition of receptor-mediated endocytosis by the amphiphysin SH3 domain. Curr. Biol. 7, 554-560.

Wimberly, B.T., Brodersen, D.E., Clemons, W.M., Morgan-Warren, R.J., Carter, A.P., Vonrhein, C., Hartsch, T., and Ramakrishnan, V. (2000). Structure of the $30 \mathrm{~S}$ ribosomal subunit. Nature 407, 327-339.

Yamamoto, Y., and Sakisaka, T. (2012). Molecular machinery for insertion of tail-anchored membrane proteins into the endoplasmic reticulum membrane in mammalian cells. Mol. Cell 48, 387-397.

Yang, F., Zaiyue, S., and Mingmin, G. (2016). The functional mechanisms and clinical application of read-through drugs. Yi Chuan Hered. 38, 623-633.

Yasunaga, S., Grati, M., Chardenoux, S., Smith, T.N., Friedman, T.B., Lalwani, A.K., Wilcox, E.R., and Petit, C. (2000). OTOF encodes multiple long and short isoforms: genetic evidence that the long ones underlie recessive deafness DFNB9. Am. J. Hum. Genet. 67, 591-600.

Yu, H. (1994). Structural basis for the binding of proline-rich peptides to SH3 domains. Cell 76, 933-945.

Ziman, A.P., Gómez-Viquez, N.L., Bloch, R.J., and Lederer, W.J. (2010). Excitation-contraction coupling changes during postnatal cardiac development. J. Mol. Cell. Cardiol. 48, 379-386. 


\section{Acknowledgements}

An dieser Stelle möchte ich mich ganz herzlich bei all den Menschen bedanken, die mich während meiner Doktorzeit begleitet und unterstützt haben, und die an der Entstehung dieser Arbeit beteiligt waren:

Zunächst möchte ich mich bei Prof. Dr. Jutta Gärtner für die Aufnahme in das Team der Klinik für Kinder- und Jugendmedizin bedanken. Ich bin sehr froh, dass Sie mir ermöglicht haben dieses Projekt in den exzellent ausgestatteten Laboren Ihrer Abteilung durchzuführen. Vielen Dank, dass Sie mich während der Promotionszeit begleitet haben.

Besonders möchte ich mich bei PD Dr. Lars Klinge und PD Dr. Sven Thoms für das spannende und herausfordernde Promotionsthema, und die Aufnahme in eure Arbeitsgruppe bedanken. Danke für das stetige Interesse an meiner Arbeit, für die wunderbare Betreuung und die konstruktive Kritik, die es ermöglicht hat mich weiterzuentwickeln. Danke für eure Unterstützung, ganz besonders in der Schreibphase.

Prof. Dr. Wolfgang Brück und Prof. Dr. Hubertus Jarry möchte ich für die wissenschaftliche Betreuung während der Promotionszeit und die Übernahme der damit verbundenen Aufgaben herzlich danken.

Außerdem möchte ich mich bei Dr. Ira Milosevic, Prof. Dr. Steven Johnsen und Prof. Dr. Blanche Schwappach für die Bereitschaft an der Teilnahme meines Prüfungsausschusses danken.

Ein ganz herzlicher Dank gilt Prof. Dr. Gerd Hunsmann für Ihr großes Interesse und für Ihr Vertrauen in meine Arbeit. Die finanzielle Unterstützung durch Ihre Stiftung hat die Durchführung dieses Projekts erst ermöglicht. Außerdem möchte ich mich bei der Eva Luise und Horst Köhler Stiftung für Menschen mit Seltenen Erkrankungen und dem Sonderforschungsbereich 1002 für die finanzielle Unterstützung bedanken.

Ein weiterer Dank gilt unseren Kooperationspartnern für das Teilen Eurer Expertise, Eures Equipments und Eurer Manpower:

Prof. Dr. Viacheslav Nikolaev und Tobias Goldak für die Isolation von ventrikulären Rattenkardiomyozyten im Rahmen der Dysferlin-Expressionsanalyse. 
Prof. Dr. Niels Voigt, Dr. Cristina Molina, Ines Müller und Funsho Fakuade für die Isolation und Untersuchung von ventrikulären Kardiomyozyten aus Dysferlin-defizienten und -kompetenten Mäusen.

Prof. Dr. Blanche Schwappach und Dr. Jhon Rivera-Monroy für Euer großartiges Engagement zur Untersuchung des Traffickings von Dysferlin.

Dr. Eva Wagner für Deine Unterstützung und Deinen Rat bei der Untersuchung des T-Tubulussystems in Kardiomyozyten.

Weiterhin möchte ich mich bei Corinna Dickel und Marco Schmidt für die Klonierung der Reporterkonstrukte bedanken.

Vielen Dank auch an Marc Ziegenbein für Deine Hilfe bei der Isolation von Rattenherzen und deine große Geduld bei der Durchführung der Western Blots.

Dr. Gertrude Bunt und dem MOLCl-Team möchte ich für die Einarbeitung und die technische Unterstützung beim Mikroskopieren danken.

Ein großer Dank geht an Dr. Erik Meskauskas, Dr. Werner Albig und Heike Wolfram für die organisatorische Hilfe und Beantwortung meiner vielen Fragen zur Promotion.

Ich möchte mich auch bei PD Dr. Ralph Krätzner für die Koordination aller Laborangelegenheiten und Deine Ratschläge bedanken.

Ein besonders herzlicher Dank gilt Irmgard Cierny für Deine langjährige Erfahrung und exzellente Unterstützung im Labor. Danke, dass du mich in meiner Promotionszeit begleitet hast.

Ich möchte mich ganz herzlich bei allen Mitgliedern des Labors bedanken. Ihr habt mich super aufgenommen und eine tolle Arbeitsatmosphäre geschaffen. Danke für jedes gegossene Gel, jede PCR, jeden Puffer, jedes Zellensplitten. Danke für die schönen Mittagsrunden, Kaffeepausen und die vielen Nikoläuse und Ostereier, die mich mehrmals im Jahr erfreut haben.

Ein großes Dankeschön geht auch an Anke, weil Du Dich kümmerst, wo du nur kannst. Danke für deine ehrliche und liebevolle Art. 
Ein Dankeschön gilt dem Megaoffice: Rosemol George, Julia Hofhuis, Karina Kaczmarek-Hájek, Kristina Lang, Thomas Weber, Susann Weißbach, Maria Wiese, Annika Wolf. Ein besseres Arbeitsumfeld hätte ich mir nicht vorstellen können. Ihr seid nicht nur Kollegen, sondern auch mit der Zeit Freunde geworden. Danke für Euer geballtes Wissen, die Yogaeinheiten, die mentale Unterstützung durch Stuhlkreise und Eure Ermutigungen. Ganz besonders möchte ich mich bei Julia bedanken. Danke, dass ich in deine Fußstapfen treten konnte und du mich immer unterstützt hast.

Danke an meine Freunde außerhalb des Labors für Euren offenen Ohren, die langen Gespräche über die Arbeit und Privates und eure Unterstützung während der ganzen Zeit.

Schließlich gilt meine unbeschreiblich große Dankbarkeit meiner Familie, insbesondere meinen Eltern, und meinem Mann Andrej. Danke für Eure grenzenlose Liebe, Euren Glauben in mich und Eure Geduld. Ohne Euch wäre diese Arbeit nicht zustande gekommen. Я вас люблю. 


\section{Curriculum vitae}

\section{Personal details}

Name

Kristina Bersch, née Gamper

Address

Division of Neuropediatrics

Department of Pediatric and Adolescent Medicine

University Medical Center Göttingen

Robert-Koch Straße 40

37075 Göttingen, Germany

Phone

+49-551-39-13652

Email

kristina.bersch@med.uni-goettingen.de

Date of birth

30.01.1990

\section{Education}

10/2013-present

Ph.D. program Molecular Medicine

Department of Pediatric and Adolescent Medicine

University Medical Center Göttingen

Dissertation: Dysferlin in skeletal and heart muscle: from trafficking to therapy

10/2012-04/2014 Master program Molecular Medicine

Georg-August-University, Göttingen

Fast-Track

Thesis: Mechanism of dysferlin-induced membrane tubulation

Grade: 1.3

10/2009-09/2012 Bachelor program Molekulare Medizin

Georg-August-University, Göttingen

Thesis: Characterization of the putative tumor suppressor Cyld as Plk1 and Cep192-interacting protein

Grade: 1.5

$07 / 2009$

High School Degree Abitur

Gymnasium Johanneum, Lüneburg

Grade: 1.6

\section{Publications}

Hofhuis, J., Bersch, K., Büssenschütt, R., Drzymalski, M., Liebetanz, D., Nikolaev, V.O., Wagner, S., Maier, L.S., Gärtner, J., Klinge, L., et al. (2017). Dysferlin mediates membrane tubulation and links T-tubule biogenesis to muscular dystrophy. J Cell Sci jcs.198861. 